\title{
Oxidation of Matrix Material in Helium with Varied Moisture Content
}

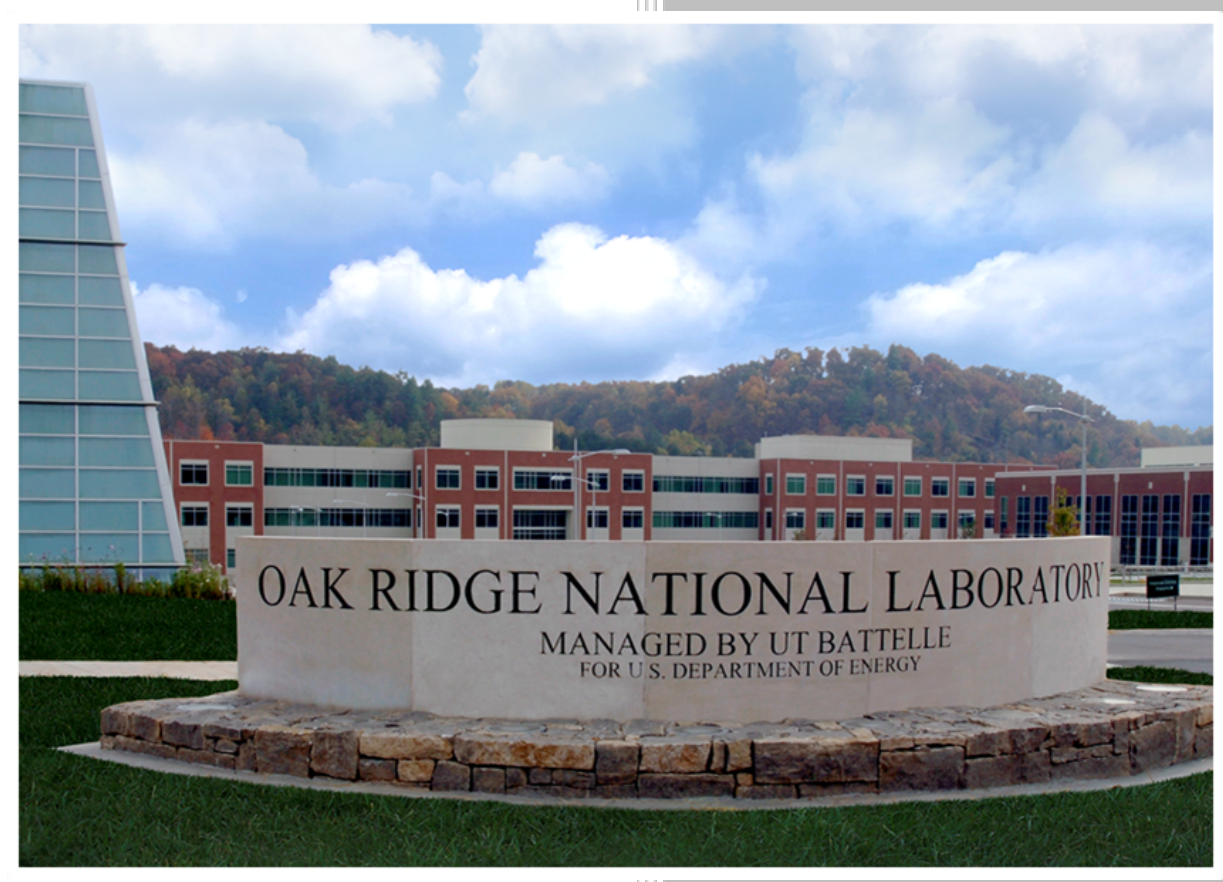

Approved for public release.

Distribution is unlimited.

Tyler J. Gerczak

Cristian Contescu

Jo Jo Lee

Robert Mee

Austin Schumacher

John Stempien

Michael Trammell

November 2019 


\title{
DOCUMENT AVAILABILITY
}

Reports produced after January 1, 1996, are generally available free via US Department of Energy (DOE) SciTech Connect.

Website www.osti.gov

Reports produced before January 1, 1996, may be purchased by members of the public from the following source:

\author{
National Technical Information Service \\ 5285 Port Royal Road \\ Springfield, VA 22161 \\ Telephone 703-605-6000 (1-800-553-6847) \\ TDD 703-487-4639 \\ Fax 703-605-6900 \\ E-mail info@ntis.gov \\ Website http://classic.ntis.gov/
}

Reports are available to DOE employees, DOE contractors, Energy Technology Data Exchange representatives, and International Nuclear Information System representatives from the following source:

Office of Scientific and Technical Information

PO Box 62

Oak Ridge, TN 37831

Telephone 865-576-8401

Fax 865-576-5728

E-mail reports@osti.gov

Website http://www.osti.gov/contact.html

This report was prepared as an account of work sponsored by an agency of the United States Government. Neither the United States Government nor any agency thereof, nor any of their employees, makes any warranty, express or implied, or assumes any legal liability or responsibility for the accuracy, completeness, or usefulness of any information, apparatus, product, or process disclosed, or represents that its use would not infringe privately owned rights. Reference herein to any specific commercial product, process, or service by trade name, trademark, manufacturer, or otherwise, does not necessarily constitute or imply its endorsement, recommendation, or favoring by the United States Government or any agency thereof. The views and opinions of authors expressed herein do not necessarily state or reflect those of the United States Government or any agency thereof. 
Reactor and Nuclear Systems Division

\title{
OXIDATION OF MATRIX MATERIAL IN HELIUM WITH VARIED MOISTURE CONTENT
}

\author{
Tyler J. Gerczak \\ Cristian Contescu \\ Jo Jo Lee \\ Robert Mee \\ Austin Schumacher \\ John Stempien \\ Michael Trammell
}

November 2019

Prepared by

OAK RIDGE NATIONAL LABORATORY

Oak Ridge, TN 37831-6283

managed by

UT-BATTELLE, LLC

for the

US DEPARTMENT OF ENERGY

under contract DE-AC05-00OR22725 



\section{CONTENTS}

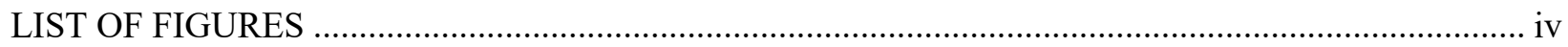

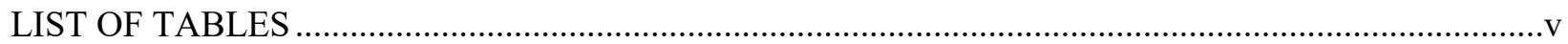

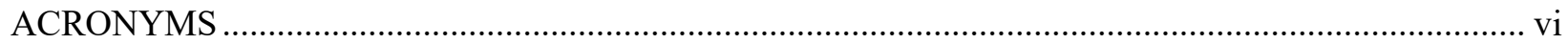

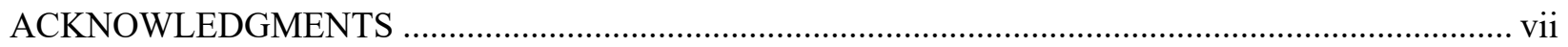

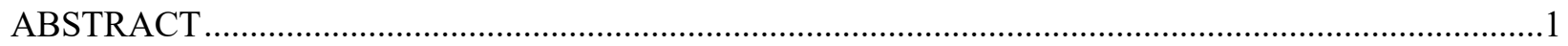

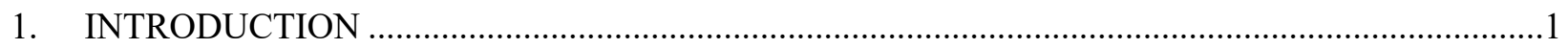

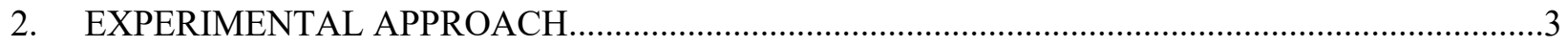

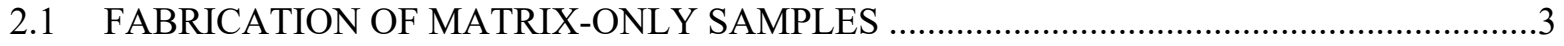

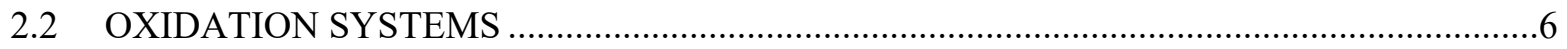

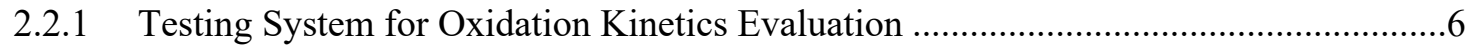

2.2.2 Testing System for High-Temperature Empirical Oxidation.......................................

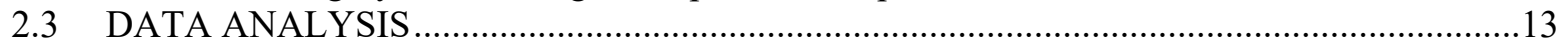

2.3.1 Data Analysis for Oxidation Kinetics Evaluation...................................................13

2.3.2 Data Analysis for High-Temperature/High Partial Pressure Empirical Oxidation.......14

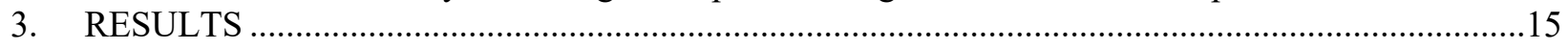

3.1 RESULTS FOR OXIDATION KINETICS EVALUATION .............................................15

3.2 RESULTS FOR HIGH-TEMPERATURE EMPIRICAL OXIDATION ...............................16

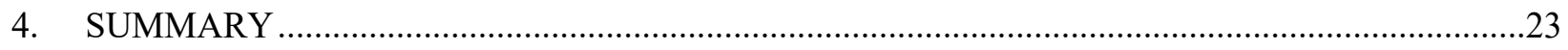

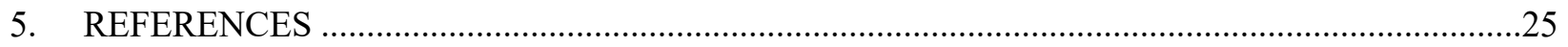

APPENDIX A. AS-FABRICATED MATRIX SAMPLE PROPERTIES ……................................... A-1

APPENDIX B. INDIVIDUAL MEASUREMENTS AND TEST CONDITIONS FOR EMPIRICAL HIGH-TEMPERATURE OXIDATION TESTING …...............................................................

APPENDIX C. INDIVIDUAL MEASUREMENTS AND TEST CONDITIONS FOR OXIDATION KINETICS EVALUATION .....................................................................................................

APPENDIX D. SELECT OPTICAL MICROGRAPHS OF SAMPLES SUBJECTED TO CROSS

SECTIONAL ANALYSIS.................................................................................................. D-1 


\section{LIST OF FIGURES}

Figure 1. Schematic of oxidant profiles for each oxidation regime; (left) diffusion-controlled regime, (center) transition regime, and (right) kinetic regime (reproduced from Kane et

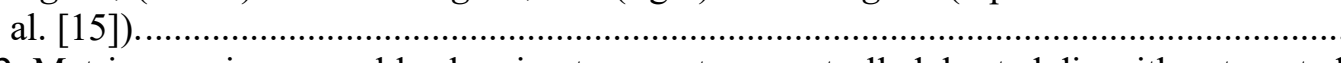

Figure 2. Matrix pressing assembly showing temperature-controlled heated die with automated

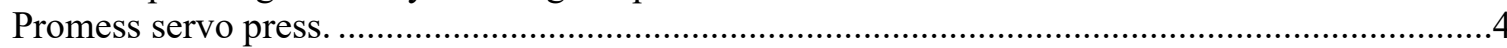

Figure 3. Examples of surface fissures prompting rejection in matrix-only samples.................................6

Figure 4. Measured density for matrix-only samples accepted and rejected based on visual criteria. Displayed mean and standard deviation bands are associated with visually accepted samples only.....

Figure 5. Schematic and image of the dual symmetrical thermogravimetric analyzer-TAG $16 / 18$ - used in this study.

Figure 6. Typical temperature profile for oxidation testing in the TAG system. ....................................8

Figure 7. Example of weight loss measurements for oxidation testing over $800-1,200{ }^{\circ} \mathrm{C}$ at $\mathrm{P}_{\mathrm{H} 2 \mathrm{O}}$ $=100 \mathrm{~Pa}$ and $\mathrm{P}_{\mathrm{H} 2}=0 \mathrm{~Pa}$, as well as $\mathrm{P}_{\mathrm{H} 2 \mathrm{O}}=100 \mathrm{~Pa}$ and $\mathrm{P}_{\mathrm{H} 2}=25 \mathrm{~Pa}$.....

Figure 8. SATS system for high-temperature empirical oxidation testing (schematic adapted from Terrani et al. [24]).....

Figure 9. Detailed view of (a) HTM furnace top, (b) alumina sample holder, (c) sample with drilled hole, and (d) sample mounting.

Figure 10. Images of sample before and after oxidation testing showing the change in surface conditions.

Figure 11. Adjusted weight loss to account for residual oxygen in the system. . .14

Figure 12. Experimental oxidations rates at $\mathrm{P}_{\mathrm{H} 2}=0$ with isothermal trend lines reflecting kinetic parameters determined from best fit for LH (left) and BLH (right) models.

Figure 13. Observed vs. predicted rates for measured oxidation data for the LH and BLH models..........16

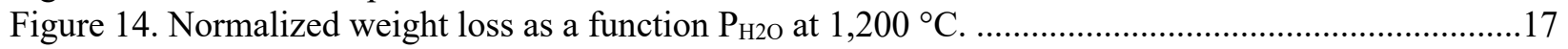

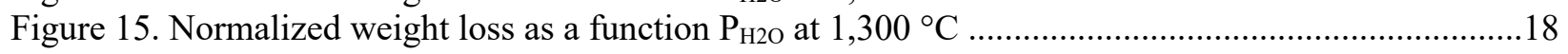

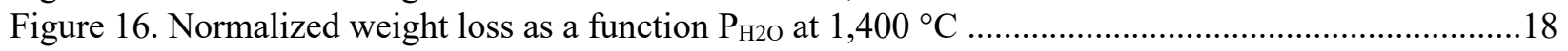

Figure 17. Normalized weight loss as a function temperature $\left(1,200-1,500{ }^{\circ} \mathrm{C}\right)$ at constant $\mathrm{P}_{\mathrm{H} 2 \mathrm{O}}$ $\left(\mathrm{P}_{\mathrm{H} 2 \mathrm{O}}=10 \mathrm{kPa}\right)$.

Figure 18. Measured oxidation rate as a function of $\mathrm{P}_{\mathrm{H} 2 \mathrm{O}}$.

Figure 19. Overview micrographs of the cross section of the an-fabricated and select oxidized samples at $1,200{ }^{\circ} \mathrm{C}, 1 \mathrm{~h}$, and varying $\mathrm{P}_{\mathrm{H} 2 \mathrm{O}}$, showing the impact of macroscopic fissures on oxidation behavior in the high-temperature oxidation testing (red box identifies the approximate area of interest presented in Figure 20; black regions are pores not filled by epoxy; $W L$ is measured, normalized weight loss.

Figure 20. Close-up micrographs highlighting (a) penetration along the exposed fissures and (b) low-density oxidized region showing apparent residual graphite flake; the red box highlights the approximate area of interest shown in (b) in the higher magnification micrograph from SE-001 $\left(1,200^{\circ} \mathrm{C}, 1 \mathrm{~h}, \mathrm{P}_{\mathrm{H} 2 \mathrm{O}}=20 \mathrm{kPa}\right)$.

Figure 21. Experimental oxidations rates at $\mathrm{P}_{\mathrm{H} 2}=0$ with isothermal trend lines reflecting kinetic parameters determined from best fit for LH (left) and BLH (right) models with hightemperature empirical oxidation results included.

Figure 22. Observed versus predicted rate for measured oxidation data for the LH and BLH models with high-temperature empirical oxidation results included. 


\section{LIST OF TABLES}

Table 1. Relevant conditions for a steam ingress events [1-7] .........................................................

Table 2. Matrix carbonization schedule, all values approximate ..........................................................

Table 3. Test matrix for oxidation kinetics evaluation in varied moisture environments $\left(\mathrm{P}_{\mathrm{H} 2 \mathrm{O}}, \mathrm{P}_{\mathrm{H} 2}\right.$ in UHP-He).

Table 4. Test matrix for high temperature steam oxidation tests...........................................................12

Table 5. Samples subjected to cross sectioning and optical microscopy (sample ID, temperature, exposure time, $\mathrm{P}_{\mathrm{H} 2 \mathrm{O}}$ )

Table 6. Experimentally determined kinetic parameters for LH and BLH models ..................................16

Table 7. Rate analysis for high-temperature oxidation testing.

Table 8. Effective oxidation kinetics for matrix-only samples in high-temperature steam. 


\section{ACRONYMS}

AGR Advanced Gas Reactor Fuel Development and Qualification Program

BLH Boltzmann Langmuir-Hinshelwood (LH)

CVD chemical vapor deposition

DOE US Department of Energy

HTGR high-temperature gas-cooled reactor

HTM high-temperature module

LH Langmuir-Hinshelwood

ORNL Oak Ridge National Laboratory

SATS Severe Accident Test Station

$\mathrm{SiC}$

SSE silicon carbide (TRISO layer)

sum of squared errors

TRISO tristructural-isotropic (coated particles)

UHP-He ultrahigh purity $\mathrm{He}$

WL weight loss 


\section{ACKNOWLEDGMENTS}

This work was supported by the US Department of Energy's Office of Nuclear Energy Advanced Reactor Technologies as part of the Advanced Gas-Cooled Reactor Fuel Qualification and Development Program. Significant support for this work was provided by Victoria Cox, Tom Geer, Michael Howell, and Daniel Newberry. 


\begin{abstract}
Exploration of the oxidation behavior of matrix material from tristructural-isotropic (TRISO) coated particle fuel elements in moisture environments provides critical data needed to predict the material's response during off-normal accident scenarios. Near-representative, matrix-only samples were fabricated to facilitate oxidation testing in varied moisture concentrations. Oxidation testing was completed over a range of temperatures and oxidizing environments to obtain the relevant oxidation kinetics parameters and empirical oxidation rates necessary to better predict and understand matrix oxidation behavior at relevant conditions. The acquired oxidations rates were fit to established models for steam oxidation of nuclear graphite, and data were acquired following an established process. The data showed good agreement over conditions typical of the kinetic regime, and they showed a departure from the kinetic model fit at elevated temperatures and steam partial pressures in helium carrier gas. The departure was confirmed to be due to the experimental conditions being beyond the kinetic regime based on destructive analysis.
\end{abstract}

\title{
1. INTRODUCTION
}

High-temperature gas-cooled reactors (HTGRs) traditionally use tristructural-isotropic (TRISO) coated particle fuel compacted in a graphite and carbonized resin matrix to produce a fuel element. The matrixmaterial surrounds the fuel particles and provides structural integrity and protection to the TRISO fuel particles. Accident scenarios in HTGRs include air and moisture ingress events at high temperatures. The likelihood of such accidents may vary among HTGR designs such that air or moisture-ingress events are design-basis accidents for one design but beyond design-basis for another design. The US Department of Energy (DOE) Advanced Gas Reactor Fuel Qualification and Development Program (AGR) initiated an experimental effort to better understand the oxidation response of each component in such events. By testing each component (matrix-only TRISO particles) separately, the oxidation behavior can be isolated, measured, and subsequently leveraged in fuel performance models to better predict performance.

Steam ingress events ultimately lead to acute corrosion of graphitic materials in the HTGR core. The extent of oxidation of graphitic materials will vary based on many parameters including, but not limited to, location in the core, duration of the accident, and the quantity of oxidant to infiltrate the system. In prismatic HTGRs, cylindrical fuel elements (called compacts) are contained in channels in large blocks of graphite. Separate channels in these blocks carry the helium coolant. These blocks will naturally act to shield the fuel from oxidants. Pebble bed HTGRs consist of a bed of spherical fuel elements where the coolant flows through the bed and directly around each pebble. Many fuel pebble designs feature an unfueled zone of matrix that protects the TRISO particles in the pebbles. Pebble bed reactors may also have large graphite core structures such as neutron reflectors, that would also consume oxidants. If oxidants were able to reach the fuel elements, oxidation of the fuel elements may lead to radionuclides being released into the coolant and an increased potential for TRISO particle degradation. Water ingress events could be caused by a moderate-sized break of a steam generator tube, steam leakage in the primary coolant system, and depressurization of the primary coolant system [1]. These events are expected to yield scenarios in which the fuel elements are exposed to variable steam partial pressures $\left(\mathrm{P}_{\mathrm{H} 2 \mathrm{O}}\right)$ and temperatures, depending on the nature of the event. Table 1 describes generic conditions that may be experienced during the varied accident conditions [1-7]. These conditions form the basis for the oxidation testing conditions discussed here-in. 
Table 1. Relevant conditions for a steam ingress events [1-7].

\begin{tabular}{ll}
\hline Peak fuel temperatures $\left({ }^{\circ} \mathrm{C}\right)$ & $1,000-1,630$ \\
\hline $\mathrm{H}_{2} \mathrm{O}$ partial pressure $(\mathrm{kPa})$ & $\leq 2$ (for tens of hours) \\
& $\leq 400$ (for up to several hours) \\
\hline Time to reach peak fuel temperature (h) & $\sim 100$ \\
\hline
\end{tabular}

The oxidation behavior of the matrix material in steam environments has not been well studied; however, the oxidation performance in air has been analyzed between $500-1,600^{\circ} \mathrm{C}$ [8,9]. The oxidation behavior for different grades of nuclear graphite in steam conditions relevant to chronic oxidation of HTGR internal components has been well established [10-12]. These tests focused primarily on the kinetic oxidation regimes $\left(\mathrm{T}<1,000{ }^{\circ} \mathrm{C}, 0.01 \leq \mathrm{P}_{\mathrm{H} 2 \mathrm{O}} \leq 3 \mathrm{kPa}\right)$ and conditions relevant to chronic oxidation to obtain oxidation kinetic parameters. These tests were identified to meet the kinetic regime and conditions relevant to chronic oxidation. These conditions are at lower temperatures and partial pressures than the peak values expected for acute moisture ingress accidents relevant. Additionally, the matrix material is a composite of natural and synthetic graphite flake and carbonized resin binder as such existing data on nuclear graphite stream oxidation may not translate directly. This defines a need to directly analyze the oxidation performance of matrix material. The experimental approaches developed for nuclear-grade graphite steam oxidation can be leveraged to investigate steam oxidation of matrix materials.

The goal of this effort is to acquire the kinetic parameters for steam oxidation of near-representative matrix-only material and to obtain empirical oxidation rates at conditions relevant to accident scenarios. The oxidation of graphitic materials follows the global reaction presented in Equation 1.

$$
\mathrm{C}_{\text {solid }}+\mathrm{H}_{2} \mathrm{O}_{\text {vapor }}=\mathrm{CO}_{\text {gas }}+\mathrm{H}_{2} \text { gas }
$$

Based on the global equation, the presence of the reaction products $\left(\mathrm{CO}_{\text {gas }}\right.$ and $\mathrm{H}_{2}$ gas $)$ will shift the equilibrium and influence the overall oxidation rate [13]. In particular, hydrogen will suppress the reaction by occupying surface sites on the graphite surface $[8,14]$. Therefore, the influence of the partial pressure of hydrogen $\left(\mathrm{P}_{\mathrm{H} 2}\right)$ must be considered when analyzing the oxidation behavior in a steam environment. The requirement for analyzing varying $\mathrm{P}_{\mathrm{H} 2}$ to determine the kinetic parameters is discussed in more detail in Section 2.3.1.

While the composite matrix material likely responds differently to oxidation compared to nuclear grade graphite, the underlying oxidation behavior likely translate based on the similarity in composition. The characteristics of the oxidation of graphite can be illustrated in three different regimes showing the observed Arrhenius temperature dependence. The specifics of each regime are described in detail by Kane et al. [15]. At low temperatures, oxidation behavior is controlled by the rate of the chemical reaction. This regime is considered the kinetic regime, and oxidation occurs uniformly throughout the material. At higher temperatures, oxidation is impacted by diffusion of the oxidant and the rate of the chemical reaction. This regime is described as the transition regime, and it is highlighted by nonuniform oxidation. Specifically, the oxidation is more pronounced at the surface, with clear penetration into the bulk. At even higher temperatures, the oxidation is controlled by the rate of oxidant diffusion to the surface of the samples. The oxidation reaction is confined to the exposed surface, and the reaction leads to a reduction in surface area; this regime is defined here as the diffusion-controlled regime. Figure 1 shows a schematic of the oxidant profiles for each regime to illustrate the different oxidation scenarios [15]. Exploration of test conditions in the kinetic regime are targeted for the determination of the kinetic 
parameters in this study, while the exploration of temperatures and steam partial pressures relevant to accident conditions are expected to probe the transition regime and/or diffusion-controlled regime.

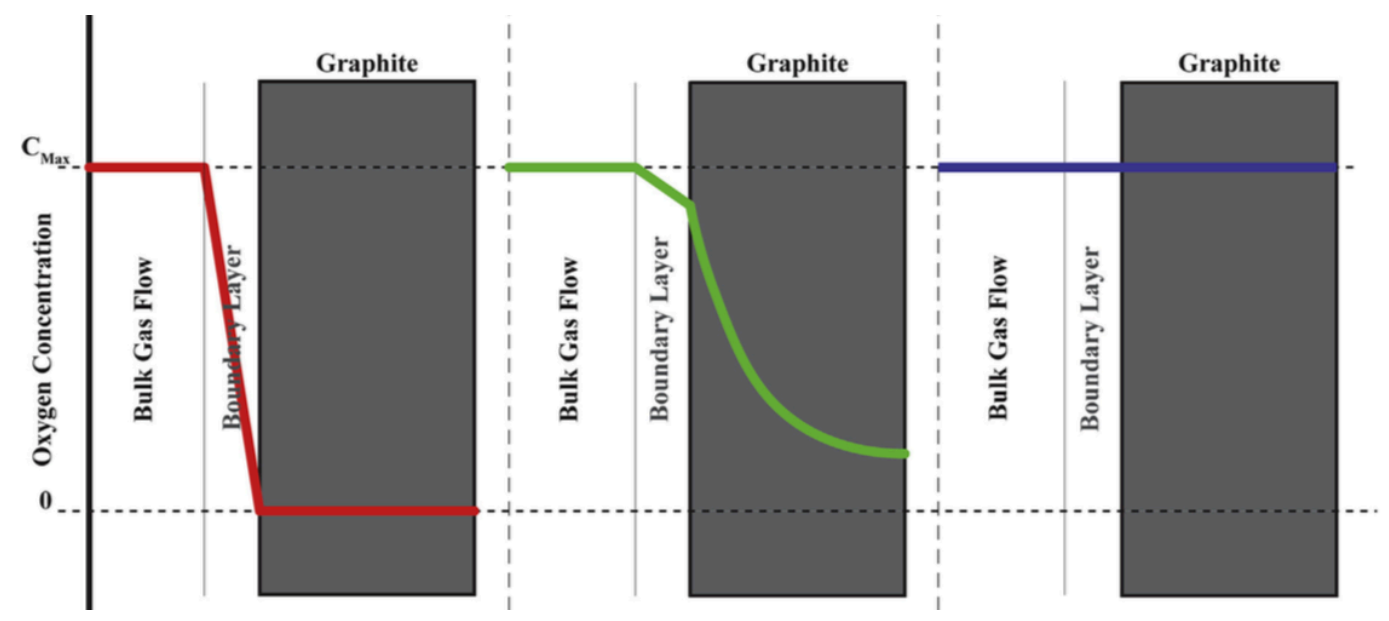

Figure 1. Schematic of oxidant profiles for each oxidation regime; (left) diffusion-controlled regime, (center) transition regime, and (right) kinetic regime (reproduced from Kane et al. [15]).

In 2012, an effort at Oak Ridge National Laboratory (ORNL) to measure the steam oxidation kinetics of various nuclear-grade graphites was initiated $[12,13,16-18]$. This past effort serves as a template for analyzing the oxidation kinetics of matrix-only material in varied moisture environments, and it includes measured oxidation rates under various $\mathrm{P}_{\mathrm{H} 2 \mathrm{O}}$ and $\mathrm{P}_{\mathrm{H} 2}$. This testing approach focused on determining the relevant kinetic parameters based on an established model, Langmuir-Hinshelwood (LH) [19], and on a new model, the Boltzmann-enhanced Langmuir-Hinshelwood (BLH) model, which accounts for the temperature dependence of the reaction order [20]. The general test matrix for these studies was adopted for the analysis of matrix-only samples. The oxidation behavior at near-accident conditions was pursued to obtain empirical rates so that oxidation behavior at extreme conditions can be predicted better, the nature of the oxidation response can be better understood. An existing high-temperature steam exposure system, the Severe Accident Test Station (SATS), was leveraged to study this behavior. This system limited the conditions which could be obtained through testing in the that the system operated a nominally atmospheric pressure.

\section{EXPERIMENTAL APPROACH}

\subsection{FABRICATION OF MATRIX-ONLY SAMPLES}

Samples for matrix oxidation testing were fabricated to meet the specification of matrix material from the AGR-5/6/7 irradiation experiment [21]. The matrix precursor materials were acquired from BWXT and consisted of a blend of natural graphite, synthetic graphite, resin binder, and hardening agent. The matrix blend used was consistent with the raw materials and the materials ratios representative of AGR-5/6/7 matrix. This matrix blend was compacted using procedures defined through the AGR program's laboratory-scale compacting efforts to produce matrix-only samples for oxidation testing.

Existing dies were utilized to produce cylindrical samples. A thin disk shape was developed for the test samples to limit density variation across the thickness of the specimen and to maintain the appropriate ratio of surface area to volume of approximately 1:1.1 to minimize volume effects during oxidation testing [8]. The selected disk geometry was approximately $2.58 \mathrm{~mm}$ thick with a $12.1 \mathrm{~mm}$ diameter. The samples were produced to meet the AGR-5/6/7 fuel specification for matrix density, with the primary 
criteria being a geometric density $\geq 1.65 \mathrm{~g} / \mathrm{cm}^{3}$ [21], while targeting a density of $1.75 \mathrm{~g} / \mathrm{cm}^{3}$ to represent AGR-5/6/7 [22].

The process to produce matrix samples included multiple steps. The fabrication process included producing a sample charge, pressing a green compact, performing sample carbonization, and conducting a final heat treatment to drive out impurities. The sample ID was tracked throughout the fabrication process, and measurements were taken at interim stages so possible variations in sample outcomes and initial density could be noted. The matrix-only samples are expected to have a similar chemical composition but a different microstructure than the AGR-5/6/7 fuel compacts. The absence of fuel particles in the matrix-only samples is expected to impact the overall orientation of the graphite flake and the local variation in matrix density. The expected texture differences likely do not impact oxidation in the kinetic regime, where oxidation occurs uniformly, but it may influence the observed oxidation rate at diffusion-dependent conditions beyond the kinetic regime [15]. While carbonization and heat treatment conditions were the same for the matrix-only samples and the fuel compacts, the equipment used was different, and the pressing procedure to make the matrix-only samples was optimized for the oxidation test samples.

Pressing was initiated by first weighing $\sim 0.62 \mathrm{~g}$ of the graphite/resin blend and then hand-pressing the material to produce a die charge. This charge was then lightly ground with SiC-grit sanding paper to achieve a sample with a mass of $\sim 0.58 \mathrm{~g}$. This step helped to ensure that the mass of the samples was consistent. A green compact was produced by hot pressing the charge in a die heated at $155{ }^{\circ} \mathrm{C}$ and subjecting it to $1.3 \mathrm{kN}$ for $60 \mathrm{~s}$ using the Promess automated servo-driven mechanical press shown in Figure 2. The green compacts were then subjected to a carbonization step to finish curing and to carbonize the resin binder. This thermal exposure was performed in a Lindberg/Blue ${ }^{\circ}$ tube furnace. The approximate carbonization schedule is shown in Table 2 and follows the same temperature profile as those used to produce fuel compacts [23]. After carbonization, the samples were subjected to a final hightemperature heat treatment at $1800{ }^{\circ} \mathrm{C}$ for one hour, increasing $20^{\circ} \mathrm{C} / \mathrm{min}$, ramping from 20 up to 1,800 ${ }^{\circ} \mathrm{C}$. The heat treatment was performed under vacuum, with a starting vacuum of $<\sim 100 \mathrm{~Pa}$ in a Thermal Technology, Inc. ASTRO furnace. This step drives out impurities present in the sample and yields the final geometry and density. Minimal geometry variation was observed after the high-temperature heat treatment compared to the post-carbonization sample.

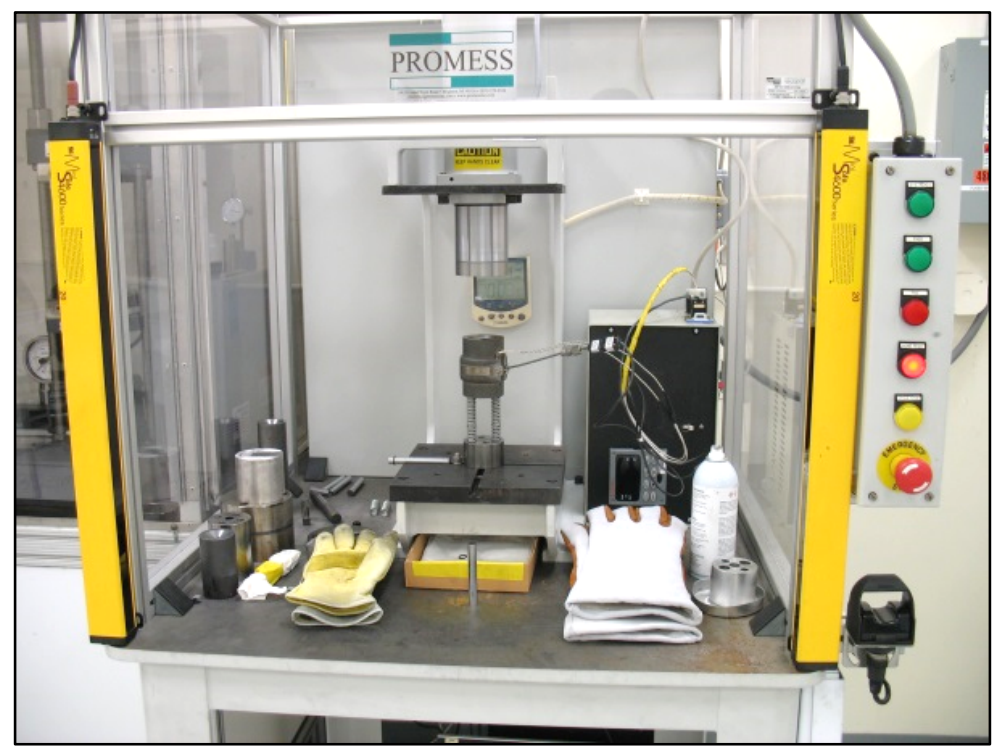

Figure 2. Matrix pressing assembly showing temperature-controlled heated die with automated Promess servo press. 
Table 2. Matrix carbonization schedule, all values approximate.

\begin{tabular}{ccc}
\hline Step $\left({ }^{\circ} \mathrm{C}\right)$ & Ramp rate $\left({ }^{\circ} \mathrm{C} / \mathrm{min}\right)$ & Step duration $(\mathrm{min})$ \\
\hline $20 \rightarrow 140$ & 4 & 30 \\
\hline $140 \rightarrow 220$ & 1 & 80 \\
\hline $220 \rightarrow 330$ & 1 & 80 \\
\hline $330 \rightarrow 420$ & 1 & 180 \\
\hline $420 \rightarrow 560$ & 1 & 170 \\
\hline $560 \rightarrow 610$ & 2 & 25 \\
\hline $610 \rightarrow 690$ & 4 & 20 \\
\hline $690 \rightarrow 900$ & 6 & 35 \\
\hline $900 \rightarrow 900$ & hold temperature & 30 \\
\hline $900 \rightarrow 20$ & 20 & 45 \\
\hline
\end{tabular}

The final heat-treated samples were subjected to dimensional inspection and density calculation according to AGR-CHAR-DAM-39, a procedure previously developed procedure for matrix-only compact dimension and density measurements from the AGR program. The ultimate length of the matrix samples did not allow for the diameter to be measured at multiple axial positions according to the procedure. Therefore, the procedure was modified. In particular, the diameter measurement was taken at the middle of the sample as opposed to the three positions used for standard cylindrical compacts, which were each one inch long. Three unique measurements around the circumference of the sample $\left(\sim 60^{\circ}\right.$ increments $)$ were taken in lieu of measurements at different axial positions. Sample dimensions and mass were measured on calibrated equipment according to applicable NQA-1 standards. This included validation of balances and calipers prior to obtaining measurements through the use of certified mass standards and gauge blocks.

An acceptance criterion was established based on a visual standard and the measured density. After the samples were prepared, their outer surfaces were visually inspected for surface irregularities. Samples with surface fissures and other gross surface features were rejected. The presence of surface fissures was an expected defect based on past experience with full-sized blank (unfueled) compacts using the AGR-5/6/7 matrix formulation and methods [23]. Examples of surface fissures prompting rejection are shown in Figure 3. Surface fissures are not expected to influence oxidation behavior in the kinetic regime due the uniform oxidation behavior, however, the presence of fissures may impact oxidation in the surface sensitive regimes beyond the kinetic regime. Samples with measured densities within two standard deviations $(\sigma)$ of the mean were considered acceptable. Figure 4 shows the inspection results for the 300 samples produced, presenting the measured density and mean and the standard deviation band for the visually accepted samples. The mean density of the final sample set after visual acceptance was 1.760 $\mathrm{g} / \mathrm{cm}^{3}$ with a standard deviation of $0.025 \mathrm{~g} / \mathrm{cm}^{3}$. Samples within a range of $2 \sigma$ were accepted for testing $\left(1.711-1.810 \mathrm{~g} / \mathrm{cm}^{3}\right)$. The majority of samples were rejected based on visual inspection (surface fissures), with only two samples rejected due to density measurements alone. The matrix-only acceptance rate was $\sim 37 \%$ which was expected based on previous experience [23]. Appendix A lists the measured properties of the as-fabricated samples and the associated acceptance criteria. 


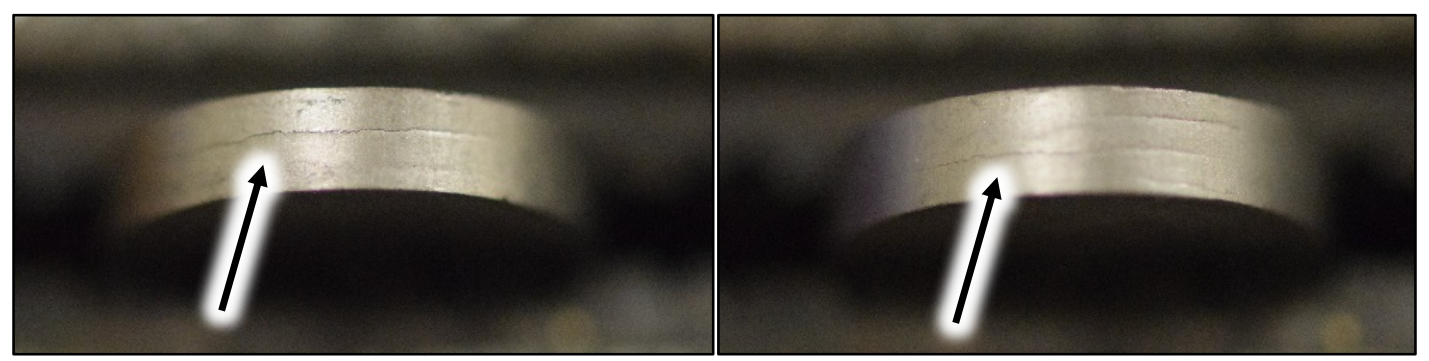

Figure 3. Examples of surface fissures prompting rejection in matrix-only samples.

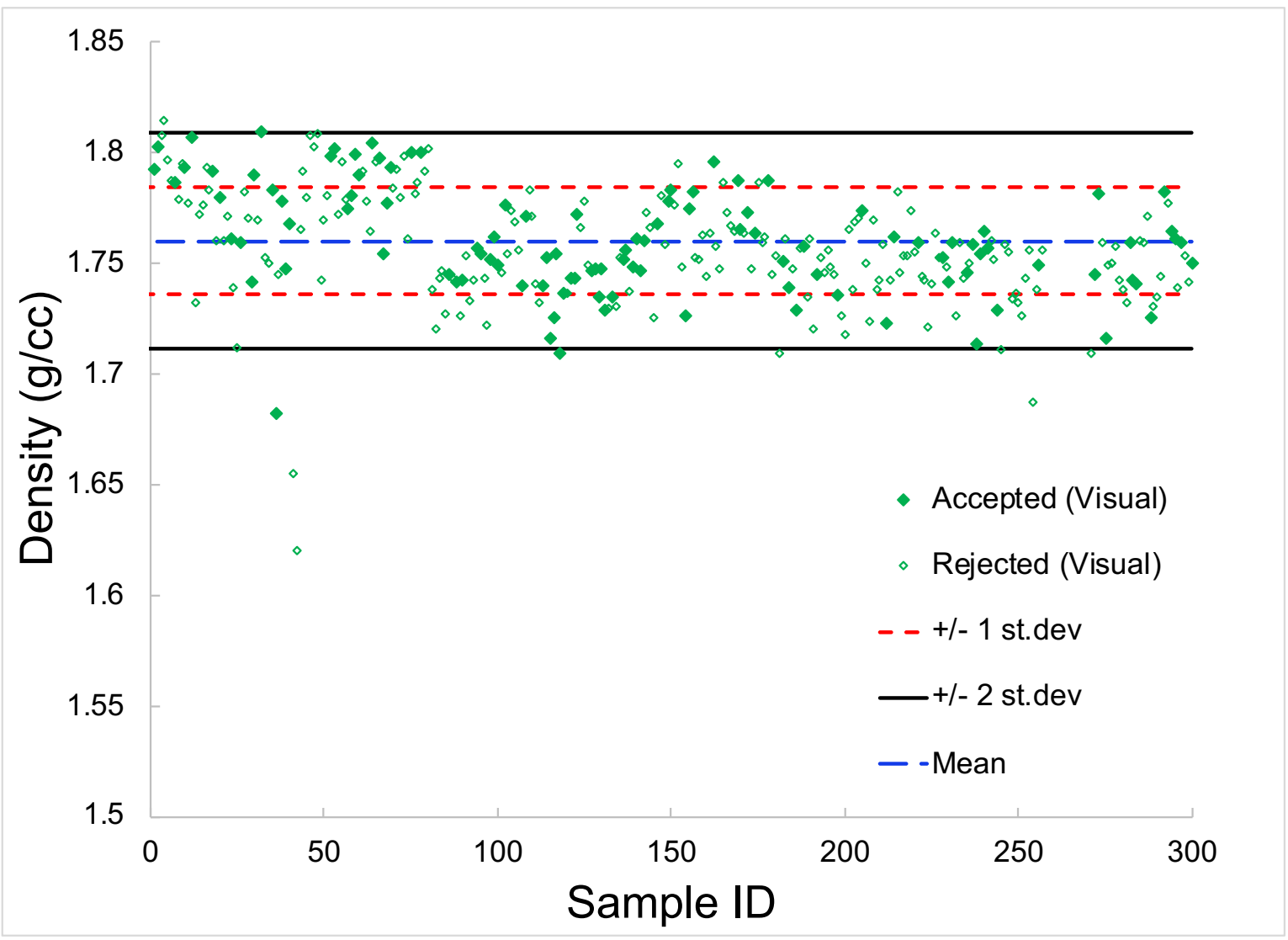

Figure 4. Measured density for matrix-only samples accepted and rejected based on visual criteria. Displayed mean and standard deviation bands are associated with visually accepted samples only.

\subsection{OXIDATION SYSTEMS}

\subsubsection{Testing System for Oxidation Kinetics Evaluation}

The oxidation behavior to obtain kinetic parameters was examined using a dual symmetrical thermogravimetric analyzer TAG 16/18 (Setaram, France). This system has been described in detail in the literature and was designed for oxidation kinetic measurements of nuclear graphite $[12,13,16-18]$. The experience obtained from steam oxidation testing of nuclear-grade graphite was leveraged to initiate and test oxidation behavior of the matrix-only material. Figure 5 shows a schematic and image of the experimental system. 


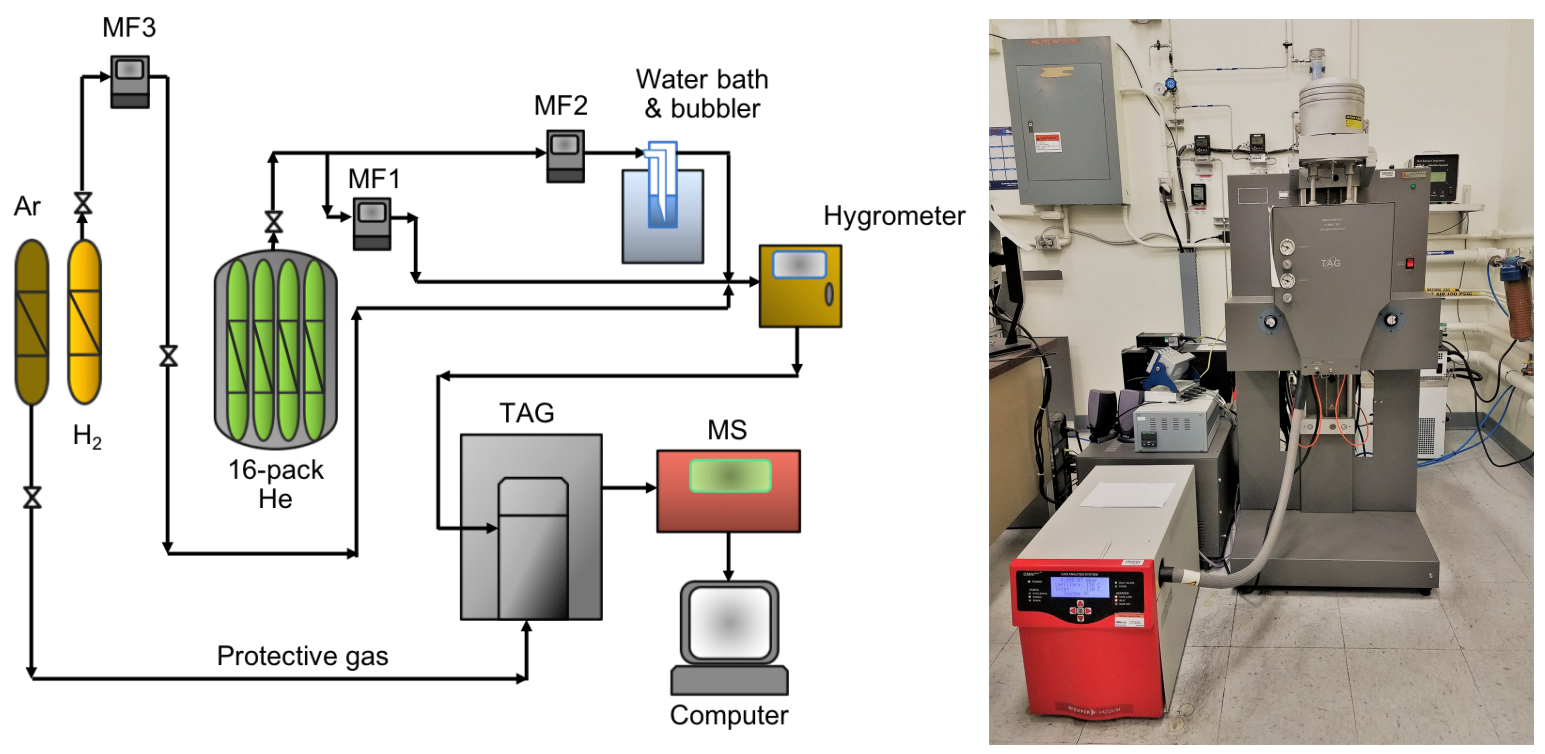

Figure 5. Schematic and image of the dual symmetrical thermogravimetric analyzer-TAG 16/18 — used in this study.

The system was operated at total flow rates of $1.5 \mathrm{~L} / \mathrm{min}$. The oxidant was delivered to the sample via ultrahigh purity helium (UHP-He) $\left(>99.999\right.$ vol. \%). The partial pressures of water vapor $\left(\mathrm{P}_{\mathrm{H} 2 \mathrm{O}}\right)$ and hydrogen $\left(\mathrm{P}_{\mathrm{H} 2}\right)$ in the UHP-He carrier gas were controlled for each exposure condition. The range of possible $\mathrm{P}_{\mathrm{H} 2 \mathrm{O}}$ was 3-1000 $\mathrm{Pa}$, and the range in $\mathrm{P}_{\mathrm{H} 2}$ was $0-100 \mathrm{~Pa}$. The temperature regime analyzed was $800-1200{ }^{\circ} \mathrm{C}$. Table 3 shows the targeted test conditions for each exposure. As previously described, this test matrix was based on tests performed to study the oxidation kinetics of nuclear-grade graphite $[12,13,16-18]$. However, this test matrix is skewed toward higher $\mathrm{P}_{\mathrm{H} 2 \mathrm{O}}$ to better reflect accident conditions and to link to the separate high-temperature oxidation tests run as part of this program.

Table 3. Test matrix for oxidation kinetics evaluation in varied moisture environments $\left(\mathbf{P}_{\mathrm{H} 2 \mathrm{O}}, \mathbf{P}_{\mathrm{H} 2}\right.$ in UHP-He).

\begin{tabular}{|c|c|c|c|c|c|c|c|c|c|c|c|}
\hline $\begin{array}{l}\text { Gas } \\
\text { compositions }\end{array}$ & $\begin{array}{l}\mathrm{P}_{\mathrm{H} 2 \mathrm{O}} \\
(\mathrm{Pa})\end{array}$ & 5 & 20 & 50 & 100 & 150 & 200 & 250 & 300 & 500 & 1000 \\
\hline \multirow{3}{*}{$\mathrm{P}_{\mathrm{H} 2}(\mathrm{~Pa})$} & $0(2 \times)^{*}$ & & $\checkmark$ & & $\checkmark$ & & $\checkmark$ & & $\checkmark$ & $\checkmark$ & $\checkmark$ \\
\hline & 25 & & $\checkmark$ & & $\checkmark$ & & $\checkmark$ & & $\checkmark$ & $\checkmark$ & \\
\hline & 100 & & $\checkmark$ & & $\checkmark$ & & $\checkmark$ & & $\checkmark$ & $\checkmark$ & \\
\hline
\end{tabular}

Multiple temperatures were analyzed for each combination of $\mathrm{P}_{\mathrm{H} 2 \mathrm{O}}$ and $\mathrm{P}_{\mathrm{H} 2}$. Oxidation rates were determined by weight loss measurements at constant temperature over holds of at least $3 \mathrm{~h}$. Temperature ramps began at the lowest temperature first, $800^{\circ} \mathrm{C}$, with $50{ }^{\circ} \mathrm{C}$ incremental steps up to $1,200{ }^{\circ} \mathrm{C}$. Longer exposure times $>5 \mathrm{~h}$ were used for lower temperatures due to the expected limited oxidation at lower temperatures $\left(<900^{\circ} \mathrm{C}\right)$ relative to the higher temperature conditions. The $1,200{ }^{\circ} \mathrm{C}$ test condition was not completed for all runs, as it was included after some initial tests had already been run to provide a link to the high-temperature empirical oxidation testing. Figure 6 shows the temperature profile for a typical oxidation kinetics testing run. The initial ramp to $1,200{ }^{\circ} \mathrm{C}$ with $0.5 \mathrm{~h}$ hold under vacuum and $1 \mathrm{~h}$ outgas serves to drive off residual moisture and other volatile species on the surface of the sample before testing. A new sample was used for each condition, that is, each combination of $\mathrm{P}_{\mathrm{H} 2 \mathrm{O}}$ and $\mathrm{P}_{\mathrm{H} 2}$. Figure 7 shows examples of the measured weight loss for $\mathrm{P}_{\mathrm{H} 2 \mathrm{O}}=100 \mathrm{~Pa}$ and $\mathrm{P}_{\mathrm{H} 2}=0 \mathrm{~Pa}$, as well as and $\mathrm{P}_{\mathrm{H} 2 \mathrm{O}}=100 \mathrm{~Pa}$ and 
$\mathrm{P}_{\mathrm{H} 2}=25 \mathrm{~Pa}$. The comparison illustrates the suppression of weight loss with the addition of $\mathrm{H}_{2}$ to the system, which is expected due the global oxidation reaction shown in Equation 1 [13].

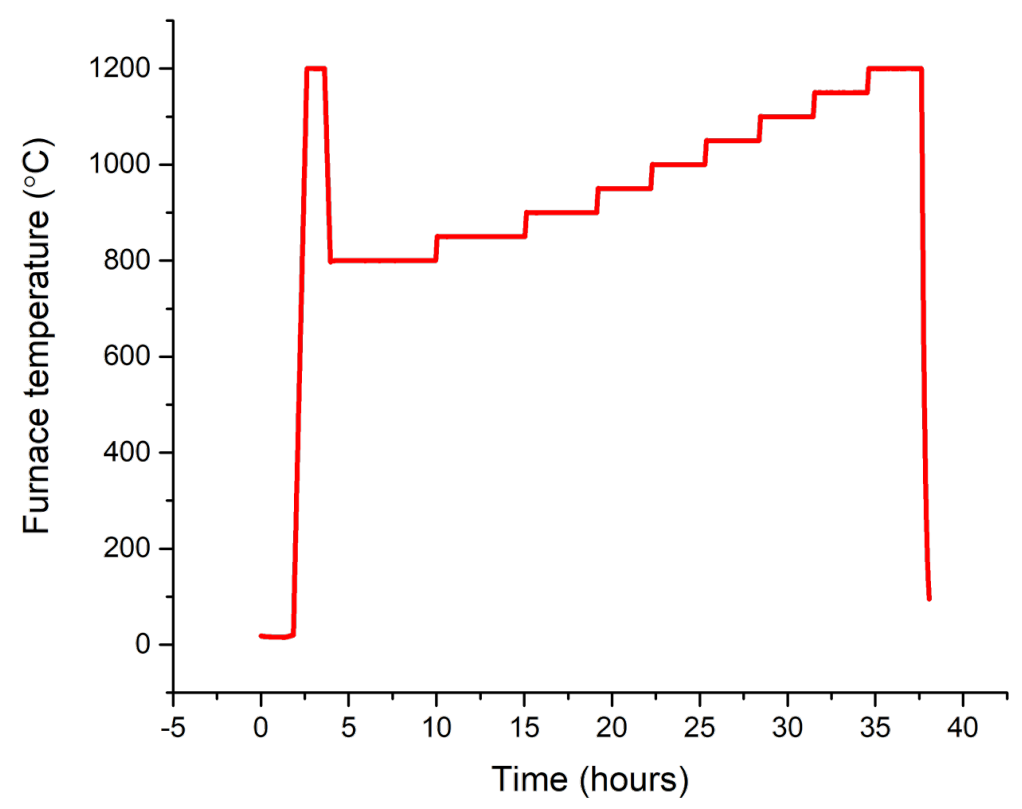

Figure 6. Typical temperature profile for oxidation testing in the TAG system. 


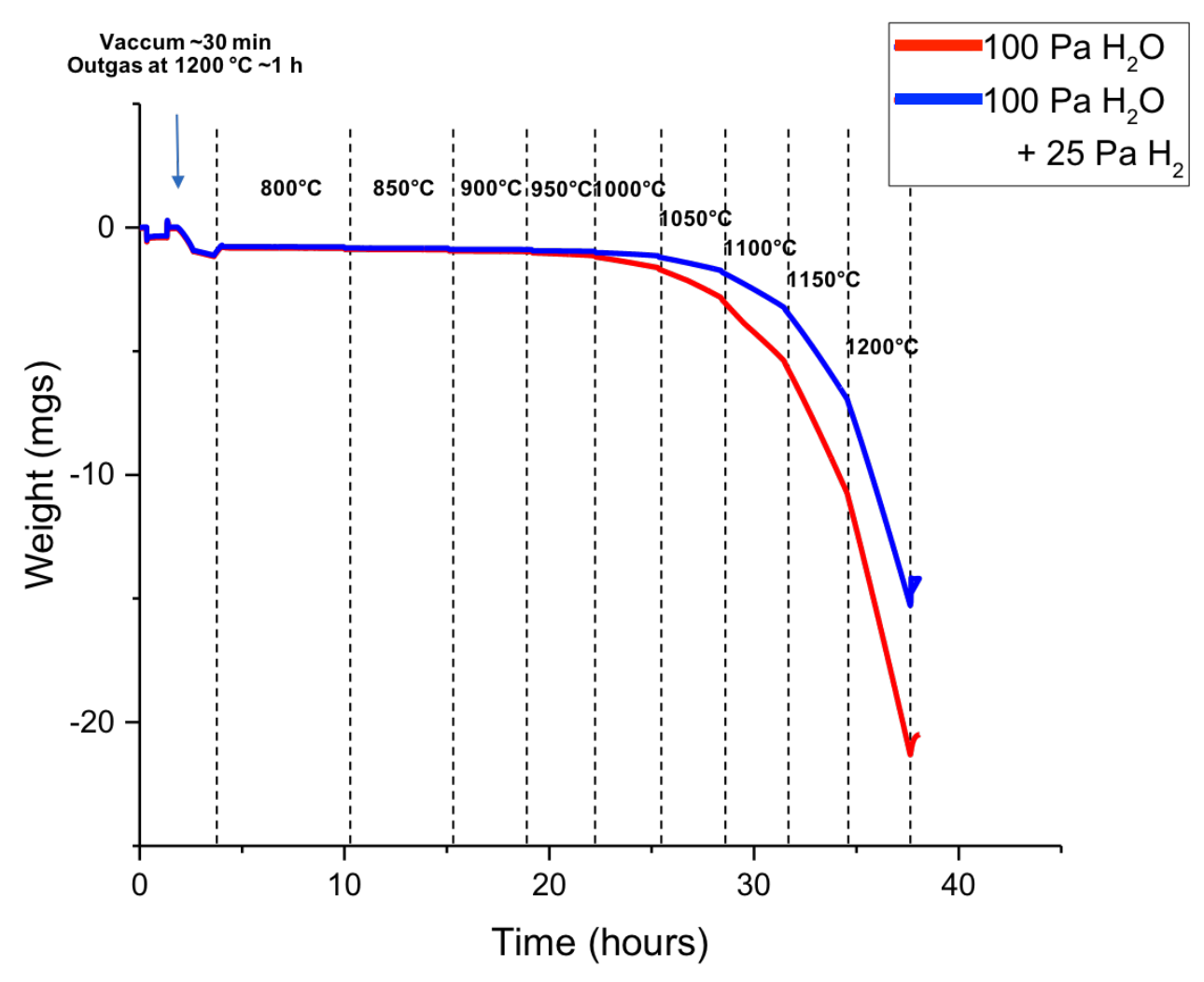

Figure 7. Example of weight loss measurements for oxidation testing over $800-1,200{ }^{\circ} \mathrm{C}$ at $P_{\mathrm{H} 2 \mathrm{O}}=100 \mathrm{~Pa}$ and $P_{\mathrm{H} 2}=0 \mathrm{~Pa}$, as well as $P_{\mathrm{H} 2 \mathrm{O}}=100 \mathrm{~Pa}$ and $P_{\mathrm{H} 2}=25 \mathrm{~Pa}$.

\subsubsection{Testing System for High-Temperature Empirical Oxidation}

Oxidation tests were conducted at temperatures higher than those in the oxidation kinetics evaluation described in the previous section, and they required a different testing system due to limitations of the TAG. The high-temperature empirical oxidation tests serve to mimic most extreme temperatures and moisture partial pressures in the reactor core. For short duration accidents or cases where sufficient core graphite exists to shield the fuel from moisture, the fuel itself may not see such high moisture partial pressures. The high-temperature module (HTM) of the SATS was identified as an appropriate test system (Figure 8). The furnace is capable of operation above $1,600{ }^{\circ} \mathrm{C}$ and up to $100 \%$ steam conditions. The standard system is described in detail by Terrani et al. [24]. 

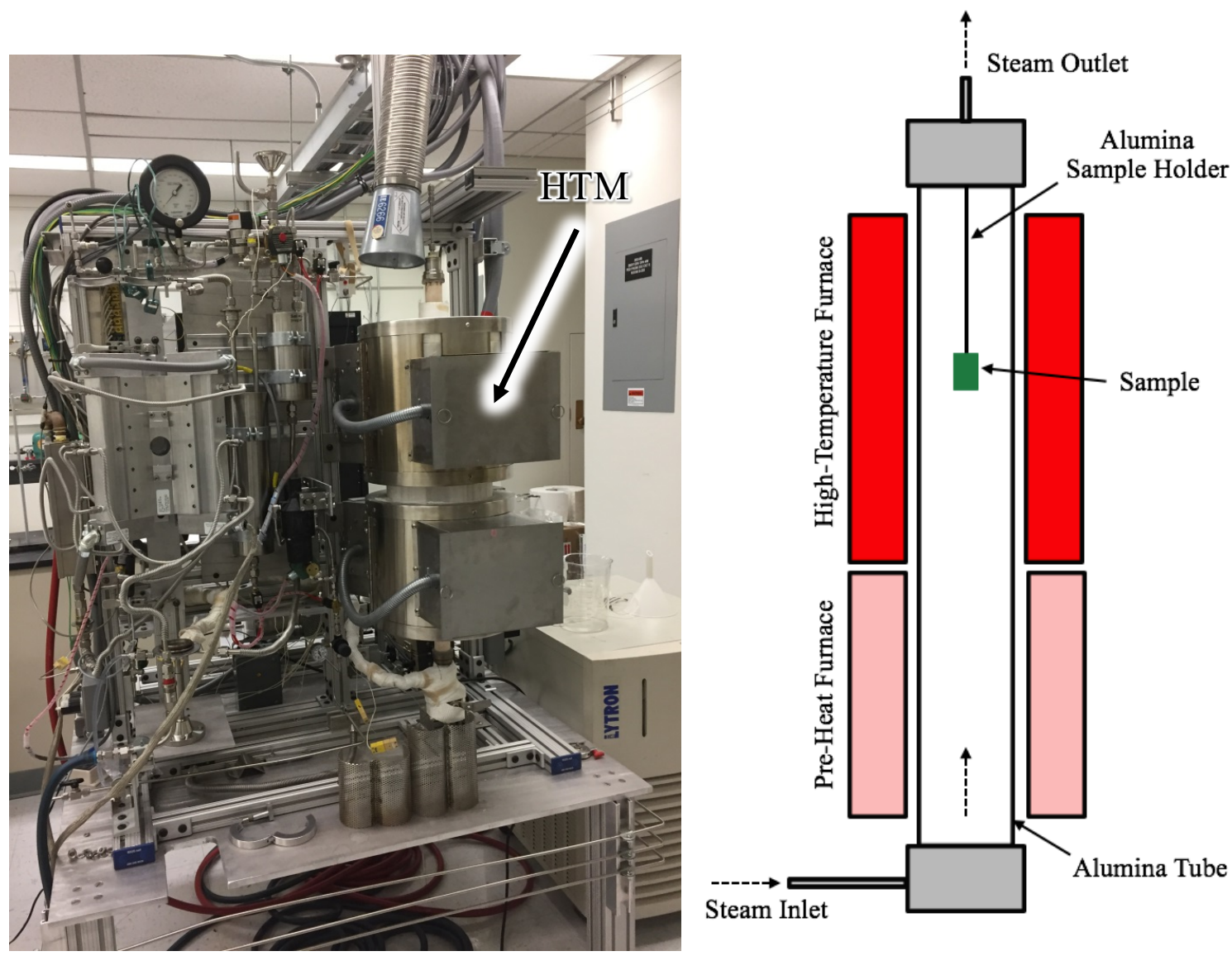

Figure 8. SATS system for high-temperature empirical oxidation testing (schematic adapted from Terrani et al. [24]).

The oxidation environment was controlled by continuously injecting water into a steam injector using a peristaltic pump. The water vapor was carried via UHP-He gas into the furnace chamber at $500 \mathrm{cc} / \mathrm{min}$. All inlet lines were wrapped with heat tape to avoid condensation. Upon entering the furnace, the steam and carrier gas enters a lower furnace chamber where the gas is preheated to $800{ }^{\circ} \mathrm{C}$. The gas then enters the HT-module where the oxidation sample resides in a constant temperature regime up to $1600{ }^{\circ} \mathrm{C}$. The matrix-only oxidation samples were suspended in the constant temperature zone of the HT-module on an alumina sample holder. A 3/16" diameter hole was drilled in each sample prior to testing (Figure 9c). The samples were hung on a chemically vapor deposited silicon carbide (CVD-SiC) rod positioned between two prongs on the alumina sample holder (Figure 9d). The gas exits the system via a gas outlet line which was wrapped in heat tape to prevent condensation. The end-cap at the steam outlet was modified from the original design to prevent back flow of oxygen at the $0.5 \mathrm{l} / \mathrm{min}$ flow rates by utilizing a high temperature compression fitting to prevent leakage into the alumina tube (Figure $9 \mathrm{a}$ and $\mathrm{b}$ ). An oxygen sensor was positioned on the outlet line to measure residual oxygen partial pressure (Figure 9a). 


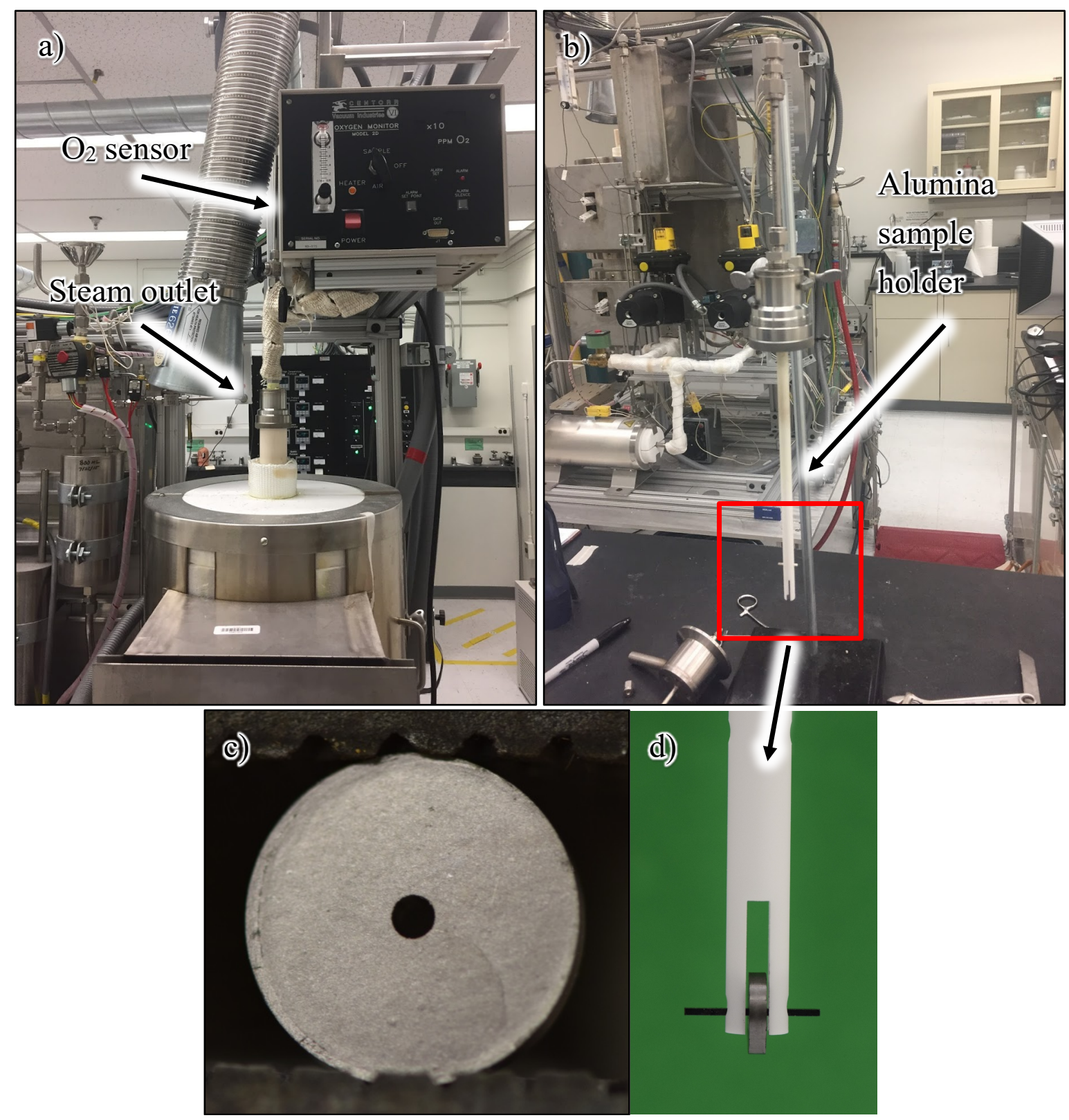

Figure 9. Detailed view of (a) HTM furnace top, (b) alumina sample holder, (c) sample with drilled hole, and (d) sample mounting.

Oxidation behavior was analyzed by directly measuring the change in weight as a function of the exposure condition and time. The matrix-only samples were subjected to a conditioning step per ASTM D7542-09 [25]. This step involved a $130{ }^{\circ} \mathrm{C} 3 \mathrm{~h}$ exposure in air to drive off excess moisture. The samples were then stored in a desiccator and were weighed after conditioning. Weight measurements were made according to AGR program procedures using check weight systems and calibrated balances. The balance was validated before and after each use with a calibrated set of check weights. The aluminum weigh pans used to receive the samples were also measured after oxidation testing, as it was not feasible to handle the samples due to the soft nature of the oxidized material.

The pre-weighed samples were suspended in the furnace system as described above. Prior to starting any run, the system was purged with UHP-He until the residual oxygen's partial pressure $\left(\mathrm{pO}_{2}\right)$ was below 
$300 \mathrm{ppm}$. Once the furnace reached the appropriate residual oxygen concentrations, the furnace was ramped to temperature at $20^{\circ} \mathrm{C} / \mathrm{min}$ up to the target temperature. When the appropriate soak temperature was reached, the steam injector was turned on to expose the samples to the water vapor in the UHP-He carrier gas. After the predefined soak time, the steam injector was turned off and the system was cooled to room temperature at a rate of $20{ }^{\circ} \mathrm{C} / \mathrm{min}$ with UHP-He flowing. After the system had cooled, the oxidized samples were removed from the furnace and dropped into the pre-weighed aluminum weigh pans by sliding the CVD-SiC rod out of the sample. The samples were stored in a desiccator until the weight of the aluminum weigh pans with samples could be measured using the same process as the pre-oxidation measurement. The final weight of the sample was determined by subtracting the weight of the aluminum weigh pan from the total weight. Figure 10 shows a sample before and after oxidation.
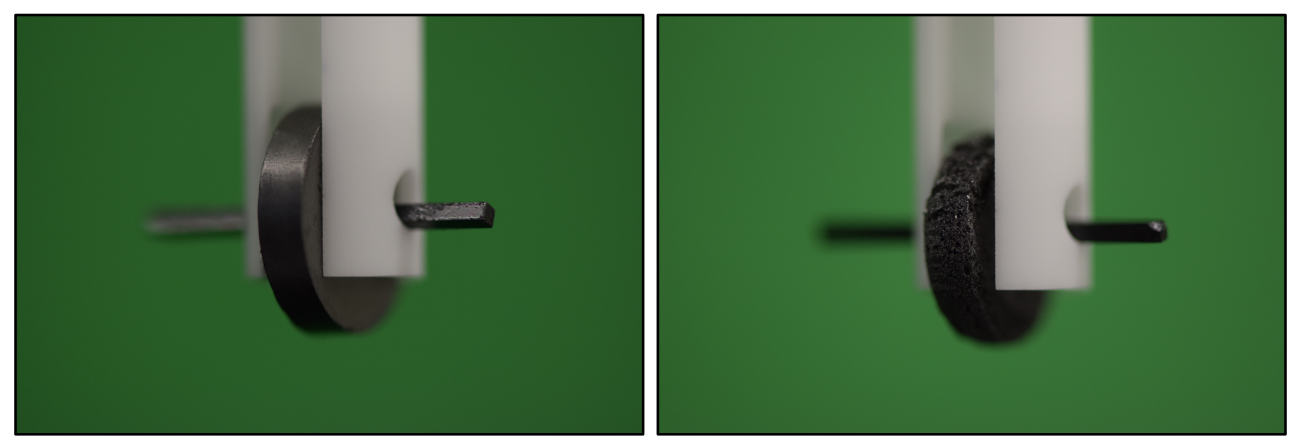

Figure 10. Images of sample before and after oxidation testing showing the change in surface conditions.

The final test matrix is presented in Table 4. An initial maximum temperature of $1,600{ }^{\circ} \mathrm{C}$ was sought; however, the oxidation kinetics at these temperatures were too rapid to facilitate testing. Temperatures of $1,200-1,500{ }^{\circ} \mathrm{C}$ were analyzed over steam partial pressures $\left(\mathrm{pH}_{2} \mathrm{O}\right)$ of $10-48 \mathrm{kPa}$. At least four tests per exposure condition (with a different sample for each test) were performed so that weight change measurements at a minimum of four different exposure times could be obtained. A series of control samples was exposed in UHP-He only at each temperature of interest to establish a baseline oxidation rate associated with the oxidation from residual, contaminant oxygen in the system. Multiple samples were run to determine the oxidation rate from change in weight as a function of time for each condition listed in Table 4. While each sample was assigned a chronological number, samples were randomly assigned for each test. Appendix B lists the change in weight for all oxidation tests, along with other relevant physical measurements (i.e., density and surface area).

Table 4. Test matrix for high temperature steam oxidation tests.

\begin{tabular}{|c|c|c|c|c|c|}
\hline \multicolumn{2}{|c|}{ Steam/temperature } & $1,200^{\circ} \mathrm{C}$ & $1,300^{\circ} \mathrm{C}$ & $1,400^{\circ} \mathrm{C}$ & $1,500^{\circ} \mathrm{C}$ \\
\hline \multirow{5}{*}{$\mathrm{pH}_{2} \mathrm{O}(\mathrm{kPa})$} & $0 *$ & $\checkmark$ & $\checkmark$ & $\checkmark$ & $\checkmark$ \\
\hline & 10 & $\checkmark$ & $\checkmark$ & $\checkmark$ & $\checkmark$ \\
\hline & 20 & $\checkmark$ & $\checkmark$ & $\checkmark$ & \\
\hline & 30 & $\checkmark$ & $\checkmark$ & $\checkmark$ & \\
\hline & 48 & $\checkmark$ & & & \\
\hline
\end{tabular}

After oxidation, select samples were subjected to cross sectioning and optical microscopy. The analysis was intended to provide insights into the oxidation behavior of the matrix-only samples at high temperatures. The optical microscopy effort also provides insight into the role of microstructural features on oxidation performance. The samples included in the optical microscopy are listed in Table 5. 
Table 5. Samples subjected to cross sectioning and optical microscopy (sample ID, temperature, exposure time, $\left.\mathbf{P}_{\mathbf{H} 2 \mathrm{O}}\right)$.

\begin{tabular}{lll}
\hline SE-020, $1,200{ }^{\circ} \mathrm{C}, 1 \mathrm{~h}, 10 \mathrm{kPa}$ & SE-001, $1,200{ }^{\circ} \mathrm{C}, 1 \mathrm{~h}, 20 \mathrm{kPa}$ & $\mathrm{SE}-113,1,200{ }^{\circ} \mathrm{C}, 1 \mathrm{~h}, 30 \mathrm{kPa}$ \\
\hline SE-198, $1,200{ }^{\circ} \mathrm{C}, 1 \mathrm{~h}, 48 \mathrm{kPa}$ & SE- $149,1,300{ }^{\circ} \mathrm{C}, 0.25 \mathrm{~h}, 20 \mathrm{kPa}$ & SE-078, $1,300{ }^{\circ} \mathrm{C}, 0.5 \mathrm{~h}, 20 \mathrm{kPa}$ \\
\hline SE-133, $1,300{ }^{\circ} \mathrm{C}, 1 \mathrm{~h}, 20 \mathrm{kPa}$ & SE-098, $1,300{ }^{\circ} \mathrm{C}, 1.5 \mathrm{~h}, 20 \mathrm{kPa}$ & SE- $064,1,400{ }^{\circ} \mathrm{C}, 1 \mathrm{~h}, 20 \mathrm{kPa}$ \\
\hline SE-242, as-fabricated & & \\
\hline
\end{tabular}

\subsection{DATA ANALYSIS}

\subsubsection{Data Analysis for Oxidation Kinetics Evaluation}

A total of 184 rate values were measured at the various temperatures $\left(800-1,200{ }^{\circ} \mathrm{C}\right)$ and gas compositions $\left(20 \mathrm{~Pa}<\mathrm{P}_{\mathrm{H} 2 \mathrm{O}}<1,000 \mathrm{~Pa}, 0<\mathrm{P}_{\mathrm{H} 2}<100 \mathrm{~Pa}\right.$ ). Appendix $\mathrm{C}$ shows the individual rate values measured at each test conditions. The kinetic parameters were determined following the same process used to determine kinetic parameters for the LH and BLH models from nuclear-grade graphite [13]. The following description of the data analysis approach is mostly reproduced from a technical report by Contescu et al. [13].

To measure the kinetic parameters for LH and BLH models, all valid data were simultaneously analyzed by solving a set of multiple nonlinear rate equations based on the global oxidation reaction, from which the most probable parameter values were found by minimization of the sum of squared errors (SSE) for $\mathrm{Y}=\log$ (Rate), where $\mathrm{Y}$ is the rate measured at any given condition, and Rate is the weight-normalized oxidation rate $\left(\mathrm{mg}_{\text {oxidized }} / \mathrm{mg}_{\text {initial }} / \mathrm{s}\right.$, or s$\left.{ }^{-1}\right)$. Two different rate equations were used for data analysis of the LH and BLH models, as follows:

- Classical LH equation $[10,19]$ :

$$
\begin{gathered}
\text { Rate }_{L H}\left(P_{H 2 O} P_{H 2}, T\right)=\frac{k_{1} P_{H 2 O}}{1+k_{2}\left(P_{H 2}\right)^{0.5}+k_{3} P_{H 2 O}} \\
k_{i}=A_{i} \exp \left(-\frac{E_{i}}{R T}\right)
\end{gathered}
$$

In these equations, $T$ is the temperature $(\mathrm{K}), E$ is the activation energy $\left(\mathrm{J} \cdot \mathrm{mol}^{-1}\right), k_{i}$ represents the three rate constants (for $i=1,2$, and 3 ), and $\mathrm{R}$ is the gas constant $\left(8.314 \mathrm{~J} \cdot \mathrm{mol}^{-1} \cdot \mathrm{K}^{-1}\right)$. This kinetic model has six parameters which must be estimated by fitting all data: three preexponential factors $\left(A_{i}, i=1,2,3\right)$ and three apparent activation energies $\left(E_{i}, i=1,2,3\right)$.

- The BLH model [16,26]:

$$
\begin{gathered}
\text { Rate }_{B L H}\left(P_{H 2 O} P_{H 2}, T\right)=\frac{k_{1}\left(P_{H 2 O}\right)^{m(T)}}{1+k_{2}\left(P_{H 2}\right)^{0.5}+k_{3}\left(P_{H 2 O}\right)^{m(T)}} \\
k_{i}=A_{i} \exp \left(-\frac{E_{i}}{R T}\right) \\
m(T)=m_{m a x}+\frac{m_{\min }-m_{\max }}{1+\exp \left(\frac{T-T_{o}}{\theta}\right)}
\end{gathered}
$$

The BLH kinetic model $[16,26]$ was developed to account for the faster increase of oxidation rates at water vapor pressures $>100 \mathrm{~Pa}$ and temperatures $>950{ }^{\circ} \mathrm{C}$ relative to that predicted by the $\mathrm{LH}$ model. These differences between the experimental rates and those predicted by the LH model were observed in prior studies on medium grain (PCEA, NBG-17), superfine grain (IG-110) graphite, and superfine grain 
(Graphite 2114) graphite in a similar range of oxidant pressures and temperatures $[13,26]$. The BLH model was introduced to represent all data with a unique, more robust model. The BLH model accounts for this increased rate by introducing a correction to the LH model, assuming that the reaction order for the oxidant (water) depends on temperature, $m(T)$. This dependence, expressed by Equation 6, was best modeled by the integral Boltzmann distribution function with four new parameters: $m_{\min }$ and $m_{\max }$, which define the range of apparent reaction order to which a characteristic temperature is associated with the inflection of the $m(T)$ function, and $\theta$, which is a scaling parameter equal to the inverse slope of $m(T)$ at $T_{o}$. With these changes, the BLH model has ten parameters that must be estimated from the collected data.

\subsubsection{Data Analysis for High-Temperature/High Partial Pressure Empirical Oxidation}

Multiple time intervals were run for each test condition listed in Table 4 with a new sample for each run. The normalized weight loss was calculated from the difference in weight pre- and post-oxidation, divided by the pre-oxidation weight. The contribution to weight loss from residual oxygen in the system was determined by applying a linear fit to the baseline $\left(\mathrm{P}_{\mathrm{H} 20}=0 \mathrm{kPa}\right)$ tests for each of the temperatures of interests. This linear relationship was used to determine the normalized weight loss at equivalent exposure conditions for $\mathrm{P}_{\mathrm{H} 20}=10-48 \mathrm{kPa}$. The weight-normalized contribution to weight loss from the residual oxygen calculated from the linear fit was subtracted from the measured weight loss for the oxidized samples at equivalent exposure conditions to obtain an adjusted weight loss for each condition. Figure 11 illustrates this adjustment for $1200^{\circ} \mathrm{C}, 10 \mathrm{kPa}$ exposures.

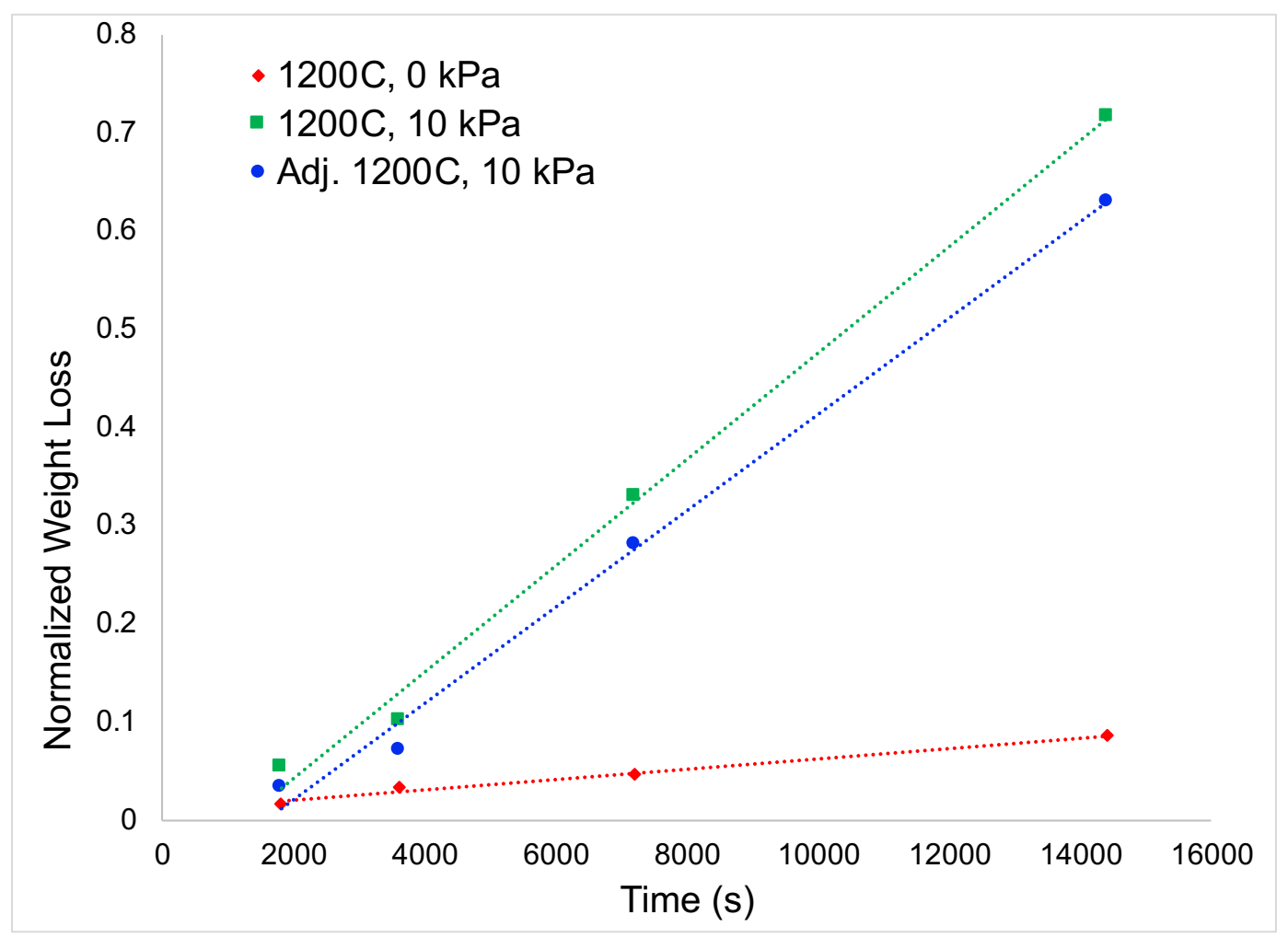

Figure 11. Adjusted weight loss to account for residual oxygen in the system.

The weight normalized oxidation rate $\left(s^{-1}\right)$ was determined for each condition by a linear fit of the adjusted weight loss for each condition at a specific temperature and $\mathrm{P}_{\mathrm{H} 20}$, where the slope of the fit is the rate in reciprocal seconds $\left(s^{-1}\right)$. The standard error for the oxidation rate was determined by a least-square fit of data at each measured condition. 


\section{RESULTS}

\subsection{RESULTS FOR OXIDATION KINETICS EVALUATION}

Appendix $\mathrm{C}$ provides the oxidation rate data acquired through testing and the corresponding test conditions. The rate data over the range of analyzed conditions $\left(\mathrm{P}_{\mathrm{H} 2 \mathrm{O}}, \mathrm{P}_{\mathrm{H} 2}, \mathrm{~T}\right)$ were fit to the analytical solution in Equation 7 and Equation 8 for the LH and BLH models, respectively. Equation 7 and Equation 8 were obtained by combining the equations presented in Section 2.3.1, which describe the LH (Equation 2 and Equation 3) and BLH (Equation 4-Equation 6) models. From this fit, the preexponential factors $\left(A_{i}\right)$ and apparent activation energies $\left(E_{i}\right)$ for each term can be obtained, along with the apparent reactor order $(m(T))$. Figure 12 shows the $\mathrm{LH}$ and $\mathrm{BLH}$ fit to the experimental oxidation rate data for $16 \mathrm{~Pa}<\mathrm{P}_{\mathrm{H} 2 \mathrm{O}}<$ $688 \mathrm{~Pa}, \mathrm{P}_{\mathrm{H} 2}=0$, and $850{ }^{\circ} \mathrm{C}<\mathrm{T}<1,200{ }^{\circ} \mathrm{C}$ where the individual data points represent the measured data and the isotherms represent the fits to the analytical solutions.

$$
\begin{aligned}
& \text { Rate }_{L H}\left(P_{H 2 O} P_{H 2}, T\right)=\frac{A_{1} \exp \left(-\frac{E_{1}}{R T}\right)\left(P_{H 2 O}\right)}{1+A_{2} \exp \left(-\frac{E_{2}}{R T}\right)\left(P_{H 2}\right)^{0.5}+A_{3} \exp \left(-\frac{E_{3}}{R T}\right)\left(P_{H 2 O}\right)}
\end{aligned}
$$

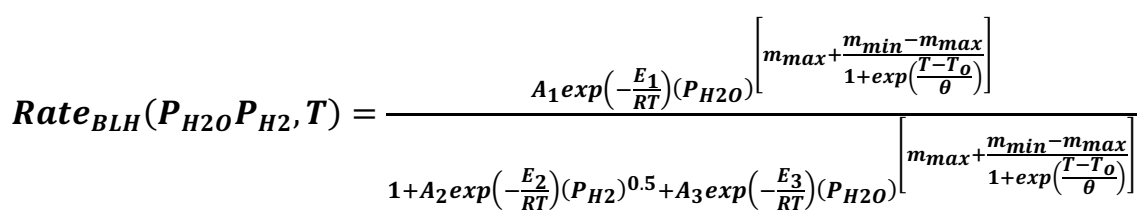
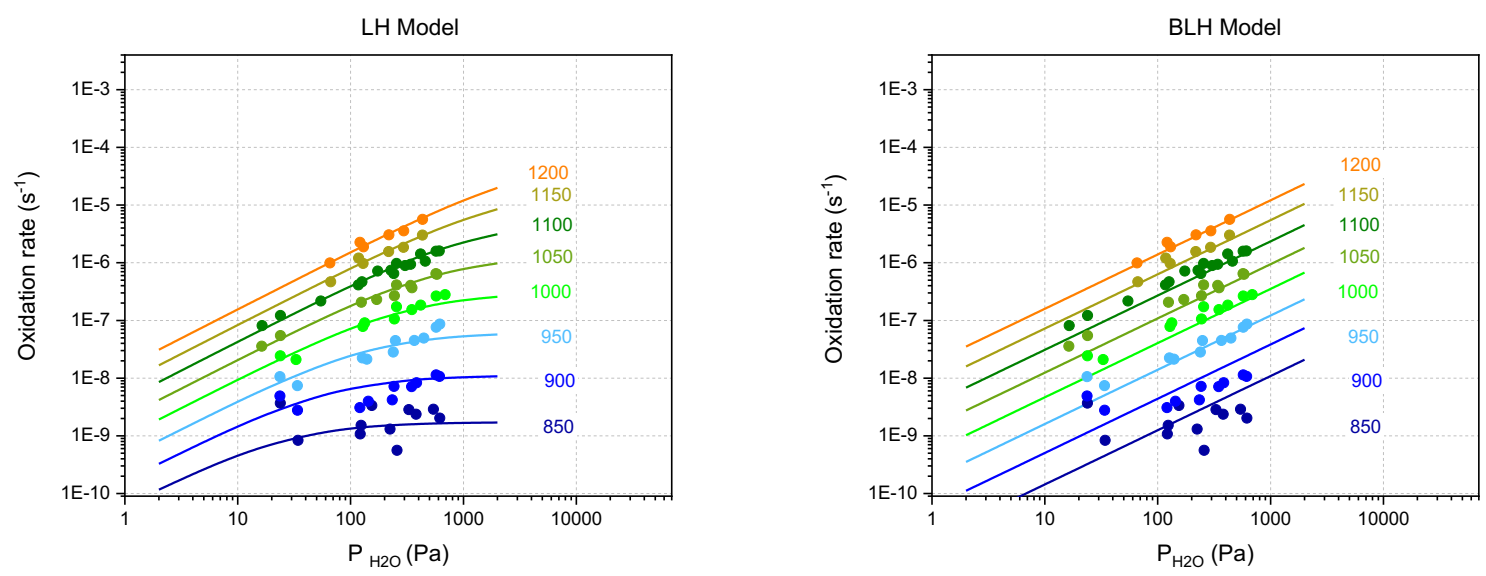

Figure 12. Experimental oxidations rates at $P_{H 2}=0$ with isothermal trend lines reflecting kinetic parameters determined from best fit for LH (left) and BLH (right) models.

The parameters for both LH and BLH models are listed in Table 6. The parameters were determined by a least squares analysis based on the minimization of the SSE for $\ln ($ Rate $)$ [13]. Comparison of the isothermal trend lines in Figure 12 suggests that at higher temperature $\left(>950{ }^{\circ} \mathrm{C}\right)$ and at higher pressures $\left(\mathrm{P}_{\mathrm{H} 2 \mathrm{O}}>200 \mathrm{~Pa}\right)$, the BLH model better represents the data, while at lower temperatures and pressures, the LH better represents the data. This suggested trend was previously observed for nuclear-grade graphite, but the variation at higher temperatures and pressures was more pronounced than that suggested in this data set [26]. 
Table 6. Experimentally determined kinetic parameters for LH and BLH models

\begin{tabular}{cc|cl|cc}
\hline & LH model & \multicolumn{5}{c}{ BLH model } \\
\hline$A_{1}$ & $2.8 \mathrm{E}-2(\mathrm{~Pa})^{-1}$ & $A_{1}$ & $1.1 \mathrm{E}+2(\mathrm{~Pa} \cdot \mathrm{s})^{-\mathrm{m}}$ & $m_{\max }$ & 0.94 \\
\hline$A_{2}$ & $4.0 \mathrm{E}-10(\mathrm{~Pa})^{-0.5}$ & $A_{2}$ & $6.6 \mathrm{E}-5(\mathrm{~Pa})^{-0.5}$ & $m_{\min }$ & 0.11 \\
\hline$A_{3}$ & $2.1 \mathrm{E}-16(\mathrm{~Pa})^{-1}$ & $A_{3}$ & $3.4 \mathrm{E}-4(\mathrm{~Pa})^{-\mathrm{m}}$ & $T_{0}$ & $1146 \mathrm{~K}$ \\
\hline$E_{1}$ & $181 \mathrm{~kJ} / \mathrm{mol}$ & $E_{1}$ & $276 \mathrm{~kJ} / \mathrm{mol}$ & $\theta$ & $75 \mathrm{~K}$ \\
\hline$E_{2}$ & $-223 \mathrm{~kJ} / \mathrm{mol}$ & $E_{2}$ & $-87 \mathrm{~kJ} / \mathrm{mol}$ & & \\
\hline$E_{3}$ & $-318 \mathrm{~kJ} / \mathrm{mol}$ & $E_{3}$ & $42 \mathrm{~kJ} / \mathrm{mol}$ & & \\
\hline
\end{tabular}

The quality of fit for the LH and BLH models is shown in Figure 13. The double logarithmic plot compares the observed rate to the predicted rate for the same test conditions for both oxidation tests with $\mathrm{H}_{2}$ present (red circles) and without $\mathrm{H}_{2}$ present (blue circles). The quality of fit is represented by the correlation coefficient $\left(\mathrm{R}^{2}\right)$ for the linear fit of the data. Perfect agreement follows a linear relationship with $\mathrm{R}^{2}=1.0$. The $\mathrm{R}^{2}$ value for the LH fit was 0.98 , and for the BLH fit it was 0.97 . This indicates both models represent the data accurately over the range of conditions studied. The suggestion that the BLH model represents the data better at higher temperatures and higher pressures indicates the quality of fit at the higher rates $(>1 \mathrm{E}-7)$ compared to the lower rates $(<1 \mathrm{E}-7)$. Here, the higher rates are associated with higher temperatures and pressures, where less scatter is observed, as compared to the rates associated with lower temperatures and pressures, where more scatter is observed. There is less scatter in the data at the lower rates $(<1 \mathrm{E}-7)$ for the LH model than for the BLH model. This suggests that the LH model is a better representation of low $\mathrm{P}_{\mathrm{H} 2 \mathrm{O}}$ and low $\mathrm{T}$, while the $\mathrm{BLH}$ model is a better representation at high $\mathrm{P}_{\mathrm{H} 2 \mathrm{O}}$ and high $\mathrm{T}$.
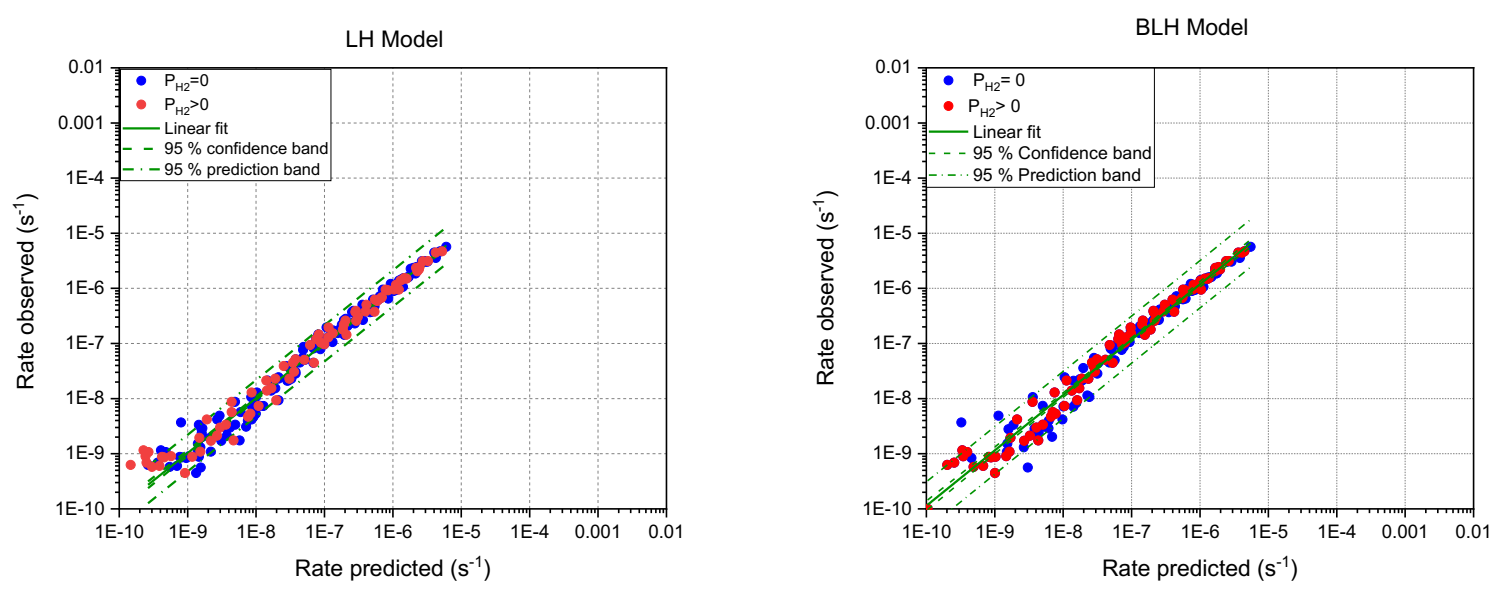

Figure 13. Observed vs. predicted rates for measured oxidation data for the LH and BLH models.

\subsection{RESULTS FOR HIGH-TEMPERATURE EMPIRICAL OXIDATION}

The normalized weight loss as a function of exposure time shows the impact of temperature and $\mathrm{P}_{\mathrm{H} 2 \mathrm{O}}$ on oxidation at test conditions relevant to accident conditions. Figure 14 through Figure 16 show normalized weight loss as a function of time for $1,200{ }^{\circ} \mathrm{C}, 1,300{ }^{\circ} \mathrm{C}$, and $1,400{ }^{\circ} \mathrm{C}$ over the range of $\mathrm{P}_{\mathrm{H} 2 \mathrm{O}}$ analyzed for each temperature. Figure 17 shows the oxidation behavior at $\mathrm{P}_{\mathrm{H} 2 \mathrm{O}}=10 \mathrm{kPa}$ from $1,200-1,500{ }^{\circ} \mathrm{C}$ to illustrate the impact of temperature at a constant $\mathrm{P}_{\mathrm{H} 2 \mathrm{O}}$. A linear fit was applied to the data to determine the oxidation rate $\left(\mathrm{s}^{-1}\right)$, as discussed in Section 2.3.2 (Table 7 lists rate analysis and associated uncertainty of the fit). The analysis indicates that the oxidation rate increases with increasing $\mathrm{P}_{\mathrm{H} 2 \mathrm{O}}$ up to $30 \mathrm{kPa}$. Testing at $1,200{ }^{\circ} \mathrm{C}$ analyzed $\mathrm{P}_{\mathrm{H} 2 \mathrm{O}}>30 \mathrm{kPa}$. The results at $1,200{ }^{\circ} \mathrm{C}$ showed that the rate at $\mathrm{P}_{\mathrm{H} 2 \mathrm{O}}=48 \mathrm{kPa}$ was similar to the rate at $\mathrm{P}_{\mathrm{H} 2 \mathrm{O}}=30 \mathrm{kPa}$, suggesting a saturation effect above $\mathrm{P}_{\mathrm{H} 2 \mathrm{O}}=30 \mathrm{kPa}$. The constant 
pressure analysis shown in Figure 17 highlights the overall impact of temperature. This analysis clearly indicates that oxidation increases with increasing temperature, as expected in a kinetic process. Multiple tests were run for select conditions at $\mathrm{P}_{\mathrm{H} 2 \mathrm{O}}=20 \mathrm{kPa}$ to determine the repeatability of the analyses.

Variation in the measured normalized weight loss was observed. The variability is not expected to be due to density differences. At $1,200{ }^{\circ} \mathrm{C}, \mathrm{P}_{\mathrm{H} 2 \mathrm{O}}=20 \mathrm{kPa}, 2 \mathrm{~h}$ exposures, the densities of the three samples ranged from $1.783-1.792 \mathrm{~g} / \mathrm{cm}^{3}$, which represents a $0.33-0.84 \%$ difference in density. However, this does not reflect the overall increase in weight loss observed across the three samples, which showed a $\sim 49 \%$ difference in magnitude between the lowest recorded weight loss and the maximum weight loss for the analyzed condition. The variation is expected to be associated with microstructural feature variation such as exposed pore structure and fissures.

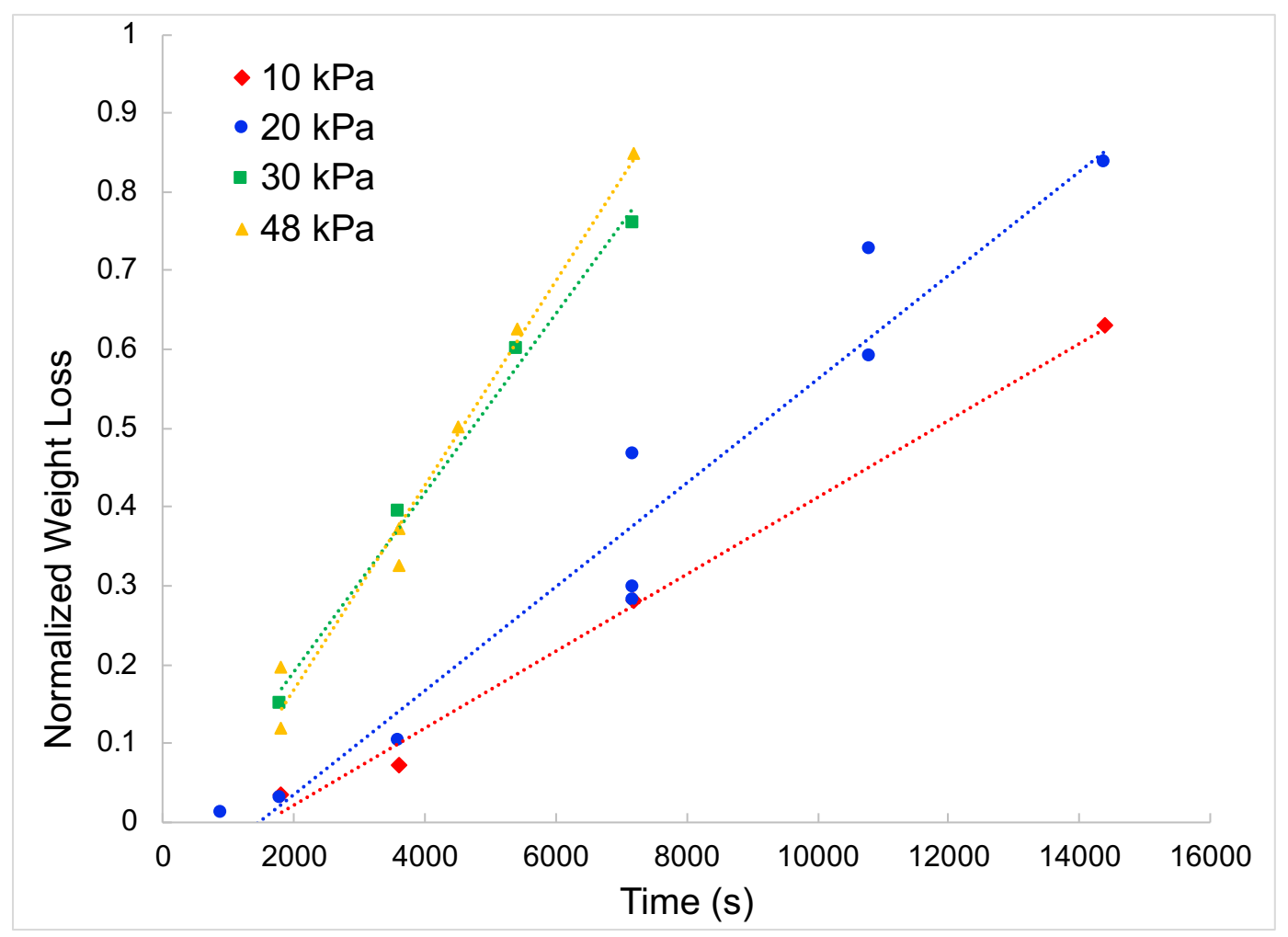

Figure 14. Normalized weight loss as a function $\mathrm{P}_{\mathrm{H} 2 \mathrm{O}}$ at $1,200{ }^{\circ} \mathrm{C}$. 


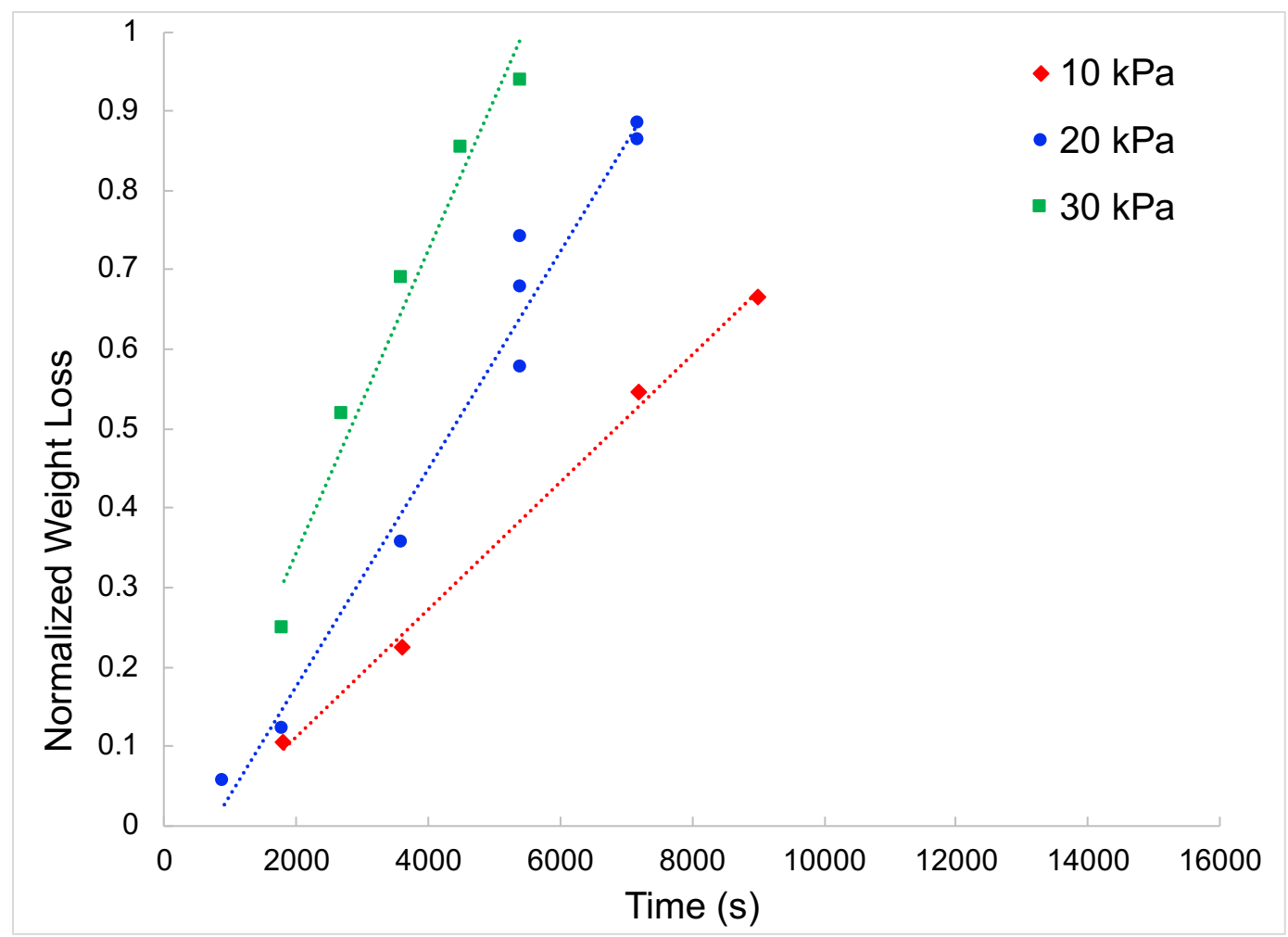

Figure 15. Normalized weight loss as a function $\mathrm{P}_{\mathrm{H}} \mathrm{O}$ at $1,300{ }^{\circ} \mathrm{C}$

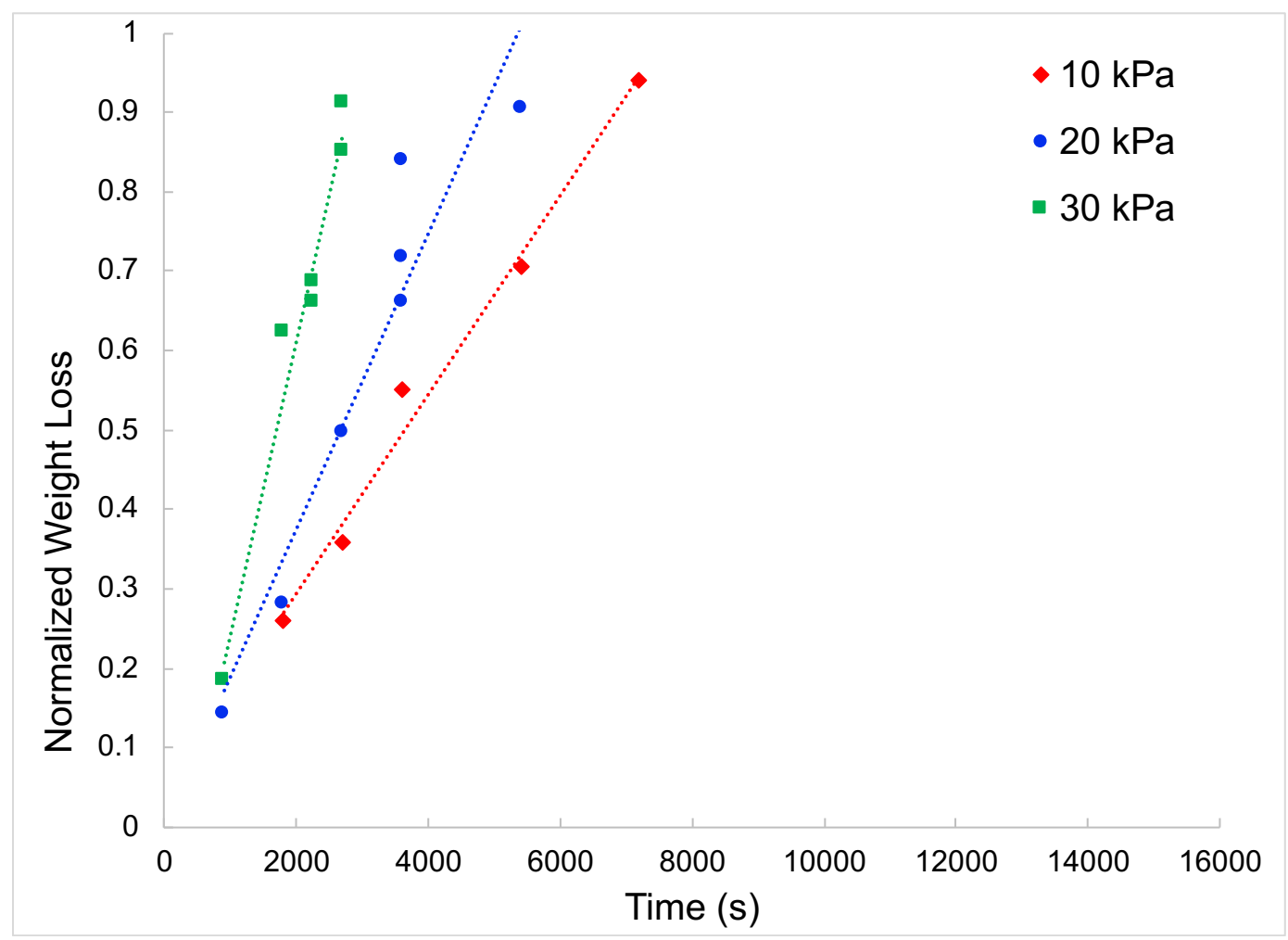

Figure 16. Normalized weight loss as a function $\mathrm{P}_{\mathrm{H} 2 \mathrm{O}}$ at $1,400{ }^{\circ} \mathrm{C}$ 


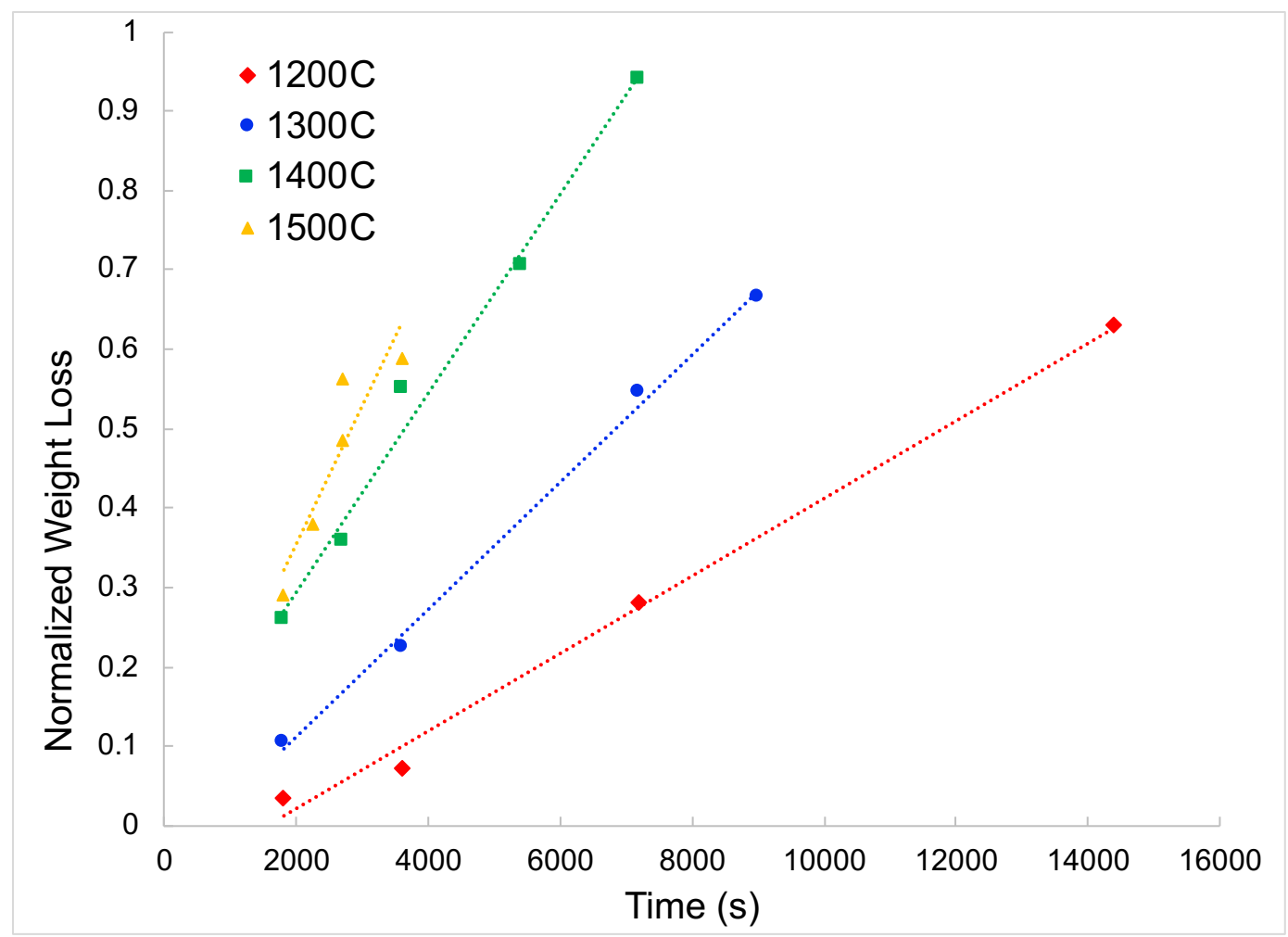

Figure 17. Normalized weight loss as a function temperature $\left(1,200-1,500{ }^{\circ} \mathrm{C}\right)$ at constant $\mathrm{P}_{\mathrm{H} 2 \mathrm{O}}\left(\mathrm{P}_{\mathrm{H} 2 \mathrm{O}}=10 \mathrm{kPa}\right)$.

The measured rates are presented in Table 7 and illustrated in Figure 18. The measured rates were fit to an Arrhenius relationship defining an effective rate equation for each $\mathrm{P}_{\mathrm{H} 2 \mathrm{O}}$ analyzed, equivalent to (3. Table 8 lists the activation energy $(E)$ and pre-exponential term $(A)$ associated with the Arrhenius relationship. The Arrhenius relationship is empirically derived and appropriate only over the range of conditions (including oxidant flow rate) analyzed.

Table 7. Rate analysis for high-temperature oxidation testing.

\begin{tabular}{cccc} 
Temperature $\left({ }^{\circ} \mathrm{C}\right)$ & $\mathrm{P}_{\text {H2O }}(\mathrm{kPa})$ & Rate $\left(\mathrm{s}^{-1}\right)^{*}$ & $\mathrm{R}^{2^{\wedge}}$ \\
\hline 1200 & 10 & $4.89 \pm 0.26 \times 10^{-5}$ & 0.99 \\
\hline 1200 & 20 & $6.59 \pm 0.60 \times 10^{-5}$ & 0.95 \\
\hline 1200 & 30 & $1.13 \pm 0.07 \times 10^{-4}$ & 0.99 \\
\hline 1200 & 48 & $1.30 \pm 0.08 \times 10^{-4}$ & 0.98 \\
\hline 1300 & 10 & $8.03 \pm 0.32 \times 10^{-5}$ & 1.00 \\
\hline 1300 & 20 & $1.37 \pm 0.09 \times 10^{-4}$ & 0.97 \\
\hline 1300 & 30 & $1.90 \pm 0.21 \times 10^{-4}$ & 0.97 \\
\hline 1400 & 10 & $1.25 \pm 0.09 \times 10^{-4}$ & 0.99 \\
\hline 1400 & 20 & $1.86 \pm 0.26 \times 10^{-4}$ & 0.91 \\
\hline 1400 & 30 & $3.71 \pm 0.36 \times 10^{-4}$ & 0.96 \\
\hline 1500 & 10 & $1.71 \pm 0.45 \times 10^{-4}$ & 0.83 \\
\hline
\end{tabular}

*error reported in standard error from linear regression analysis

${ }^{\wedge} \mathrm{R}^{2}$ value is rounded to two significant figures 


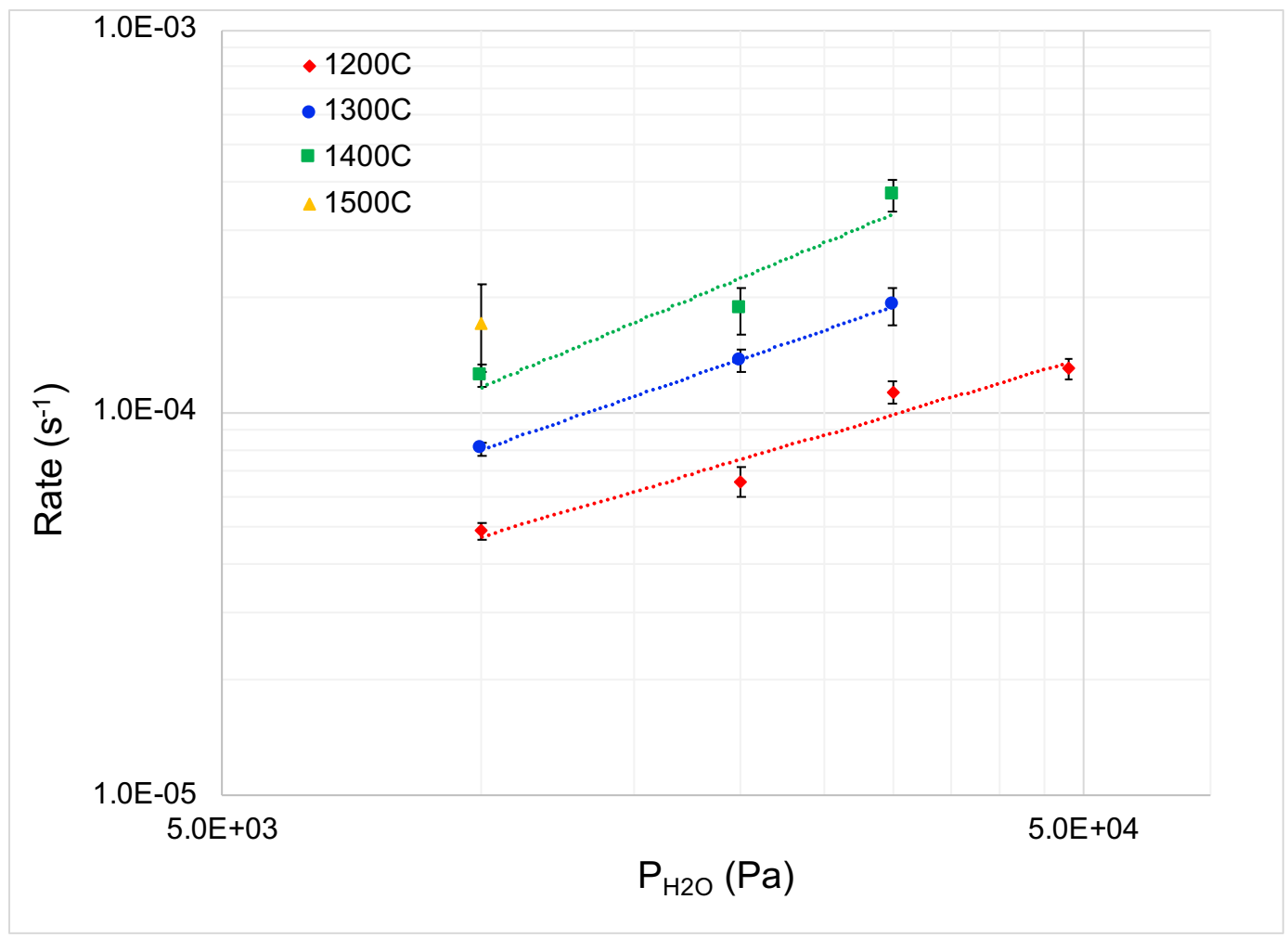

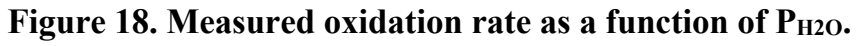

Table 8. Effective oxidation kinetics for matrix-only samples in high-temperature steam.

\begin{tabular}{ccc}
$\mathrm{P}_{\mathrm{H} 2 \mathrm{O}}(\mathrm{kPa})$ & $A\left(\mathrm{~s}^{-1}\right)$ & $E(\mathrm{~kJ} / \mathrm{mol})$ \\
\hline 10 & 0.09 & 91.6 \\
\hline 20 & 0.43 & 107.1 \\
\hline 30 & 2.18 & 121.3
\end{tabular}

Select samples were axially cross sectioned and optically imaged to show the nature of the oxidation behavior. Figure 19 shows a series of optical micrographs from an as-fabricated sample and from samples exposed to $1,200{ }^{\circ} \mathrm{C}$ for $1 \mathrm{~h}$ at different $\mathrm{P}_{\mathrm{H} 2 \mathrm{O}}(20-48 \mathrm{kPa})$. Appendix D shows optical micrographs from all that were samples subjected to cross sectional analysis. Fissures running perpendicular to the pressing direction were identified in the as-fabricated samples (Figure 19a). The presence of fissures was not unexpected based on previous observations for this matrix recipe [23]. A uniform oxidation layer is apparent around the outer surface of the oxidized samples (Figure 19b-d) with an apparently unaffected central region. Localized oxidation penetrating the bulk was also observed along the inner surface of fissures interesting the surface. This oxidized region appears to have a lower overall density relative to the bulk. The low-density oxidized regions are indicated by a darker color (relative to the bulk) and increased porosity, while pores that are not back-filled with epoxy appear black. The fissures serve as pathways for oxidation to penetrate the interior of the sample. Clear evidence of this is shown in the close-up micrograph in Figure 20a, in which oxidation has preferentially occurred along the exposed surface of the fissure which has intersected the sample surface. The samples exposed to higher $\mathrm{P}_{\mathrm{H} 2 \mathrm{O}}$ show significant oxidation along the fissures, leading to nonuniform oxidation of the sample. Close-up micrographs of the oxidation regions are shown in Figure 20b; the low-density oxidized material shows flake-like grains surrounded by epoxy, with an apparent gradient from loose graphitic flake to dense matrix material moving from exposed surfaces toward the bulk which has not experienced significant oxidation. 


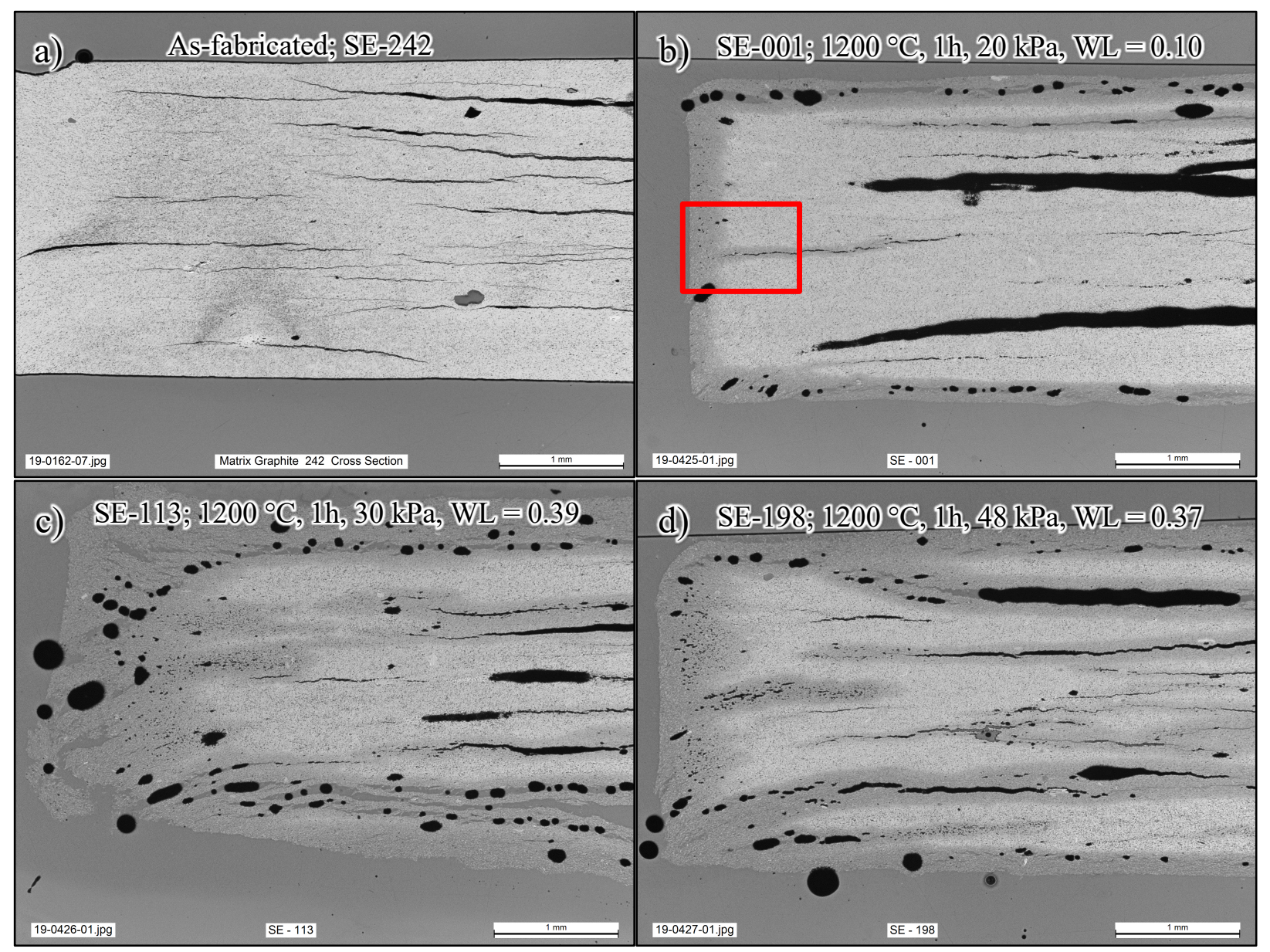

Figure 19. Overview micrographs of the cross section of the an-fabricated and select oxidized samples at $1,200{ }^{\circ} \mathrm{C}, 1 \mathrm{~h}$, and varying $\mathrm{P}_{\mathrm{H} 2 \mathrm{O}}$, showing the impact of macroscopic fissures on oxidation behavior in the high-temperature oxidation testing (red box identifies the approximate area of interest presented in Figure 20; black regions are pores not filled by epoxy; $W L$ is measured, normalized weight loss.

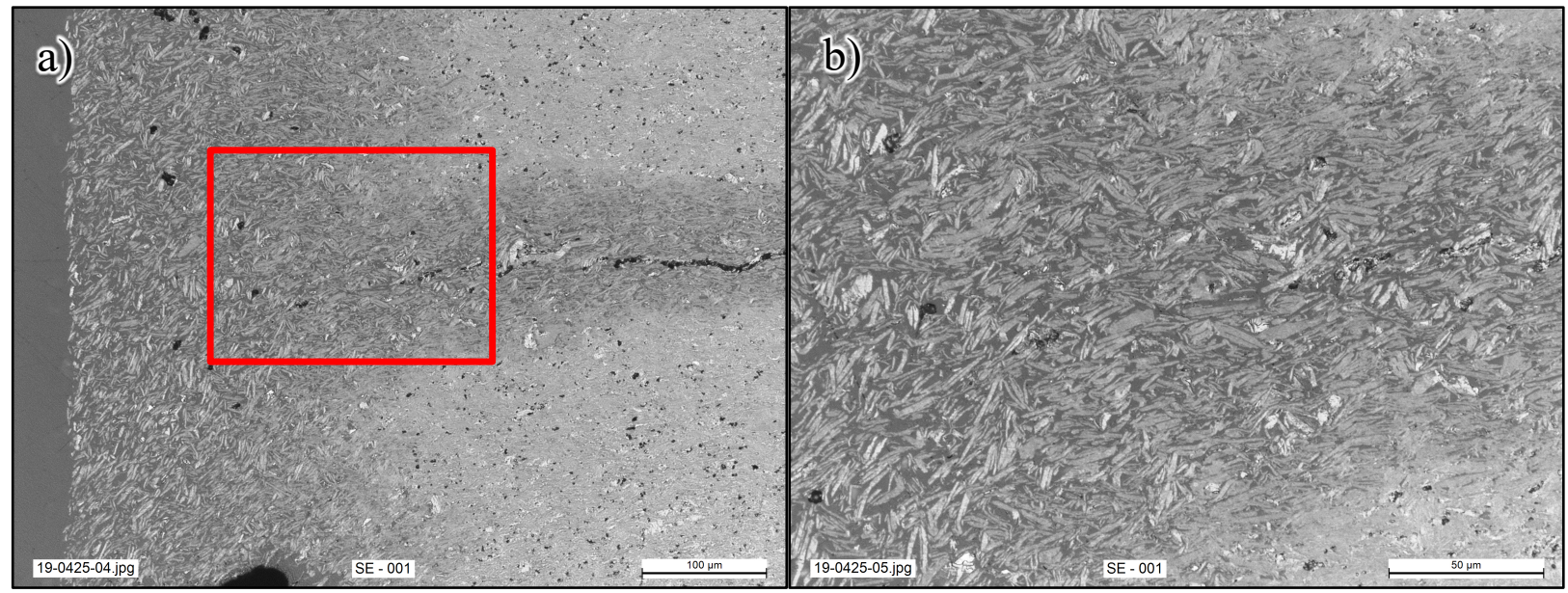

Figure 20. Close-up micrographs highlighting (a) penetration along the exposed fissures and (b) low-density oxidized region showing apparent residual graphite flake; the red box highlights the approximate area of interest shown in (b) in the higher magnification micrograph from SE-001 $\left(1,200{ }^{\circ} \mathrm{C}, 1 \mathrm{~h}, \mathrm{P}_{\mathrm{H} 2 \mathrm{O}}=20 \mathrm{kPa}\right)$. 
The preferential oxidation observed at the surface confirms that the oxidation reaction is beyond the purely kinetic regime. Based on the optical micrographs, the system appears to be in the transition regime (Figure 1), as there is clearly a partially oxidized region penetrating from the surface. However, the matrix-only samples are not a heterogenous material, consisting of a partially graphitized resin binder, natural graphite flake, and synthetic graphite flake. Each of these components is expected to have a different oxidation response. Because of the composite nature of the matrix-only samples, it is possible that the reaction is in the diffusion-controlled regime for the partially graphitized resin binder and in the transition regime for the graphite flake components, as they appear to preferentially remain in the low-density, oxidized regions.

The optical micrographs confirm the influence of exposed surface area on the oxidation behavior. The distribution of fissures in the samples likely explains the observed sample variance in high-temperature empirical oxidation tests. Here the presence of exposed fissures increases the effective surface area. In the kinetic regime, this would not impact the results, as the oxidation occurs uniformly. However, in the transition and diffusion-controlled regimes, the oxidation reaction is surface dependent, so the increased effective surface area will lead to an increase in the effective oxidation rate for the sample.

The high-temperature empirical oxidation rate data for $1,200-1,400{ }^{\circ} \mathrm{C}$ obtained from tests in the HTM were compared with the oxidation kinetics data from the lower-temperature TAG analysis in Figure 21. Figure 21 shows the LH and BLH models fit to the data acquired from the TAG analysis, which produced the kinetic parameters listed in Table 6. The data points below 1,000 Pa are from the TAG analysis, and the $\mathrm{LH}$ and BLH models were fit to these data. The data points for $\mathrm{P}_{\mathrm{H} 2 \mathrm{O}} \geq 10,000 \mathrm{~Pa}$ from the HTM tests were plotted and compared to the LH and BLH model predictions. Figure 22 shows the observed vs. predicted rates for measured oxidation data for the LH and BLH models, with high-temperature empirical oxidation results included. The correlation coefficient $\left(\mathrm{R}^{2}\right)$ for each fit with the high temperature data included is 0.98 for the LH model and 0.97 for the BLH model. The BLH model shows good agreement with the $1,200{ }^{\circ} \mathrm{C}$ data based on the comparison of the predicted rate vs. the measured oxidation rate. This would corroborate the assessment that the BLH model better captures the oxidation behavior at higher temperatures and $\mathrm{P}_{\mathrm{H} 2 \mathrm{O}}$ [13]. The appropriateness of the $\mathrm{BLH}$ model at $1,200{ }^{\circ} \mathrm{C}$ should be questioned, as the destructive analysis indicates that the samples are beyond the kinetic regime. This is supported for the higher temperature conditions in which both models overpredict the oxidation rates at $1,300{ }^{\circ} \mathrm{C}$ and $1,400{ }^{\circ} \mathrm{C}$. This is expected to be a result of the oxidation no longer being in the kinetic regime at the elevated temperatures. The optical micrographs indicate that oxidation was in the transition regime where both chemical kinetic and mass transfer phenomena are significant. An accurate model for that regime would have to include both of these effects. 

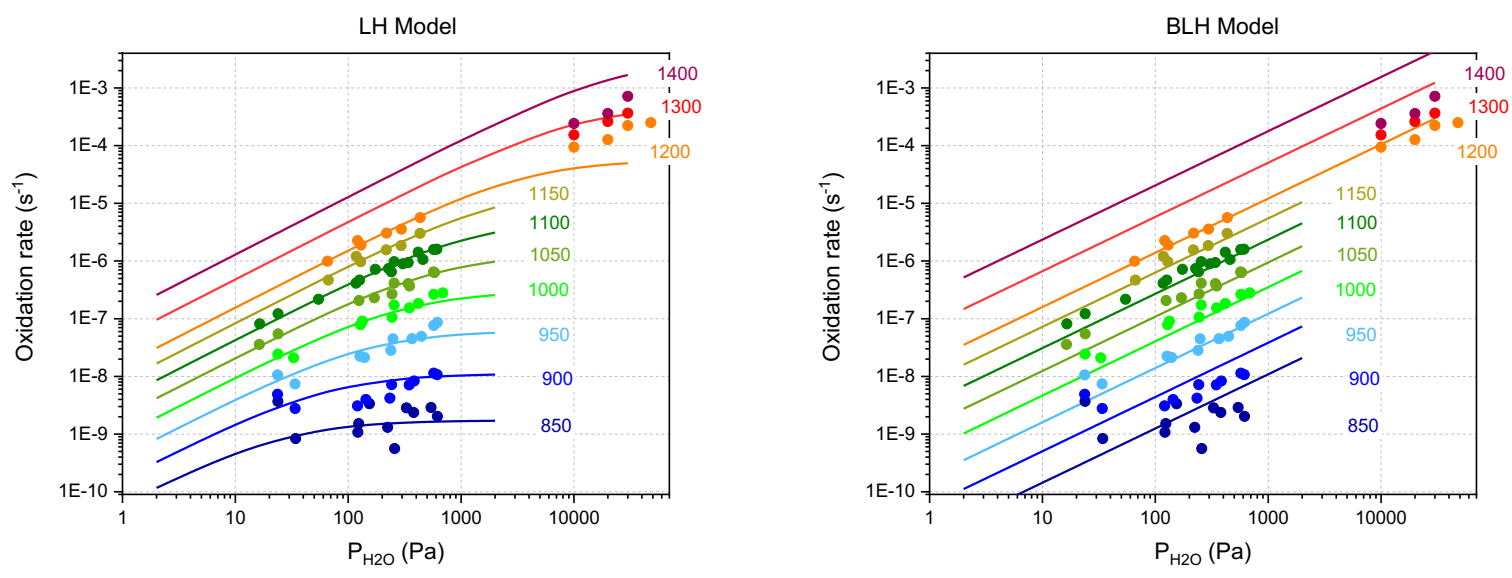

Figure 21. Experimental oxidations rates at $P_{\mathrm{H} 2}=0$ with isothermal trend lines reflecting kinetic parameters determined from best fit for LH (left) and BLH (right) models with high-temperature empirical oxidation results included.
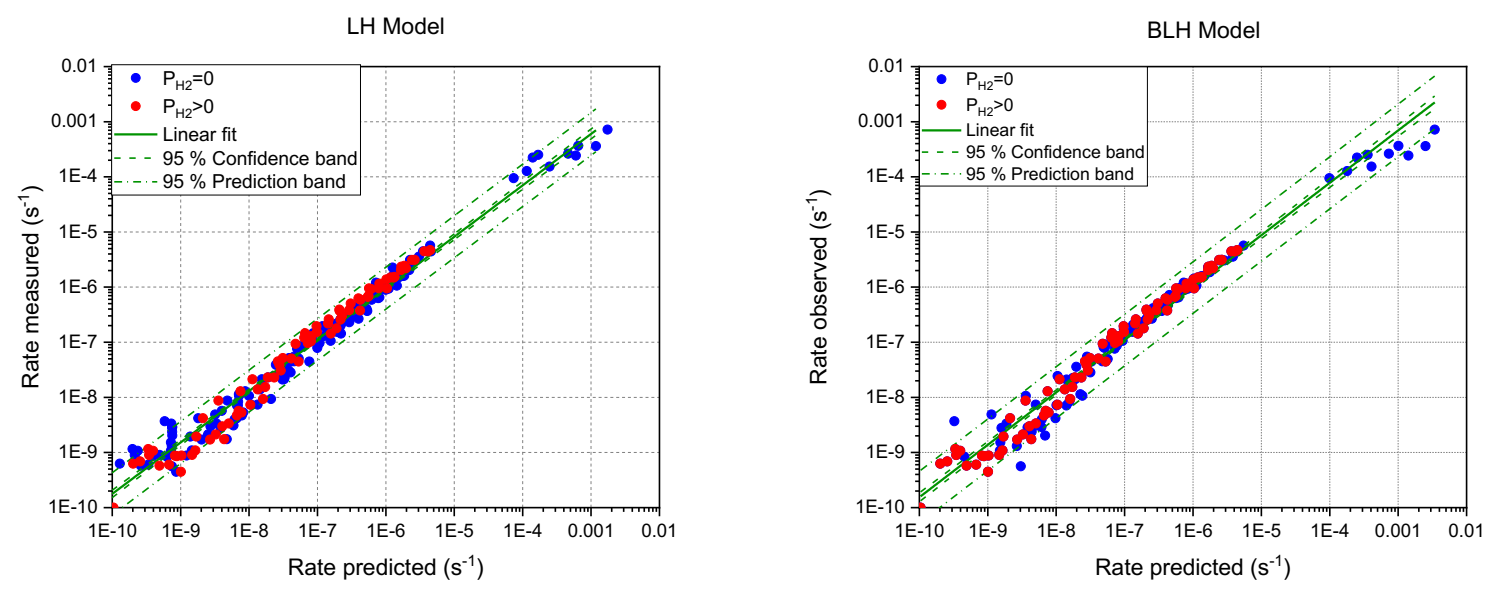

Figure 22. Observed versus predicted rate for measured oxidation data for the $\mathrm{LH}$ and BLH models with high-temperature empirical oxidation results included.

\section{SUMMARY}

This study established separate-effects testing of the oxidation performance of HTGR matrix material in varied moisture environments. Matrix-only samples were produced specifically for this investigation, with properties near representative of the AGR-5/6/7 pedigree and with density serving as the primary target and minimal fissuring as the secondary target. Investigation of the oxidation behavior was conducted over a wide range of oxidation conditions that spanned the kinetic regime and beyond. The range in conditions allowed for analysis of the chemical oxidation kinetics and the conditions relevant to extreme accident scenarios. The oxidation rate data in the oxidation kinetics evaluation were fit to two established models - - LH and BLH - to determine the kinetic parameters (Table 6). Both models fit the data reasonably well, with the $\mathrm{LH}$ model better representing the data at low temperatures and pressures $\left(\mathrm{P}_{\mathrm{H} 2 \mathrm{O}}\right)$, and the BLH model better representing the data at higher temperatures and pressures $\left(\mathrm{P}_{\mathrm{H} 2 \mathrm{O}}\right)$. This observation is consistent with prior analysis conducted for nuclear grade graphite. Ultimately, the obtained kinetic parameters can be leveraged in fuel performance models to determine the response of 
matrix material in various scenarios involving moisture ingress. The empirical oxidation testing at high temperatures $\left(1200 \leq \mathrm{T} \leq 1500^{\circ} \mathrm{C}\right)$ and high pressures $\left(\mathrm{P}_{\mathrm{H} 2 \mathrm{O}} \geq 10 \mathrm{kPa}\right)$ showed the expected trends, with increasing oxidation rate as a function of temperature. At a constant temperature, the testing showed oxidation rates increased with increasing $\mathrm{P}_{\mathrm{H} 2 \mathrm{O}}$, with apparent saturation beginning at $\sim 30 \mathrm{kPa}$. An Arrhenius relationship was fit to the varying oxidation rates according variable $\mathrm{P}_{\mathrm{H} 2 \mathrm{O}}$ at a given temperature. Comparison of the empirical high-temperature/high- $\mathrm{P}_{\mathrm{H} 2 \mathrm{O}}$ oxidation rates with the LH and BLH models showed that the models overpredicted the oxidation rate. This is justified, since a departure from the kinetic regimes into a diffusion dependent regime (transition or diffusion-controlled regime) is expected and was confirmed based on the observed deviation from the LH and BLH fits and by the surface dependence of the oxidation reaction shown in the optical microscopy of cross sectioned samples. This destructive analysis also highlighted the composite nature of the matrix-only samples, in which apparent selective oxidation of the carbonized resin binder is occurring, as residual graphite flake material appears to be remaining in the oxidized surface regions. Furthermore, the fissures in the samples acted as pathways for transport of oxidants from the sample surface to its interior. Differences in the number and structure of fissures from sample-to-sample also led to apparent variation in sample oxidation rate at hightemperatures/partial pressures beyond the kinetic regime. Sample-to-sample variation was not observed in the kinetic regime tests because kinetic oxidation occurs more uniformly throughout the sample an is not limited by oxidant mass transport effects that become more significant at higher temperatures.

Future work should target oxidation testing of matrix-only samples without fissures to isolate the high temperature matrix oxidation behavior given the variation of oxidation response in matrix material with fissures during testing beyond the kinetic regime. This testing would be more representative of a separate effects test. Matrix material from AGR-1 and AGR-2 experiments may satisfy this case. A systematic pursuit of matrix formulations, precursor materials (natural and synthetic graphite flake and resin), and processing routes may also be warranted. This would allow the exploration of fully dense material with minimal defects such as fissures or pores as well as materials with different microstructures. The motivation is to understand how the defect structure and matrix microstructure impacts the response to interactions with oxidants. Other areas of relevant pursuit may involve oxidation tests of surrogate fuel compacts containing non-fueled particles to better simulate the exact nature of the fissures in graphitic matrix material of fuel elements. 


\section{REFERENCES}

1. Preliminary Safety Information Document for the Standard MHTGR, Vol. 1, HTGR-86-024, Stone and Webster Engineering Corp., Boston, MA (1986).

2. F.C. Montgomery, "Evaluation of Need for Integral Fuel Oxidation Tests," DOE-HTGR-86002, GA Technologies, Inc. (1987).

3. Z. Yanhua, S. Lei, and W. Yan, "Water-ingress analysis for the $200 \mathrm{MWe}$ pebble-bed modular high temperature gas-cooled reactor," Nuclear Engineering and Design, 240 (2010) 3095-3107.

4. M. Richards, "REACT_COMPACT: A Computer code for Modeling Graphite Corrosion and Fuel Hydrolysis," Proceedings of the HTR 2016, Las Vegas, NV, November, (2016).

5. N. Iniotakis, and C.B. von der Decken, "Radiological consequences of a depressurized accident combined with water ingress in an HTR Module-200," Nuclear Engineering and Design, 109 (1988) 299-305.

6. G.H. Lohnert, "The consequences of water ingress into the primary circuit of an HTRModule-From design basis accident to hypothetical postulates," Nuclear Engineering and Design, 134 (1992) 159-176.

7. J. Wolters, R. Bongartz, W. Jahn, and R. Moormann, "The Significance of Water Ingress Accidents in Small HTRs," Nuclear Engineering and Design, 109, (1988) 289-294.

8. C. I. Contescu et al., "Practical Aspects for Characterizing Air Oxidation of Graphite," Journal of Nuclear Materials 381, (2008)15-24.

9. J. J. Lee, T. K. Ghosh, and S. K. Loyalka, "Oxidation Rate of Graphitic Matrix Material in the Kinetic Regime for VHTR Air Ingress Accident Scenarios," Journal of Nuclear Materials 451 (2014) 48-54.

10. C. Velasquez, G. Hightower, and R. Burnette, "The Oxidation of H-451 Graphite by Steam," GA-A14951, General Atomic Company (1978).

11. L. G. Overholser and J. P. Blakely, "Oxidation of Graphite by Low Concentrations of Water Vapor and Carbon Dioxide in Helium." Carbon 2 (1965) 385-394.

12. C. I. Contescu, R. W. Mee, et al., "Oxidation of PCEA Nuclear Graphite by Low Water Concentrations in Helium," Journal of Nuclear Materials 453 (2014) 225-232.

13. C. I. Contescu, Y. (Jo Jo) Lee, and R. W. Mee, "Oxidation Kinetics by Water Vapor of Nuclear Grade Graphite Grade 2114,” ORNL/TM-2018/1057, Oak Ridge National Laboratory, Oak Ridge, TN (2018).

14. R. C. Giberson and J. P. Walker, "Reaction of Nuclear Graphite with Water Vapor. Part I. Effect of Hydrogen and Water Vapor Partial Pressures, Carbon 3 (1966) 521-525.

15. J. J. Kane, C. I. Contescu. R. E. Smith, G. Strydom, and W. E. Windes, "Understanding the Reaction of Nuclear Graphite with Molecular Oxygen: Kinetics, Transport, and Structural Evolution” Journal of Nuclear Materials 493 (2017) 343-367.

16. C. I. Contescu and R. Mee, "Status of Chronic Oxidation Studies of Graphite," ORNL/TM2016/195. Oak Ridge National Laboratory, Oak Ridge, TN (2018).

17. C. I. Contescu, T. D. Burchell, and R. W. Mee, "Accelerated Oxidation Studies of PCEA Nuclear Graphite by Low Concentrations of Water and Hydrogen in Helium," ORNL/TM2013/524, Oak Ridge National Laboratory, Oak Ridge, TN (2013).

18. C. I. Contescu, T. D. Burchell, and R. W. Mee, "Kinetics of Chronic Oxidation of NBG-17 Nuclear Graphite by Water Vapor," ORNL/TM-2015/142, Oak Ridge National Laboratory, Oak Ridge, TN (2015).

19. P. L. Walker, Jr., F. Rusinko, Jr., and L. G. Austin, "Gas Reactions of Carbon,” $A d v$. Catalysis 11 (1959) 133-221.

20. T. H. Hurt and J. M. Calo, "Semi-Global Intrinsic Kinetics for Char Combustion Modeling," Combustion and Flame 125 (2001)138-1149. 
21. D. W. Marshall, “AGR-5/6/7 Fuel Specification.” SPC-1352-R5, Idaho National Laboratory, Idaho Falls, ID (2015).

22. B. P. Collin, “AGR-5/6/7 Irradiation Experiment Test Plan,” PLN-5245, Idaho National Laboratory, Idaho Falls, ID (2017).

23. M. P. Trammel and B. C. Jolly, "AGC-4 Compact Fabrication Study.” Oak Ridge National Laboratory, Oak Ridge, TN (2014).

24. K. A. Terrani and C. M. Silva, "High Temperature Steam Oxidation of SiC Coating Layer of TRISO Fuel Particles," Journal of Nuclear Materials 460 (2015) 160-165.

25. "Standard Test Method for Air Oxidation of Carbon and Graphite in the Kinetic Regime." ASTM D7542-09 (2016).

26. C. I. Contescu, R. W. Mee, Y. (Jo Jo) Lee, J. D. Arregui-Mena, N. C. Gallego, T. D. Burchell, J. J. Kane, and W. E. Windes, Beyond the Classical Kinetic Model for Chronic Graphite Oxidation by Moisture in High Temperature Gas-Cooled Reactors," Carbon 127 (2018) 158-169. 


\section{APPENDIX A. AS-FABRICATED MATRIX SAMPLE PROPERTIES}

Table A-1. As-fabricated matrix-only sample properties and acceptance status. Measured properties include diameter (dia.), density $(\rho)^{\wedge}$, weight ${ }^{\wedge}$, and surface area-to-volume ratio (SA:V). All measured properties (except $\mathrm{SA}: \mathrm{V}$ ) represent the mean where $\sigma$ is the standard deviation.

\begin{tabular}{|c|c|c|c|c|c|c|c|c|c|c|c|}
\hline $\begin{array}{l}\text { Sample } \\
\text { ID }\end{array}$ & $\begin{array}{l}\text { Dia. } \\
(\mathbf{m m})\end{array}$ & $\begin{array}{c}\sigma \text {-Dia. } \\
(\mathbf{m m})\end{array}$ & $\begin{array}{c}\text { Length } \\
\text { (mm) }\end{array}$ & $\begin{array}{c}\sigma- \\
\text { Length } \\
(\mathbf{m m})\end{array}$ & $\begin{array}{c}\text { Weight } \\
\text { (g) }\end{array}$ & $\begin{array}{c}\rho \\
\left(\mathrm{g} / \mathbf{c m}^{3}\right)\end{array}$ & $\begin{array}{c}\sigma-\rho \\
\left(\mathrm{g} / \mathrm{cm}^{3}\right)\end{array}$ & SA:V & $\begin{array}{c}\text { Status } \\
\text { (visual) }\end{array}$ & $\begin{array}{l}\text { Status } \\
(\rho)\end{array}$ & $\begin{array}{l}\text { Status } \\
\text { (final) }\end{array}$ \\
\hline SE-001 & 12.156 & 0.003 & 2.538 & 0.012 & 0.528 & 1.792 & 0.001 & $1: 1.12$ & Accept & Accept & Accept \\
\hline SE-002 & 12.147 & 0.000 & 2.525 & 0.006 & 0.527 & 1.803 & 0.006 & $1: 1.12$ & Accept & Accept & Accept \\
\hline SE-003 & 12.151 & 0.000 & 2.521 & 0.003 & 0.528 & 1.808 & 0.003 & $1: 1.12$ & Reject & Accept & Reject \\
\hline SE-004 & 12.143 & 0.001 & 2.514 & 0.016 & 0.528 & 1.815 & 0.016 & $1: 1.13$ & Reject & Reject & Reject \\
\hline SE-005 & 12.143 & 0.004 & 2.539 & 0.012 & 0.528 & 1.797 & 0.012 & $1: 1.12$ & Reject & Accept & eject \\
\hline SE-006 & 12.132 & 0.002 & 2.552 & 0.007 & 0.527 & 1.788 & 0.007 & 1:1.11 & Reject & Accept & Reject \\
\hline SE-007 & 12.153 & 0.001 & 2.548 & 0.013 & 0.528 & 1.786 & 0.013 & 1:1.11 & Accept & Accept & Accept \\
\hline SE-008 & 12.157 & 0.002 & 2.561 & 0.007 & 0.529 & 1.779 & 0.007 & 1:1.11 & Reject & Accept & Reject \\
\hline SE-009 & 12.146 & 0.003 & 2.542 & 0.009 & 0.529 & 1.795 & 0.009 & $1: 1.12$ & Reject & Accept & Reject \\
\hline SE-010 & 12.152 & 0.002 & 2.540 & 0.005 & 0.528 & 1.794 & 0.005 & 1:1.12 & Accept & Accept & Accept \\
\hline SE-011 & 12.146 & 0.001 & 2.559 & 0.000 & 0.527 & 1.777 & 0.000 & 1:1.11 & Reject & Accept & Reject \\
\hline SE-012 & 12.135 & 0.000 & 2.520 & 0.014 & 0.527 & 1.807 & 0.014 & 1:1.12 & Accept & Accept & Accept \\
\hline SE-013 & 12.148 & 0.002 & 2.628 & 0.009 & 0.528 & 1.732 & 0.009 & $1: 1.09$ & Reject & Accept & eject \\
\hline SE-014 & 12.138 & 0.000 & 2.572 & 0.016 & 0.528 & 1.773 & 0.016 & 1:1.11 & Reject & Accept & Reject \\
\hline SE-015 & 12.137 & 0.002 & 2.569 & 0.004 & 0.528 & 1.776 & 0.004 & 1:1.11 & Reject & Accept & eject \\
\hline SE-016 & 12.119 & 0.000 & 2.547 & 0.011 & 0.527 & 1.794 & 0.011 & $1: 1.12$ & Reject & Accept & Reject \\
\hline SE-017 & 12.152 & 0.001 & 2.546 & 0.012 & 0.527 & 1.783 & 0.012 & 1:1.11 & Reject & Accept & eject \\
\hline SE-018 & 12.145 & 0.001 & 2.543 & 0.002 & 0.528 & 1.792 & 0.002 & $1: 1.12$ & Accept & Accept & Accept \\
\hline SE-019 & 12.149 & 0.002 & 2.584 & 0.006 & 0.527 & 1.761 & 0.006 & 1:1.10 & Reject & Accept & eject \\
\hline SE-020 & 12.151 & 0.002 & 2.555 & 0.012 & 0.527 & 1.780 & 0.012 & 1:1.11 & Accept & Accept & Accept \\
\hline SE-021 & 12.152 & 0.001 & 2.583 & 0.011 & 0.527 & 1.760 & 0.011 & 1:1.10 & Reject & Accept & Reject \\
\hline SE-022 & 12.166 & 0.001 & 2.553 & 0.010 & 0.526 & 1.771 & 0.010 & $1: 1.11$ & Reject & Accept & Reject \\
\hline SE-023 & 12.171 & 0.001 & 2.576 & 0.023 & 0.528 & 1.762 & 0.023 & 1:1.11 & Accept & Accept & Accept \\
\hline SE-024 & 12.151 & 0.002 & 2.607 & 0.015 & 0.526 & 1.739 & 0.015 & $1: 1.10$ & Reject & Accept & Reject \\
\hline SE-025 & 12.158 & 0.001 & 2.654 & 0.014 & 0.528 & 1.712 & 0.014 & $1: 1.08$ & Reject & Accept & Reject \\
\hline SE-026 & 12.155 & 0.001 & 2.577 & 0.007 & 0.526 & 1.759 & 0.007 & 1:1.11 & Accept & Accept & Accept \\
\hline SE-027 & 12.154 & 0.002 & 2.550 & 0.004 & 0.527 & 1.782 & 0.004 & 1:1.11 & Reject & Accept & Reject \\
\hline SE-028 & 12.140 & 0.003 & 2.573 & 0.010 & 0.527 & 1.771 & 0.010 & 1:1.11 & Reject & Accept & Reject \\
\hline SE-029 & 12.145 & 0.003 & 2.613 & 0.004 & 0.527 & 1.742 & 0.004 & $1: 1.09$ & Accept & Accept & Accept \\
\hline SE-030 & 12.160 & 0.001 & 2.535 & 0.003 & 0.527 & 1.790 & 0.003 & 1:1.12 & Accept & Accept & Accept \\
\hline SE-031 & 12.149 & 0.001 & 2.574 & 0.002 & 0.528 & 1.770 & 0.002 & $1: 1.11$ & Reject & Accept & Reject \\
\hline SE-032 & 12.132 & 0.002 & 2.518 & 0.005 & 0.527 & 1.809 & 0.005 & $1: 1.12$ & Accept & Accept & Accept \\
\hline SE-033 & 12.170 & 0.001 & 2.642 & 0.015 & 0.539 & 1.753 & 0.015 & 1:1.09 & Reject & Accept & Reject \\
\hline SE-034 & 12.176 & 0.000 & 2.641 & 0.002 & 0.538 & 1.751 & 0.002 & $1: 1.09$ & Reject & Accept & Reject \\
\hline SE-035 & 12.147 & 0.001 & 2.552 & 0.014 & 0.527 & 1.783 & 0.014 & $1: 1.11$ & Accept & Accept & Accept \\
\hline SE-036 & 12.189 & 0.001 & 2.677 & 0.001 & 0.525 & 1.682 & 0.001 & $1: 1.08$ & Accept & Reject & Reject \\
\hline SE-037 & 12.164 & 0.003 & 2.604 & 0.013 & 0.528 & 1.745 & 0.013 & 1:1.10 & Reject & Accept & Reject \\
\hline SE-038 & 12.164 & 0.004 & 2.555 & 0.011 & 0.528 & 1.779 & 0.011 & 1:1.11 & Accept & Accept & Accept \\
\hline
\end{tabular}




\begin{tabular}{|c|c|c|c|c|c|c|c|c|c|c|c|}
\hline $\begin{array}{l}\text { Sample } \\
\text { ID }\end{array}$ & $\begin{array}{c}\text { Dia. } \\
\text { (mm) }\end{array}$ & $\begin{array}{c}\sigma \text {-Dia. } \\
(\mathbf{m m})\end{array}$ & $\begin{array}{c}\text { Length } \\
(\mathrm{mm})\end{array}$ & $\begin{array}{c}\sigma- \\
\text { Length } \\
(\mathbf{m m})\end{array}$ & $\begin{array}{c}\text { Weight } \\
\text { (g) }\end{array}$ & $\underset{\left(\mathrm{g} / \mathrm{cm}^{3}\right)}{\rho}$ & $\begin{array}{c}\sigma-\rho \\
\left(\mathrm{g} / \mathrm{cm}^{3}\right)\end{array}$ & SA:V & $\begin{array}{c}\text { Status } \\
\text { (visual) }\end{array}$ & $\begin{array}{c}\text { Status } \\
(\rho)\end{array}$ & $\begin{array}{l}\text { Status } \\
\text { (final) }\end{array}$ \\
\hline SE-039 & 2.138 & 0.002 & 2.611 & 0.008 & 0.528 & 1.747 & 0.008 & $1: 1.10$ & Accept & Accept & Accept \\
\hline SE-040 & 12.152 & 0.007 & 2.568 & 0.015 & 0.527 & 1.768 & 0.015 & $1: 1.11$ & Accept & Accept & Accept \\
\hline SE-041 & 12.479 & 0.233 & 2.596 & 0.006 & 0.526 & 1.655 & 0.006 & $1: 1.09$ & eject & eject & Reject \\
\hline SE-042 & 12.193 & 0.002 & 2.760 & 0.016 & 0.522 & 1.620 & 0.016 & $1: 1.05$ & eject & eject & Reject \\
\hline SE-043 & 12.132 & 0.002 & 2.588 & 0.010 & 0.528 & 1.765 & 0.010 & $1: 1.10$ & eject & Accept & Reject \\
\hline SE-044 & 12.138 & 0.002 & 2.544 & 0.016 & 0.528 & 1.792 & 0.016 & $1: 1.12$ & eject & Accept & Reject \\
\hline SE-045 & 12.137 & 0.000 & 2.561 & 0.011 & 0.527 & 1.780 & 0.011 & $1: 1.11$ & eject & Accept & Reject \\
\hline SE-046 & 12.146 & 0.001 & 2.515 & 0.004 & 0.527 & 1.808 & 0.004 & $1: 1.12$ & Reject & Accept & Reject \\
\hline SE-047 & 12.135 & 0.003 & 2.531 & 0.010 & 0.528 & 1.803 & 0.010 & $1: 1.12$ & eject & Accept & Reject \\
\hline SE-048 & 12.131 & 0.004 & 2.522 & 0.009 & 0.527 & 1.808 & 0.009 & $1: 1.12$ & eject & Accept & Reject \\
\hline SE-049 & 12.128 & 0.003 & 2.619 & 0.022 & 0.527 & 1.743 & 0.022 & 1:1.09 & eject & Accept & eject \\
\hline SE-050 & 12.127 & 0.000 & 2.580 & 0.010 & 0.527 & 1.770 & 0.010 & $1: 1.11$ & eject & Accept & Reject \\
\hline SE-051 & 12.134 & 0.004 & 2.567 & 0.003 & 0.529 & 1.781 & .003 & 1:1.11 & eject & Accept & eject \\
\hline SE-052 & 12.142 & 0.003 & 2.535 & 0.005 & 0.528 & 1.799 & 0.005 & $1: 1.12$ & Accept & Accept & Accept \\
\hline SE-053 & 12.121 & 0.005 & 2.541 & 0.013 & 0.529 & 1.802 & 0.013 & 1:1.12 & Accept & Accept & Accept \\
\hline SE-054 & 12.131 & 0.003 & 2.578 & 0.007 & 0.528 & 1.772 & 0.007 & 1:1.11 & eject & Accept & eject \\
\hline SE-055 & 12.126 & 0.002 & 2.549 & 0.013 & 0.529 & 1.796 & 0.013 & $1: 1.11$ & eject & Accept & Reject \\
\hline SE-056 & 12.135 & 0.003 & 2.570 & 0.012 & 0.529 & 1.779 & 0.012 & 1:1.11 & eject & Accept & eject \\
\hline SE-057 & 12.129 & 0.003 & 2.579 & 0.007 & 0.529 & 1.775 & 0.007 & 1:1.11 & Accept & Accept & Accept \\
\hline SE-058 & 12.136 & 0.002 & 2.563 & 0.026 & 0.528 & 1.781 & 0.026 & $1: 1.11$ & ccept & Accept & ccept \\
\hline SE-059 & 12.128 & 0.001 & 2.541 & 0.016 & 0.528 & 1.800 & 0.016 & $1: 1.12$ & Accept & Accept & Accept \\
\hline SE-060 & 12.135 & 0.004 & 2.552 & 0.011 & 0.528 & 1.790 & 0.011 & $1: 1.11$ & ccept & Accept & Accept \\
\hline SE-061 & 12.138 & 0.002 & 2.544 & 0.015 & 0.527 & 1.792 & 0.015 & $1: 1.12$ & Reject & Accept & Reject \\
\hline SE-062 & 12.135 & 0.003 & 2.560 & 0.007 & 0.527 & 1.778 & 0.007 & 1:1.11 & eject & Accept & eject \\
\hline SE-063 & 12.139 & 0.002 & 2.588 & 0.016 & 0.528 & 1.765 & 0.016 & $1: 1.10$ & eject & Accept & Reject \\
\hline SE-064 & 12.137 & 0.001 & 2.524 & 0.005 & 0.527 & 1.805 & 0.005 & 1:1.12 & Accept & Accept & Accept \\
\hline SE-065 & 12.124 & 0.001 & 2.545 & 0.015 & 0.528 & 1.796 & 0.015 & $1: 1.12$ & eject & Accept & Reject \\
\hline SE-066 & 12.117 & 0.001 & 2.526 & 0.004 & 0.524 & 1.798 & 0.004 & $1: 1.12$ & Accept & Accept & Accept \\
\hline SE-067 & 12.158 & 0.001 & 2.591 & 0.006 & 0.528 & 1.754 & 0.006 & $1: 1.10$ & Accept & Accept & Accept \\
\hline SE-068 & 12.150 & 0.003 & 2.555 & 0.007 & 0.527 & 1.778 & 0.007 & $1: 1.11$ & Accept & Accept & Accept \\
\hline SE-069 & 12.153 & 0.001 & 2.533 & 0.001 & 0.527 & 1.794 & 0.001 & $1: 1.12$ & Accept & Accept & Accept \\
\hline SE-070 & 12.143 & 0.002 & 2.553 & 0.009 & 0.527 & 1.784 & 0.009 & $1: 1.11$ & Reject & Accept & Reject \\
\hline SE-071 & 12.137 & 0.002 & 2.537 & 0.012 & 0.526 & 1.793 & 0.012 & 1:1.12 & Reject & Accept & Reject \\
\hline SE-072 & 12.130 & 0.002 & 2.570 & 0.008 & 0.529 & 1.780 & 0.008 & 1:1.11 & Reject & Accept & Reject \\
\hline SE-073 & 12.136 & 0.002 & 2.543 & 0.005 & 0.529 & 1.799 & 0.005 & $1: 1.12$ & Reject & Accept & Reject \\
\hline SE-074 & 12.181 & 0.035 & 2.565 & 0.003 & 0.527 & 1.761 & 0.003 & $1: 1.11$ & Reject & Accept & Reject \\
\hline SE-075 & 12.123 & 0.005 & 2.541 & 0.011 & 0.528 & 1.800 & 0.011 & $1: 1.12$ & Accept & Accept & Accept \\
\hline SE-076 & 12.132 & 0.004 & 2.565 & 0.003 & 0.528 & 1.781 & 0.003 & 1:1.11 & Reject & Accept & Reject \\
\hline SE-077 & 12.141 & 0.002 & 2.558 & 0.020 & 0.529 & 1.787 & 0.020 & $1: 1.11$ & Reject & Accept & Reject \\
\hline SE-078 & 12.145 & 0.002 & 2.509 & 0.006 & 0.523 & 1.800 & 0.006 & 1:1.13 & Accept & Accept & Accept \\
\hline SE-079 & 12.154 & 0.000 & 2.543 & 0.011 & 0.529 & 1.791 & 0.011 & 1:1.12 & Reject & Accept & Reject \\
\hline SE-080 & 12.140 & 0.001 & 2.521 & 0.005 & 0.526 & 1.802 & 0.005 & $1: 1.12$ & Reject & Accept & Reject \\
\hline SE-081 & 12.180 & 0.002 & 2.587 & 0.006 & 0.524 & 1.738 & 0.006 & $1: 1.10$ & Reject & Accept & Reject \\
\hline SE-082 & 12.183 & 0.001 & 2.617 & 0.016 & 0.525 & 1.721 & 0.016 & $1: 1.09$ & Reject & Accept & Reject \\
\hline
\end{tabular}




\begin{tabular}{|c|c|c|c|c|c|c|c|c|c|c|c|}
\hline $\begin{array}{l}\text { Sample } \\
\text { ID }\end{array}$ & $\begin{array}{c}\text { Dia. } \\
\text { (mm) }\end{array}$ & $\begin{array}{c}\sigma-\text {-Dia. } \\
(\mathbf{m m})\end{array}$ & $\begin{array}{c}\text { Length } \\
\text { (mm) }\end{array}$ & $\begin{array}{c}\sigma- \\
\text { Length } \\
(\mathbf{m m})\end{array}$ & $\begin{array}{c}\text { Weight } \\
\text { (g) }\end{array}$ & $\begin{array}{c}\rho \\
\left(\mathbf{g} / \mathbf{c m}^{3}\right)\end{array}$ & $\begin{array}{c}\sigma-\rho \\
\left(\mathrm{g} / \mathrm{cm}^{3}\right)\end{array}$ & SA:V & $\begin{array}{c}\text { Status } \\
\text { (visual) }\end{array}$ & $\begin{array}{l}\text { Status } \\
(\rho)\end{array}$ & $\begin{array}{l}\text { Status } \\
\text { (final) }\end{array}$ \\
\hline SE-083 & 12.205 & 0.003 & 2.578 & 0.011 & 526 & 1.743 & 0.011 & $1: 1.10$ & eject & Accept & Reject \\
\hline SE-084 & 12.163 & 0.004 & 2.594 & 0.014 & 0.527 & 1.747 & 0.014 & $1: 1.10$ & eject & Accept & Reject \\
\hline SE-085 & 12.188 & 0.002 & 2.604 & 0.024 & 0.525 & 1.728 & 0.024 & 1:1.10 & eject & Accept & Reject \\
\hline SE-086 & 12.185 & 0.004 & 2.578 & 0.007 & 0.525 & 1.745 & 0.007 & $1: 1.10$ & Accept & Accept & Accept \\
\hline SE-087 & 12.203 & 0.003 & 2.575 & 0.003 & 0.525 & 1.744 & 0.003 & 1:1.10 & Reject & Accept & Reject \\
\hline SE-088 & 12.207 & 0.002 & 2.579 & 0.013 & 0.526 & 1.742 & 0.013 & $1: 1.10$ & Accept & Accept & Accept \\
\hline SE-089 & 12.189 & 0.003 & 2.607 & 0.010 & 0.525 & 1.726 & 0.010 & $1: 1.10$ & eject & Accept & Reject \\
\hline SE-090 & 12.191 & 0.006 & 2.582 & 0.014 & 0.525 & 1.743 & 0.014 & 1:1.10 & Accept & Accept & Accept \\
\hline SE-091 & 12.188 & 0.002 & 2.566 & 0.012 & 0.525 & 1.753 & 0.012 & 1:1.11 & eject & Accept & Reject \\
\hline SE-092 & 12.187 & 0.003 & 2.601 & 0.016 & 0.526 & 1.734 & 0.016 & $1: 1.10$ & eject & Accept & eject \\
\hline SE-093 & 12.203 & 0.001 & 2.585 & 0.015 & 0.527 & 1.742 & 0.015 & $1: 1.10$ & eject & Accept & Reject \\
\hline SE-094 & 12.179 & 0.002 & 2.568 & 0.005 & 0.526 & 1.757 & 0.005 & 1:1.11 & Accept & Accept & Accept \\
\hline SE-095 & 12.175 & 0.001 & 2.577 & 0.010 & 0.526 & 1.754 & 0.010 & $1: 1.10$ & Accept & Accept & Accept \\
\hline SE-096 & 12.191 & 0.001 & 2.588 & 0.008 & 0.527 & 1.744 & 0.008 & $1: 1.10$ & eject & Accept & Reject \\
\hline SE-097 & 12.211 & 0.004 & 2.596 & 0.013 & 0.524 & 1.722 & 0.013 & $1: 1.10$ & eject & Accept & eject \\
\hline SE-098 & 12.197 & 0.002 & 2.568 & 0.019 & 0.526 & 1.752 & 0.019 & 1:1.11 & Accept & Accept & Accept \\
\hline SE-099 & 12.199 & 0.002 & 2.555 & 0.008 & 0.526 & 1.762 & 0.008 & 1:1.11 & Accept & Accept & Accept \\
\hline SE-100 & 12.199 & 0.002 & 2.570 & 0.015 & 0.526 & 1.750 & 0.015 & $1: 1.11$ & Accept & Accept & Accept \\
\hline SE-101 & 12.169 & 0.001 & 2.593 & 0.017 & 0.527 & 1.746 & 0.017 & $: 1.10$ & eject & Accept & Reject \\
\hline SE-102 & 12.155 & 0.003 & 2.546 & 0.016 & 0.525 & 1.777 & 0.016 & 1:1.11 & Accept & Accept & Accept \\
\hline SE-103 & 12.173 & 0.001 & 2.585 & 0.016 & 0.528 & 1.754 & 0.016 & $1: 1.10$ & eject & Accept & Reject \\
\hline SE-104 & 12.157 & 0.004 & 2.564 & 0.019 & 0.528 & 1.774 & 0.019 & 1:1.11 & eject & ccept & Reject \\
\hline SE-105 & 12.171 & 0.000 & 2.563 & 0.004 & 0.528 & 1.769 & 0.004 & 1:1.11 & eject & Accept & Reject \\
\hline SE-106 & 12.169 & 0.004 & 2.585 & 0.014 & 0.528 & 1.756 & 0.014 & $1: 1.10$ & eject & Accept & Reject \\
\hline SE-107 & 12.120 & 0.006 & 2.627 & 0.023 & 0.527 & 1.740 & 0.023 & $1: 1.09$ & Accept & Accept & Accept \\
\hline SE-108 & 12.153 & 0.002 & 2.565 & 0.011 & 0.527 & 1.772 & 0.011 & 1:1.11 & Accept & Accept & Accept \\
\hline SE-109 & 12.133 & 0.004 & 2.557 & 0.012 & 0.527 & 1.784 & 0.012 & 1:1.11 & Reject & Accept & Reject \\
\hline SE-110 & 12.156 & 0.005 & 2.564 & 0.005 & 0.527 & 1.772 & 0.005 & $1: 1.11$ & eject & Accept & Reject \\
\hline SE-111 & 12.139 & 0.002 & 2.615 & 0.010 & 0.527 & 1.741 & 0.010 & 1:1.09 & eject & Accept & Reject \\
\hline SE-112 & 12.183 & 0.002 & 2.607 & 0.036 & 0.527 & 1.732 & 0.036 & $1: 1.10$ & Reject & Accept & Reject \\
\hline SE-113 & 12.192 & 0.006 & 2.594 & 0.027 & 0.527 & 1.740 & 0.027 & $1: 1.10$ & Accept & Accept & Accept \\
\hline SE-114 & 12.100 & 0.019 & 2.612 & 0.016 & 0.527 & 1.753 & 0.016 & $1: 1.10$ & Accept & Accept & Accept \\
\hline SE-115 & 12.201 & 0.003 & 2.621 & 0.017 & 0.526 & 1.716 & 0.017 & $1: 1.09$ & Accept & Accept & Accept \\
\hline SE-116 & 12.187 & 0.005 & 2.617 & 0.007 & 0.527 & 1.726 & 0.007 & 1:1.09 & Accept & Accept & Accept \\
\hline SE-117 & 12.169 & 0.004 & 2.579 & 0.017 & 0.526 & 1.754 & 0.017 & $1: 1.10$ & Accept & Accept & Accept \\
\hline SE-118 & 12.191 & 0.005 & 2.639 & 0.008 & 0.527 & 1.709 & 0.008 & 1:1.09 & Accept & Reject & Reject \\
\hline SE-119 & 12.162 & 0.007 & 2.611 & 0.010 & 0.527 & 1.737 & 0.010 & 1:1.09 & Accept & Accept & Accept \\
\hline SE-120 & 12.194 & 0.006 & 2.594 & 0.020 & 0.526 & 1.736 & 0.020 & $1: 1.10$ & Reject & Accept & Reject \\
\hline SE-121 & 12.169 & 0.003 & 2.603 & 0.004 & 0.528 & 1.744 & 0.004 & $1: 1.10$ & Accept & Accept & Accept \\
\hline SE-122 & 12.180 & 0.001 & 2.583 & 0.009 & 0.525 & 1.743 & 0.009 & $1: 1.10$ & Accept & Accept & Accept \\
\hline SE-123 & 12.130 & 0.003 & 2.578 & 0.011 & 0.528 & 1.772 & 0.011 & 1:1.11 & Accept & Accept & Accept \\
\hline SE-124 & 12.139 & 0.006 & 2.576 & 0.009 & 0.527 & 1.767 & 0.009 & $1: 1.11$ & Reject & Accept & Reject \\
\hline SE-125 & 12.160 & 0.004 & 2.557 & 0.012 & 0.528 & 1.778 & 0.012 & 1:1.11 & Reject & Accept & Reject \\
\hline SE-126 & 12.165 & 0.008 & 2.595 & 0.004 & 0.528 & 1.749 & 0.004 & $1: 1.10$ & Reject & Accept & Reject \\
\hline
\end{tabular}




\begin{tabular}{|c|c|c|c|c|c|c|c|c|c|c|c|}
\hline $\begin{array}{l}\text { Sample } \\
\text { ID }\end{array}$ & $\begin{array}{c}\text { Dia. } \\
\text { (mm) }\end{array}$ & $\begin{array}{c}\sigma \text {-Dia. } \\
(\mathrm{mm})\end{array}$ & $\begin{array}{c}\text { Length } \\
\text { (mm) }\end{array}$ & $\begin{array}{c}\sigma- \\
\text { Length } \\
(\mathbf{m m})\end{array}$ & $\begin{array}{l}\text { Weight } \\
\text { (g) }\end{array}$ & $\begin{array}{c}\rho \\
\left(\mathrm{g} / \mathbf{c m}^{3}\right)\end{array}$ & $\begin{array}{c}\sigma-\rho \\
\left(\mathrm{g} / \mathrm{cm}^{3}\right)\end{array}$ & SA:V & $\begin{array}{c}\text { Status } \\
\text { (visual) }\end{array}$ & $\begin{array}{c}\text { Status } \\
(\rho)\end{array}$ & $\begin{array}{l}\text { Status } \\
\text { (final) }\end{array}$ \\
\hline SE-127 & 2.084 & .019 & 626 & 0.007 & 0.526 & 1.747 & 0.007 & 1:1.09 & ccept & Accept & ccept \\
\hline SE-128 & 12.174 & 0.004 & 2.591 & 0.018 & 0.527 & 1.748 & 0.018 & $1: 1.10$ & ccept & Accept & ccept \\
\hline SE-129 & 2.175 & 0.004 & 2.612 & 0.016 & 0.528 & 1.735 & 0.016 & $1: 1.09$ & Accept & Accept & Accept \\
\hline SE-130 & 12.172 & 0.003 & 2.578 & 0.017 & 0.524 & 1.747 & 0.017 & $1: 1.10$ & Accept & Accept & Accept \\
\hline SE-131 & 12.171 & 0.005 & 2.618 & 0.009 & 0.527 & 1.729 & 0.009 & 1:1.09 & Accept & Accept & Accept \\
\hline SE-132 & 12.170 & 0.005 & 2.617 & 0.013 & 0.527 & 1.730 & 0.013 & $1: 1.09$ & eject & Accept & Reject \\
\hline SE-133 & 12.169 & 0.005 & 2.613 & 0.005 & 0.527 & 1.735 & 0.005 & $1: 1.09$ & Accept & Accept & Accept \\
\hline SE-134 & 12.180 & 0.003 & 2.611 & 0.012 & 0.527 & 1.730 & 0.012 & 1:1.09 & eject & Accept & eject \\
\hline SE-135 & 12.167 & 0.005 & 2.588 & 0.006 & 0.527 & 1.753 & 0.006 & $1: 1.10$ & Reject & Accept & Reject \\
\hline SE-136 & 12.152 & 0.013 & 2.596 & 0.015 & 0.527 & 1.752 & 0.015 & $1: 1.10$ & Accept & Accept & Iccept \\
\hline SE-137 & 12.160 & 0.003 & 2.584 & 0.008 & 0.527 & 1.756 & 0.008 & $1: 1.10$ & Accept & Accept & Accept \\
\hline SE-138 & 12.117 & 0.018 & 2.630 & 0.006 & 0.527 & 1.738 & 0.006 & 1:1.09 & Reject & Accept & Reject \\
\hline SE-139 & 12.159 & 0.005 & 2.595 & 0.015 & 0.527 & 1.749 & 0.015 & $1: 1.10$ & Accept & Accept & ccept \\
\hline SE-140 & 12.148 & 0.003 & 2.584 & 0.006 & 0.528 & 1.761 & 0.006 & $1: 1.10$ & Accept & Accept & Accept \\
\hline SE-141 & 12.140 & 0.001 & 2.617 & 0.008 & 0.529 & 1.747 & 0.006 & $1: 1.09$ & cept & cept & Accept \\
\hline SE-142 & 12.143 & 0.001 & 2.594 & 0.008 & 0.529 & 1.761 & 0.006 & $1: 1.10$ & Accept & Accept & Accept \\
\hline SE-143 & 12.136 & 0.001 & 2.579 & 0.009 & 0.529 & 1.773 & 0.006 & 1.11 & eject & ept & eject \\
\hline SE-144 & 12.153 & 0.002 & 2.585 & 0.004 & 0.530 & 1.767 & 0.003 & $1: 1.10$ & eject & Accept & Reject \\
\hline SE-145 & 12.137 & 0.001 & 2.654 & 0.011 & 0.530 & 1.725 & 0.007 & 1.08 & eject & Accept & Reject \\
\hline SE-146 & 12.153 & 0.001 & 2.580 & 0.006 & 0.529 & 1.768 & 0.004 & $1: 1.10$ & Accept & Accept & Accept \\
\hline SE-147 & 12.148 & 0.002 & 2.568 & 0.016 & 0.530 & 1.781 & 0.011 & $1: 1.11$ & eject & Accept & Reject \\
\hline SE-148 & 12.132 & 0.004 & 2.603 & 0.010 & 0.529 & 1.758 & 0.007 & $1: 1.10$ & eject & ccept & Reject \\
\hline SE-149 & 12.086 & 0.010 & 2.599 & 0.010 & 0.530 & 1.778 & 0.010 & $1: 1.10$ & Accept & Accept & Accept \\
\hline SE-150 & 12.139 & 0.003 & 2.566 & 0.003 & 0.530 & 1.783 & 0.003 & $1: 1.11$ & Accept & ccept & Accept \\
\hline SE-151 & 12.157 & 0.002 & 2.564 & 0.007 & 0.529 & 1.776 & 0.005 & $1: 1.11$ & Reject & Accept & Reject \\
\hline SE-152 & 12.142 & 0.002 & 2.541 & 0.001 & 0.528 & 1.795 & 0.001 & $1: 1.12$ & eject & Accept & Reject \\
\hline SE-153 & 12.152 & 0.001 & 2.603 & 0.001 & 0.528 & 1.748 & 0.001 & 1:1.10 & Reject & Accept & Reject \\
\hline SE-154 & 12.184 & 0.001 & 2.588 & 0.016 & 0.521 & 1.727 & 0.010 & $1: 1.10$ & Accept & Accept & Accept \\
\hline SE-155 & 12.159 & 0.002 & 2.563 & 0.004 & 0.528 & 1.775 & 0.003 & 1:1.11 & Accept & Accept & Accept \\
\hline SE-156 & 12.162 & 0.002 & 2.545 & 0.003 & 0.527 & 1.783 & 0.003 & 1:1.11 & Accept & Accept & Accept \\
\hline SE-157 & 12.164 & 0.003 & 2.589 & 0.001 & 0.527 & 1.752 & 0.003 & $1: 1.10$ & eject & Accept & Reject \\
\hline SE-158 & 12.162 & 0.002 & 2.589 & 0.007 & 0.527 & 1.752 & 0.005 & $1: 1.10$ & Reject & Accept & Reject \\
\hline SE-159 & 12.156 & 0.003 & 2.580 & 0.001 & 0.528 & 1.763 & 0.002 & $1: 1.10$ & Reject & Accept & Reject \\
\hline SE-160 & 12.164 & 0.001 & 2.604 & 0.018 & 0.528 & 1.744 & 0.012 & 1:1.10 & Reject & Accept & Reject \\
\hline SE-161 & 12.155 & 0.003 & 2.579 & 0.006 & 0.528 & 1.763 & 0.005 & $1: 1.10$ & Reject & Accept & Reject \\
\hline SE-162 & 12.157 & 0.000 & 2.535 & 0.002 & 0.529 & 1.796 & 0.001 & 1:1.12 & Accept & Accept & Accept \\
\hline SE-163 & 12.151 & 0.004 & 2.581 & 0.005 & 0.526 & 1.758 & 0.005 & $1: 1.10$ & Reject & Accept & Reject \\
\hline SE-164 & 12.166 & 0.001 & 2.583 & 0.037 & 0.525 & 1.747 & 0.025 & $1: 1.10$ & Reject & Accept & Reject \\
\hline SE-165 & 12.163 & 0.001 & 2.529 & 0.002 & 0.525 & 1.787 & 0.002 & $1: 1.12$ & Reject & Accept & Reject \\
\hline SE-166 & 12.172 & 0.001 & 2.549 & 0.001 & 0.526 & 1.773 & 0.001 & $1: 1.11$ & Reject & Accept & Reject \\
\hline SE-167 & 12.164 & 0.001 & 2.559 & 0.007 & 0.526 & 1.767 & 0.005 & 1:1.11 & Reject & Accept & Reject \\
\hline SE-168 & 12.179 & 0.000 & 2.561 & 0.004 & 0.527 & 1.765 & 0.003 & $1: 1.11$ & Reject & Accept & Reject \\
\hline SE-169 & 12.164 & 0.002 & 2.535 & 0.003 & 0.527 & 1.788 & 0.003 & 1:1.12 & Accept & Accept & Accept \\
\hline SE-170 & 12.168 & 0.002 & 2.562 & 0.005 & 0.526 & 1.766 & 0.004 & 1:1.11 & Accept & Accept & Accept \\
\hline
\end{tabular}




\begin{tabular}{|c|c|c|c|c|c|c|c|c|c|c|c|}
\hline $\begin{array}{l}\text { Sample } \\
\text { ID }\end{array}$ & $\begin{array}{c}\text { Dia. } \\
\text { (mm) }\end{array}$ & $\begin{array}{c}\sigma \text {-Dia. } \\
(\mathbf{m m})\end{array}$ & $\begin{array}{c}\text { Length } \\
\text { (mm) }\end{array}$ & $\begin{array}{c}\sigma- \\
\text { Length } \\
(\mathbf{m m})\end{array}$ & $\begin{array}{c}\text { Weight } \\
\text { (g) }\end{array}$ & $\underset{\left(\mathrm{g} / \mathrm{cm}^{3}\right)}{\rho}$ & $\begin{array}{c}\sigma-\rho \\
\left(\mathrm{g} / \mathrm{cm}^{3}\right)\end{array}$ & SA:V & $\begin{array}{c}\text { Status } \\
\text { (visual) }\end{array}$ & $\begin{array}{c}\text { Status } \\
(\rho)\end{array}$ & $\begin{array}{l}\text { Status } \\
\text { (final) }\end{array}$ \\
\hline SE-171 & 2.169 & 0.001 & 2.565 & 0.002 & 0.526 & 1.764 & 0.001 & 1:1.11 & eject & Accept & Reject \\
\hline SE-172 & 12.177 & 0.001 & 2.551 & 0.011 & 0.527 & 1.773 & 0.008 & $1: 1.11$ & Accept & Accept & Accept \\
\hline SE-173 & 12.157 & 0.003 & 2.593 & 0.002 & 0.526 & 1.748 & 0.003 & 1:1.10 & eject & Accept & Reject \\
\hline SE-174 & 12.176 & 0.002 & 2.567 & 0.003 & 0.527 & 1.763 & 0.003 & $1: 1.11$ & Accept & Accept & Accept \\
\hline SE-175 & 12.169 & 0.003 & 2.536 & 0.001 & 0.527 & 1.787 & 0.002 & $1: 1.12$ & Reject & Accept & Reject \\
\hline SE-176 & 12.170 & 0.000 & 2.573 & 0.002 & 0.527 & 1.760 & 0.002 & 1:1.11 & eject & Accept & Reject \\
\hline SE-177 & 12.172 & 0.002 & 2.568 & 0.001 & 0.527 & 1.762 & 0.002 & 1:1.11 & eject & Accept & Reject \\
\hline SE-178 & 12.169 & 0.000 & 2.531 & 0.004 & 0.526 & 1.788 & 0.003 & $1: 1.12$ & Accept & Accept & Accept \\
\hline SE-179 & 12.171 & 0.004 & 2.596 & 0.004 & 0.527 & 1.746 & 0.004 & $1: 1.10$ & eject & Accept & Reject \\
\hline SE-180 & 12.173 & 0.002 & 2.581 & 0.002 & 0.527 & 1.754 & 0.002 & $1: 1.10$ & eject & Accept & eject \\
\hline SE-181 & 12.202 & 0.001 & 2.615 & 0.002 & 0.523 & 1.709 & 0.001 & $1: 1.09$ & eject & eject & eject \\
\hline SE-182 & 12.183 & 0.004 & 2.584 & 0.007 & 0.527 & 1.751 & 0.006 & $1: 1.10$ & Accept & Accept & Accept \\
\hline SE-183 & 12.179 & 0.005 & 2.571 & 0.004 & 0.528 & 1.761 & 0.005 & $1: 1.11$ & eject & Accept & eject \\
\hline SE-184 & 12.171 & 0.006 & 2.604 & 0.005 & 0.527 & 1.739 & 0.005 & $1: 1.10$ & Accept & Accept & Accept \\
\hline SE-185 & 12.183 & 0.002 & 2.589 & 0.002 & 0.527 & 1.748 & 0.002 & 1.10 & eject & cept & Reject \\
\hline SE-186 & 12.184 & 0.003 & 2.615 & 0.003 & 0.527 & 1.729 & 0.003 & $1: 1.09$ & Accept & Accept & Accept \\
\hline SE-187 & 12.191 & 0.001 & 2.576 & 0.000 & 0.528 & 1.757 & 0.001 & $1: 1.10$ & eject & ccept & Reject \\
\hline SE-188 & 12.170 & 0.004 & 2.578 & 0.001 & 0.527 & 1.758 & 0.003 & $1: 1.10$ & Accept & Accept & Accept \\
\hline SE-189 & 12.177 & 0.004 & 2.607 & 0.002 & 0.527 & 1.735 & 0.003 & $1: 1.10$ & eject & Accept & Reject \\
\hline SE-190 & 12.180 & 0.001 & 2.567 & 0.006 & 0.527 & 1.761 & 0.004 & $1: 1.11$ & eject & ccept & Reject \\
\hline SE-191 & 12.178 & 0.004 & 2.633 & 0.009 & 0.528 & 1.720 & 0.006 & 1:1.09 & Reject & Accept & Reject \\
\hline SE-192 & 12.193 & 0.000 & 2.588 & 0.002 & 0.527 & 1.745 & 0.001 & 1.10 & ccept & ccept & ccept \\
\hline SE-193 & 12.163 & 0.004 & 2.587 & 0.004 & 0.527 & 1.753 & 0.004 & 1:1.10 & eject & Accept & Reject \\
\hline SE-194 & 12.190 & 0.002 & 2.589 & 0.000 & 0.528 & 1.746 & 0.001 & $1: 1.10$ & eject & Accept & Reject \\
\hline SE-195 & 12.190 & 0.003 & 2.572 & 0.004 & 0.527 & 1.756 & 0.003 & 1:1.11 & eject & Accept & Reject \\
\hline SE-196 & 12.177 & 0.001 & 2.589 & 0.003 & 0.527 & 1.748 & 0.002 & $1: 1.10$ & eject & Accept & Reject \\
\hline SE-197 & 12.175 & 0.001 & 2.592 & 0.003 & 0.527 & 1.745 & 0.002 & $1: 1.10$ & eject & Accept & Reject \\
\hline SE-198 & 12.173 & 0.005 & 2.604 & 0.004 & 0.526 & 1.736 & 0.005 & $1: 1.10$ & Accept & Accept & Accept \\
\hline SE-199 & 12.179 & 0.006 & 2.622 & 0.005 & 0.527 & 1.726 & 0.006 & 1:1.09 & eject & Accept & Reject \\
\hline SE-200 & 12.167 & 0.000 & 2.641 & 0.004 & 0.528 & 1.718 & 0.002 & $1: 1.09$ & eject & Accept & Reject \\
\hline SE-201 & 12.173 & 0.001 & 2.567 & 0.000 & 0.527 & 1.766 & 0.001 & 1:1.11 & eject & Accept & Reject \\
\hline SE-202 & 12.172 & 0.002 & 2.605 & 0.002 & 0.527 & 1.739 & 0.002 & $1: 1.10$ & Reject & Accept & Reject \\
\hline SE-203 & 12.173 & 0.001 & 2.562 & 0.001 & 0.527 & 1.768 & 0.001 & 1:1.11 & Reject & Accept & Reject \\
\hline SE-204 & 12.160 & 0.002 & 2.567 & 0.004 & 0.528 & 1.770 & 0.004 & $1: 1.11$ & Reject & Accept & Reject \\
\hline SE-205 & 12.164 & 0.002 & 2.550 & 0.001 & 0.526 & 1.774 & 0.002 & 1:1.11 & Accept & Accept & Accept \\
\hline SE-206 & 12.164 & 0.002 & 2.597 & 0.001 & 0.528 & 1.750 & 0.002 & $1: 1.10$ & Reject & Accept & Reject \\
\hline SE-207 & 12.169 & 0.002 & 2.629 & 0.002 & 0.527 & 1.724 & 0.002 & $1: 1.09$ & Reject & Accept & Reject \\
\hline SE-208 & 12.163 & 0.002 & 2.564 & 0.007 & 0.527 & 1.769 & 0.005 & 1:1.11 & Reject & Accept & Reject \\
\hline SE-209 & 12.166 & 0.003 & 2.608 & 0.002 & 0.527 & 1.738 & 0.003 & $1: 1.10$ & Reject & Accept & Reject \\
\hline SE-210 & 12.184 & 0.006 & 2.587 & 0.011 & 0.526 & 1.743 & 0.008 & $1: 1.10$ & Reject & Accept & Reject \\
\hline SE-211 & 12.169 & 0.001 & 2.576 & 0.004 & 0.527 & 1.759 & 0.003 & $1: 1.11$ & Reject & Accept & Reject \\
\hline SE-212 & 12.176 & 0.004 & 2.625 & 0.001 & 0.527 & 1.723 & 0.003 & 1:1.09 & Accept & Accept & Accept \\
\hline SE-213 & 12.168 & 0.003 & 2.604 & 0.005 & 0.528 & 1.743 & 0.004 & $1: 1.10$ & Reject & Accept & Reject \\
\hline SE-214 & 12.170 & 0.003 & 2.572 & 0.003 & 0.527 & 1.762 & 0.003 & 1:1.11 & Accept & Accept & Accept \\
\hline
\end{tabular}




\begin{tabular}{|c|c|c|c|c|c|c|c|c|c|c|c|}
\hline $\begin{array}{l}\text { Sample } \\
\text { ID }\end{array}$ & $\begin{array}{c}\text { Dia. } \\
\text { (mm) }\end{array}$ & $\begin{array}{c}\sigma \text {-Dia. } \\
(\mathbf{m m})\end{array}$ & $\begin{array}{c}\text { Length } \\
(\mathrm{mm})\end{array}$ & $\begin{array}{c}\sigma- \\
\text { Length } \\
(\mathbf{m m})\end{array}$ & $\begin{array}{c}\text { Weight } \\
\text { (g) }\end{array}$ & $\underset{\left(\mathrm{g} / \mathrm{cm}^{3}\right)}{\rho}$ & $\begin{array}{c}\sigma-\rho \\
\left(\mathrm{g} / \mathrm{cm}^{3}\right)\end{array}$ & SA:V & $\begin{array}{c}\text { Status } \\
\text { (visual) }\end{array}$ & $\begin{array}{c}\text { Status } \\
(\rho)\end{array}$ & $\begin{array}{l}\text { Status } \\
\text { (final) }\end{array}$ \\
\hline SE-215 & 2.159 & .000 & 2.551 & 0.002 & 0.528 & 1.782 & 0.002 & 1:1.11 & eject & Accept & Reject \\
\hline SE-216 & 12.184 & 0.001 & 2.587 & 0.004 & 0.527 & 1.746 & 0.003 & $1: 1.10$ & eject & Accept & Reject \\
\hline SE-217 & 12.159 & 0.003 & 2.592 & 0.004 & 0.528 & 1.754 & 0.003 & 1:1.10 & eject & Accept & Reject \\
\hline SE-218 & 12.164 & 0.005 & 2.592 & 0.006 & 0.528 & 1.753 & 0.005 & $1: 1.10$ & Reject & Accept & Reject \\
\hline SE-219 & 12.167 & 0.002 & 2.558 & 0.007 & 0.528 & 1.774 & 0.005 & 1:1.11 & Reject & Accept & Reject \\
\hline SE-220 & 12.163 & 0.002 & 2.586 & 0.005 & 0.528 & 1.756 & 0.004 & $1: 1.10$ & eject & Accept & Reject \\
\hline SE-221 & 12.178 & 0.002 & 2.572 & 0.001 & 0.527 & 1.759 & 0.001 & 1:1.11 & Accept & Accept & Accept \\
\hline SE-222 & 12.179 & 0.001 & 2.592 & 0.007 & 0.527 & 1.744 & 0.005 & 1:1.10 & Reject & Accept & Reject \\
\hline SE-223 & 12.169 & 0.000 & 2.602 & 0.006 & 0.527 & 1.742 & 0.004 & $1: 1.10$ & Reject & Accept & Reject \\
\hline SE-224 & 12.172 & 0.002 & 2.631 & 0.002 & 0.527 & 1.721 & 0.002 & 1:1.09 & eject & Accept & Reject \\
\hline SE-225 & 12.174 & 0.005 & 2.598 & 0.004 & 0.526 & 1.741 & 0.004 & $1: 1.10$ & eject & Accept & Reject \\
\hline SE-226 & 12.176 & 0.002 & 2.565 & 0.002 & 0.527 & 1.764 & 0.002 & 1:1.11 & Reject & Accept & Reject \\
\hline SE-227 & 12.186 & 0.002 & 2.581 & 0.004 & 0.528 & 1.752 & 0.003 & $1: 1.10$ & eject & Accept & Reject \\
\hline SE-228 & 12.172 & 0.002 & 2.584 & 0.002 & 0.527 & 1.753 & 0.002 & $1: 1.10$ & Accept & Accept & Accept \\
\hline SE-229 & 12.186 & 0.003 & 2.586 & 0.016 & 0.527 & 1.748 & 0.011 & $1: 1.10$ & eject & ccept & Reject \\
\hline SE-230 & 12.179 & 0.003 & 2.597 & 0.002 & 0.527 & 1.741 & 0.003 & $1: 1.10$ & Accept & Accept & Accept \\
\hline SE-231 & 12.170 & 0.002 & 2.577 & 0.000 & 0.527 & 1.759 & 0.001 & $1: 1.10$ & Accept & Accept & Accept \\
\hline SE-232 & 12.186 & 0.004 & 2.619 & 0.002 & 0.527 & 1.726 & 0.003 & $1: 1.09$ & Reject & Accept & Reject \\
\hline SE-233 & 12.177 & 0.001 & 2.574 & 0.004 & 0.527 & 1.759 & 0.003 & 1:1.11 & eject & Accept & Reject \\
\hline SE-234 & 12.179 & 0.004 & 2.594 & 0.000 & 0.527 & 1.744 & 0.003 & $1: 1.10$ & Reject & Accept & Reject \\
\hline SE-235 & 12.166 & 0.004 & 2.595 & 0.001 & 0.527 & 1.746 & 0.003 & $1: 1.10$ & Accept & Accept & Accept \\
\hline SE-236 & 12.102 & 0.016 & 2.594 & 0.005 & 0.522 & 1.750 & 0.012 & $1: 1.10$ & eject & ccept & Reject \\
\hline SE-237 & 12.179 & 0.004 & 2.574 & 0.001 & 0.527 & 1.758 & 0.003 & 1:1.11 & Accept & Accept & Accept \\
\hline SE-238 & 12.166 & 0.004 & 2.648 & 0.005 & 0.528 & 1.714 & 0.004 & $1: 1.08$ & Accept & Accept & Accept \\
\hline SE-239 & 12.167 & 0.002 & 2.579 & 0.005 & 0.526 & 1.755 & 0.004 & $1: 1.10$ & Accept & Accept & Accept \\
\hline SE-240 & 12.166 & 0.003 & 2.565 & 0.007 & 0.526 & 1.765 & 0.005 & $1: 1.11$ & Accept & Accept & Accept \\
\hline SE-241 & 12.182 & 0.005 & 2.574 & 0.002 & 0.527 & 1.757 & 0.004 & 1:1.11 & Accept & Accept & Accept \\
\hline SE-242 & 12.171 & 0.004 & 2.574 & 0.005 & 0.527 & 1.761 & 0.004 & $1: 1.11$ & Reject & Accept & Reject \\
\hline SE-243 & 12.170 & 0.002 & 2.591 & 0.005 & 0.528 & 1.752 & 0.004 & 1:1.10 & Reject & Accept & Reject \\
\hline SE-244 & 12.172 & 0.002 & 2.623 & 0.001 & 0.528 & 1.729 & 0.001 & 1:1.09 & Accept & Accept & Accept \\
\hline SE-245 & 12.199 & 0.002 & 2.639 & 0.002 & 0.528 & 1.711 & 0.002 & $1: 1.09$ & Reject & Reject & Reject \\
\hline SE-246 & 12.177 & 0.000 & 2.577 & 0.003 & 0.528 & 1.759 & 0.002 & $1: 1.10$ & Reject & Accept & Reject \\
\hline SE-247 & 12.166 & 0.004 & 2.582 & 0.006 & 0.527 & 1.756 & 0.005 & 1:1.10 & Reject & Accept & Reject \\
\hline SE-248 & 12.182 & 0.001 & 2.610 & 0.003 & 0.527 & 1.734 & 0.002 & $1: 1.09$ & Reject & Accept & Reject \\
\hline SE-249 & 12.172 & 0.001 & 2.608 & 0.000 & 0.527 & 1.736 & 0.001 & $1: 1.10$ & Reject & Accept & Reject \\
\hline SE-250 & 12.191 & 0.002 & 2.609 & 0.004 & 0.527 & 1.732 & 0.003 & $1: 1.09$ & Reject & Accept & Reject \\
\hline SE-251 & 12.194 & 0.002 & 2.614 & 0.001 & 0.527 & 1.726 & 0.001 & $1: 1.09$ & Reject & Accept & Reject \\
\hline SE-252 & 12.167 & 0.001 & 2.603 & 0.000 & 0.528 & 1.743 & 0.001 & 1:1.10 & Reject & Accept & Reject \\
\hline SE-253 & 12.163 & 0.002 & 2.587 & 0.000 & 0.528 & 1.756 & 0.002 & $1: 1.10$ & Reject & Accept & Reject \\
\hline SE-254 & 12.184 & 0.002 & 2.681 & 0.007 & 0.527 & 1.687 & 0.005 & $1: 1.07$ & Reject & Reject & Reject \\
\hline SE-255 & 12.188 & 0.001 & 2.597 & 0.000 & 0.527 & 1.739 & 0.001 & 1:1.10 & Reject & Accept & Reject \\
\hline SE-256 & 12.171 & 0.003 & 2.588 & 0.002 & 0.527 & 1.750 & 0.003 & $1: 1.10$ & Accept & Accept & Accept \\
\hline SE-257 & 12.167 & 0.002 & 2.580 & 0.001 & 0.527 & 1.756 & 0.002 & $1: 1.10$ & Reject & Accept & Reject \\
\hline SE-258* & ------ & ------ & ------ & ------ & ----- & ------ & ------ & ----- & & Reject & Reject \\
\hline
\end{tabular}




\begin{tabular}{|c|c|c|c|c|c|c|c|c|c|c|c|}
\hline $\begin{array}{c}\text { Sample } \\
\text { ID }\end{array}$ & $\begin{array}{l}\text { Dia. } \\
\text { (mm) }\end{array}$ & $\begin{array}{c}\sigma \text {-Dia. } \\
(\mathrm{mm})\end{array}$ & $\begin{array}{c}\text { Length } \\
(\mathrm{mm})\end{array}$ & $\begin{array}{c}\sigma- \\
\text { Length } \\
(\mathbf{m m})\end{array}$ & $\begin{array}{l}\text { Weight } \\
\text { (g) }\end{array}$ & $\begin{array}{c}\rho \\
\left(\mathrm{g} / \mathbf{c m}^{3}\right)\end{array}$ & $\begin{array}{c}\sigma-\rho \\
\left(g / \mathbf{c m}^{3}\right)\end{array}$ & SA:V & $\begin{array}{c}\text { Status } \\
\text { (visual) }\end{array}$ & $\begin{array}{l}\text { Status } \\
(\rho)\end{array}$ & $\begin{array}{l}\text { Status } \\
\text { (final) }\end{array}$ \\
\hline SE-259* & ----- & ----- & ----- & ------ & ----- & ----- & ----- & ------ & & Reject & Reject \\
\hline SE-260* & ----- & P---- & ------ & ------ & ------ & ------ & ----- & ------ & & Reject & Reject \\
\hline SE-261* & ----- & ---- & ----- & ------ & ----- & - & - ----- & ----- & & Reject & Reject \\
\hline SE-262* & ----- & ----- & $\begin{array}{l}---- \\
\end{array}$ & ----- & ----- & $\begin{array}{l}---- \\
-\end{array}$ & ----- & $\begin{array}{l}----- \\
\end{array}$ & & Reject & Reject \\
\hline SE-263* & ----- & |---- & ----- & ----- & ----- & ----- & ----- & ----- & & Reject & Reject \\
\hline SE-264* & ------ & ----- & ------ & ------ & ------ & $-\cdots$ & ------ & ----- & & Reject & Reject \\
\hline SE-265* & ----- & ----- & ------ & ------ & ------ & ----- & ----- & ----- & & Reject & Reject \\
\hline SE-266* & --.-- & ----- & ----- & ------ & ------ & ----- & --.-- & ----- & & Reject & Reject \\
\hline SE-267* & ------ & ----- & ------ & ----- & ------ & ----- & ------ & ----- & & Reject & Reject \\
\hline SE-268* & ----- & ----- & ----- & ----- & ----- & ----- & ----- & ----- & & Reject & Reject \\
\hline SE-269* & ----- & ----- & ----- & ------ & ------ & ----- & ------ & ----- & & Reject & Reject \\
\hline SE-270* & - ----- & ----- & $\begin{array}{l}----- \\
\end{array}$ & ------ & ------ & $\begin{array}{l}----- \\
\end{array}$ & ------ & ----- & & Reject & Reject \\
\hline SE-271 & 12.176 & 0.004 & 2.644 & 0.005 & 0.526 & 1.709 & 0.004 & $1: 1.08$ & Reject & Reject & Reject \\
\hline SE-272 & 12.193 & 0.003 & 2.585 & 0.001 & 0.527 & 1.745 & 0.002 & $1: 1.10$ & Accept & Accept & Accept \\
\hline SE-273 & 12.171 & 0.000 & 2.546 & 0.001 & 0.528 & 1.781 & 0.001 & 1:1.11 & Accept & Accept & Accept \\
\hline SE-274 & 12.180 & 0.001 & 2.574 & 0.004 & 0.528 & 1.759 & 0.003 & 1:1.11 & Reject & Accept & Reject \\
\hline SE-275 & 12.190 & 0.003 & 2.627 & 0.001 & 0.526 & 1.716 & 0.002 & $1: 1.09$ & Accept & Accept & Accept \\
\hline SE-276 & 12.163 & 0.005 & 2.590 & 0.006 & 0.526 & 1.749 & 0.006 & $1: 1.10$ & Reject & Accept & Reject \\
\hline SE-277 & 12.167 & 0.002 & 2.591 & 0.001 & 0.527 & 1.750 & 0.002 & $1: 1.10$ & Reject & Accept & Reject \\
\hline SE-278 & 12.185 & 0.002 & 2.573 & 0.001 & 0.527 & 1.757 & 0.002 & 1:1.11 & Reject & Accept & Reject \\
\hline SE-279 & 12.176 & 0.004 & 2.595 & 0.002 & 0.527 & 1.743 & 0.003 & 1:1.10 & Reject & Accept & eject \\
\hline SE-280 & 12.181 & 0.001 & 2.604 & 0.002 & 0.527 & 1.738 & 0.001 & 1:1.10 & Reject & Accept & Reject \\
\hline SE-281 & 12.196 & 0.001 & 2.604 & 0.000 & 0.527 & 1.733 & 0.001 & $1: 1.10$ & Reject & Accept & Reject \\
\hline SE-282 & 12.178 & 0.002 & 2.561 & 0.001 & 0.525 & 1.760 & 0.002 & 1:1.11 & Accept & Accept & Accept \\
\hline SE-283 & 12.180 & 0.004 & 2.595 & 0.003 & 0.527 & 1.742 & 0.004 & $1: 1.10$ & Accept & Accept & Accept \\
\hline SE-284 & 12.184 & 0.003 & 2.603 & 0.000 & 0.528 & 1.741 & 0.002 & 1:1.10 & Accept & Accept & Accept \\
\hline SE-285 & 12.173 & 0.004 & 2.580 & 0.005 & 0.529 & 1.760 & 0.004 & 1:1.10 & Reject & Accept & Reject \\
\hline SE-286 & 12.159 & 0.001 & 2.583 & 0.000 & 0.528 & 1.759 & 0.001 & 1:1.10 & Reject & Accept & Reject \\
\hline SE-287 & 12.094 & 0.015 & 2.593 & 0.013 & 0.528 & 1.772 & 0.014 & $1: 1.10$ & Reject & Accept & Reject \\
\hline SE-288 & 12.178 & 0.002 & 2.625 & 0.001 & 0.528 & 1.725 & 0.002 & $1: 1.09$ & Accept & Accept & Accept \\
\hline SE-289 & 12.180 & 0.003 & 2.610 & 0.001 & 0.526 & 1.731 & 0.002 & 1:1.09 & Reject & Accept & Reject \\
\hline SE-290 & 12.182 & 0.004 & 2.607 & 0.004 & 0.527 & 1.735 & 0.004 & $1: 1.10$ & Reject & Accept & Reject \\
\hline SE-291 & 12.160 & 0.003 & 2.605 & 0.011 & 0.528 & 1.744 & 0.008 & 1:1.10 & Reject & Accept & Reject \\
\hline SE-292 & 12.159 & 0.003 & 2.551 & 0.002 & 0.528 & 1.782 & 0.003 & 1:1.11 & Accept & Accept & Accept \\
\hline SE-293 & 12.165 & 0.003 & 2.555 & 0.002 & 0.528 & 1.777 & 0.003 & 1:1.11 & Reject & Accept & Reject \\
\hline SE-294 & 12.103 & 0.018 & 2.596 & 0.024 & 0.527 & 1.765 & 0.021 & $1: 1.10$ & Accept & Accept & Accept \\
\hline SE-295 & 12.213 & 0.000 & 2.556 & 0.001 & 0.527 & 1.761 & 0.001 & 1:1.11 & Accept & Accept & Accept \\
\hline SE-296 & 12.195 & 0.001 & 2.596 & 0.007 & 0.527 & 1.739 & 0.005 & 1:1.10 & Reject & Accept & Reject \\
\hline SE-297 & 12.188 & 0.006 & 2.569 & 0.001 & 0.527 & 1.760 & 0.004 & 1:1.11 & Accept & Accept & Accept \\
\hline SE-298 & 12.188 & 0.004 & 2.575 & 0.004 & 0.527 & 1.754 & 0.004 & $1: 1.10$ & Reject & Accept & Reject \\
\hline SE-299 & 12.168 & 0.001 & 2.601 & 0.001 & 0.527 & 1.742 & 0.001 & $1: 1.10$ & Reject & Accept & Reject \\
\hline SE-300 & 12.176 & 0.001 & 2.590 & 0.004 & 0.528 & 1.750 & 0.003 & 1:1.10 & Accept & Accept & Accept \\
\hline
\end{tabular}

*SE-258-SE-270 were dropped after final heat treatment and therefore rejected.

${ }^{\wedge}$ weight and density are reported for predrilled samples 



\section{APPENDIX B. INDIVIDUAL MEASUREMENTS AND TEST CONDITIONS FOR EMPIRICAL HIGH-TEMPERATURE OXIDATION TESTING}

Table B-1. Results from empirical high-temperature oxidation testing showing weight loss for test conditions: $1,200-1,500{ }^{\circ} \mathrm{C}$ and $10-48 \mathrm{kPa}$

\begin{tabular}{|c|c|c|c|c|c|c|c|c|c|}
\hline Temp. & $\begin{array}{c}\mathbf{P}_{\mathrm{H} 20} \\
(\mathbf{k P a})\end{array}$ & $\begin{array}{l}\text { Exposure } \\
\text { time (s) }\end{array}$ & $\begin{array}{c}\text { Sample } \\
\text { ID }\end{array}$ & $\begin{array}{c}\text { Pre- } \\
\text { oxidation } \\
\text { weight (g) }\end{array}$ & $\begin{array}{c}\text { Post- } \\
\text { oxidation } \\
\text { weight (g) }\end{array}$ & $\begin{array}{l}\text { Weight } \\
\text { loss (g) }\end{array}$ & $\begin{array}{l}\text { Normalized } \\
\text { weight loss }\end{array}$ & $\begin{array}{c}\text { Residual } \\
\text { oxygen } \\
\text { weight } \\
\text { loss } \\
\end{array}$ & $\begin{array}{c}\text { Adjusted } \\
\text { oxidation } \\
\text { weight } \\
\text { loss } \\
\end{array}$ \\
\hline \multirow{28}{*}{$1200^{\circ} \mathrm{C}$} & \multirow{4}{*}{10} & 1800 & SE-002 & 0.5185 & 0.4901 & 0.0284 & $5.47 \mathrm{E}-02$ & $2.06 \mathrm{E}-02$ & $3.42 \mathrm{E}-02$ \\
\hline & & 3600 & SE-020 & 0.5183 & 0.4654 & 0.0529 & $1.02 \mathrm{E}-01$ & 2.99E-02 & 7.22E-02 \\
\hline & & 7200 & SE-139 & 0.5175 & 0.3466 & 0.1708 & $3.30 \mathrm{E}-01$ & $4.86 \mathrm{E}-02$ & $2.82 \mathrm{E}-01$ \\
\hline & & 14400 & SE-141 & 0.5202 & 0.1477 & 0.3725 & $7.16 \mathrm{E}-01$ & $8.60 \mathrm{E}-02$ & $6.30 \mathrm{E}-01$ \\
\hline & \multirow{9}{*}{20} & 900 & SE-007 & 0.5190 & 0.5049 & 0.0140 & $2.70 \mathrm{E}-02$ & $1.59 \mathrm{E}-02$ & $1.11 \mathrm{E}-02$ \\
\hline & & 1800 & SE-030 & 0.5180 & 0.4921 & 0.0259 & $5.00 \mathrm{E}-02$ & $2.06 \mathrm{E}-02$ & $2.95 \mathrm{E}-02$ \\
\hline & & 3600 & SE-001 & 0.5191 & 0.4500 & 0.0691 & $1.33 \mathrm{E}-01$ & 2.99E-02 & $1.03 \mathrm{E}-01$ \\
\hline & & 7200 & SE-018 & 0.5188 & 0.3474 & 0.1714 & $3.30 \mathrm{E}-01$ & $4.86 \mathrm{E}-02$ & $2.82 \mathrm{E}-01$ \\
\hline & & 7200 & SE-066 & 0.5149 & 0.2500 & 0.2649 & $5.14 \mathrm{E}-01$ & $4.86 \mathrm{E}-02$ & $4.66 \mathrm{E}-01$ \\
\hline & & 7200 & SE-035 & 0.5179 & 0.3384 & 0.1795 & $3.47 \mathrm{E}-01$ & $4.86 \mathrm{E}-02$ & $2.98 \mathrm{E}-01$ \\
\hline & & 10800 & SE-038 & 0.5188 & 0.1770 & 0.3418 & $6.59 \mathrm{E}-01$ & $6.73 \mathrm{E}-02$ & $5.92 \mathrm{E}-01$ \\
\hline & & 10800 & SE-090 & 0.5162 & 0.1062 & 0.4100 & 7.94E-01 & $6.73 \mathrm{E}-02$ & 7.27E-01 \\
\hline & & 14400 & SE-059 & 0.5194 & 0.0398 & 0.4796 & $9.23 \mathrm{E}-01$ & $8.60 \mathrm{E}-02$ & 8.37E-01 \\
\hline & \multirow{4}{*}{30} & 1800 & SE-107 & 0.5182 & 0.4297 & 0.0885 & $1.71 \mathrm{E}-01$ & $2.06 \mathrm{E}-02$ & $1.50 \mathrm{E}-01$ \\
\hline & & 3600 & SE-113 & 0.5178 & 0.2987 & 0.2191 & 4.23E-01 & $2.99 \mathrm{E}-02$ & $3.93 \mathrm{E}-01$ \\
\hline & & 5400 & SE-137 & 0.5181 & 0.1874 & 0.3307 & $6.38 \mathrm{E}-01$ & $3.93 \mathrm{E}-02$ & $5.99 \mathrm{E}-01$ \\
\hline & & 7200 & SE-114 & 0.5174 & 0.0990 & 0.4184 & 8.09E-01 & $4.86 \mathrm{E}-02$ & $7.60 \mathrm{E}-01$ \\
\hline & \multirow{7}{*}{48} & 1800 & SE-295 & 0.5192 & 0.4471 & 0.0721 & $1.39 \mathrm{E}-01$ & $2.06 \mathrm{E}-02$ & $1.18 \mathrm{E}-01$ \\
\hline & & 3600 & SE-297 & 0.5192 & 0.3351 & 0.1841 & $3.55 \mathrm{E}-01$ & 2.99E-02 & $3.25 \mathrm{E}-01$ \\
\hline & & 4500 & SE-300 & 0.5192 & 0.2406 & 0.2786 & $5.37 \mathrm{E}-01$ & $3.46 \mathrm{E}-02$ & $5.02 \mathrm{E}-01$ \\
\hline & & 3600 & SE-198 & 0.5174 & 0.3096 & 0.2078 & $4.02 \mathrm{E}-01$ & 2.99E-02 & $3.72 \mathrm{E}-01$ \\
\hline & & 1800 & SE-212 & 0.5181 & 0.4061 & 0.1120 & $2.16 \mathrm{E}-01$ & $2.06 \mathrm{E}-02$ & $1.96 \mathrm{E}-01$ \\
\hline & & 5400 & SE-228 & 0.5184 & 0.1741 & 0.3443 & 6.64E-01 & $3.93 \mathrm{E}-02$ & $6.25 \mathrm{E}-01$ \\
\hline & & 7200 & SE-282 & 0.5164 & 0.0534 & 0.4630 & 8.97E-01 & $4.86 \mathrm{E}-02$ & $8.48 \mathrm{E}-01$ \\
\hline & & 1800 & SE-039 & 0.5188 & 0.5099 & 0.0089 & $1.72 \mathrm{E}-02$ & ------ & ------ \\
\hline & & 3600 & SE-058 & 0.5190 & 0.5010 & 0.0181 & $3.48 \mathrm{E}-02$ & ------ & ------ \\
\hline & & 7200 & SE-067 & 0.5194 & 0.4949 & 0.0245 & 4.72E-02 & ------ & ------ \\
\hline & & 14400 & SE-102 & 0.5163 & 0.4719 & 0.0444 & $8.60 \mathrm{E}-02$ & ------ & ------ \\
\hline \multirow{2}{*}{$1300^{\circ} \mathrm{C}$} & \multirow{2}{*}{10} & 1800 & SE-010 & 0.5196 & 0.4589 & 0.0607 & $1.17 \mathrm{E}-01$ & 1.19E-02 & $1.05 \mathrm{E}-01$ \\
\hline & & 3600 & SE-032 & 0.5176 & 0.3918 & 0.1258 & $2.43 \mathrm{E}-01$ & $1.84 \mathrm{E}-02$ & $2.25 \mathrm{E}-01$ \\
\hline
\end{tabular}




\begin{tabular}{|c|c|c|c|c|c|c|c|c|c|}
\hline Temp. & $\begin{array}{l}\mathbf{P}_{\mathrm{H} 2 \mathrm{O}} \\
(\mathrm{kPa})\end{array}$ & $\begin{array}{l}\text { Exposure } \\
\text { time (s) }\end{array}$ & $\begin{array}{c}\text { Sample } \\
\text { ID }\end{array}$ & $\begin{array}{c}\text { Pre- } \\
\text { oxidation } \\
\text { weight (g) }\end{array}$ & $\begin{array}{c}\text { Post- } \\
\text { oxidation } \\
\text { weight (g) }\end{array}$ & $\begin{array}{l}\text { Weight } \\
\text { loss (g) }\end{array}$ & $\begin{array}{l}\text { Normalized } \\
\text { weight loss }\end{array}$ & $\begin{array}{c}\text { Residual } \\
\text { oxygen } \\
\text { weight } \\
\text { loss }\end{array}$ & $\begin{array}{c}\text { Adjusted } \\
\text { oxidation } \\
\text { weight } \\
\text { loss }\end{array}$ \\
\hline & & 7200 & SE-040 & 0.5169 & 0.2184 & 0.2984 & $5.77 \mathrm{E}-01$ & $3.16 \mathrm{E}-02$ & $5.46 \mathrm{E}-01$ \\
\hline & & 9000 & SE-142 & 0.5197 & 0.1534 & 0.3663 & 7.05E-01 & 3.81E-02 & $6.67 \mathrm{E}-01$ \\
\hline & & 900 & SE-149 & 0.5209 & 0.4874 & 0.0335 & $6.43 \mathrm{E}-02$ & $8.60 \mathrm{E}-03$ & $5.57 \mathrm{E}-02$ \\
\hline & & 1800 & SE-078 & 0.5144 & 0.4461 & 0.0682 & $1.33 \mathrm{E}-01$ & 1.19E-02 & $1.21 \mathrm{E}-01$ \\
\hline & & 3600 & SE-133 & 0.5181 & 0.3236 & 0.1945 & 3.75E-01 & $1.84 \mathrm{E}-02$ & $3.57 \mathrm{E}-01$ \\
\hline & 20 & 5400 & SE-098 & 0.5166 & 0.2053 & 0.3112 & $6.02 \mathrm{E}-01$ & $2.50 \mathrm{E}-02$ & $5.77 \mathrm{E}-01$ \\
\hline & 20 & 5400 & SE-057 & 0.5199 & 0.1546 & 0.3653 & 7.03E-01 & $2.50 \mathrm{E}-02$ & $6.78 \mathrm{E}-01$ \\
\hline & & 5400 & SE-095 & 0.5173 & 0.1209 & 0.3964 & 7.66E-01 & $2.50 \mathrm{E}-02$ & $7.41 \mathrm{E}-01$ \\
\hline & & 7200 & SE-130 & 0.5150 & 0.0433 & 0.4717 & $9.16 \mathrm{E}-01$ & $3.16 \mathrm{E}-02$ & 8.84E-01 \\
\hline & & 7200 & SE-012 & 0.5177 & 0.0543 & 0.4634 & $8.95 \mathrm{E}-01$ & $3.16 \mathrm{E}-02$ & 8.64E-01 \\
\hline & & 1800 & SE-214 & 0.5189 & 0.3833 & 0.1356 & $2.61 \mathrm{E}-01$ & 1.19E-02 & $2.49 \mathrm{E}-01$ \\
\hline & & 3600 & SE-205 & 0.5173 & 0.1513 & 0.3660 & $7.08 \mathrm{E}-01$ & $1.84 \mathrm{E}-02$ & $6.89 \mathrm{E}-01$ \\
\hline & 30 & 5400 & SE-230 & 0.5186 & 0.0197 & 0.4990 & $9.62 \mathrm{E}-01$ & $2.50 \mathrm{E}-02$ & $9.37 \mathrm{E}-01$ \\
\hline & & 4500 & SE-231 & 0.5191 & 0.0651 & 0.4540 & $8.75 \mathrm{E}-01$ & $2.17 \mathrm{E}-02$ & $8.53 \mathrm{E}-01$ \\
\hline & & 2700 & SE-235 & 0.5183 & 0.2416 & 0.2767 & $5.34 \mathrm{E}-01$ & $1.52 \mathrm{E}-02$ & $5.19 \mathrm{E}-01$ \\
\hline & & 1800 & SE-119 & 0.5176 & 0.5118 & 0.0058 & $1.12 \mathrm{E}-02$ & ------ & ------ \\
\hline & ----- & 3600 & SE-136 & 0.5182 & 0.5081 & 0.0101 & $1.95 \mathrm{E}-02$ & ----- & ------ \\
\hline & & 7200 & SE-140 & 0.5180 & 0.5018 & 0.0162 & $3.12 \mathrm{E}-02$ & ----- & ------ \\
\hline \multirow{18}{*}{$1400^{\circ} \mathrm{C}$} & \multirow{5}{*}{10} & 1800 & SE-086 & 0.5157 & 0.3723 & 0.1435 & $2.78 \mathrm{E}-01$ & $1.84 \mathrm{E}-02$ & $2.60 \mathrm{E}-01$ \\
\hline & & 2700 & SE-023 & 0.5189 & 0.3217 & 0.1972 & $3.80 \mathrm{E}-01$ & $2.23 \mathrm{E}-02$ & $3.58 \mathrm{E}-01$ \\
\hline & & 3600 & SE-123 & 0.5187 & 0.2192 & 0.2996 & $5.78 \mathrm{E}-01$ & $2.61 \mathrm{E}-02$ & $5.51 \mathrm{E}-01$ \\
\hline & & 5400 & SE-122 & 0.5180 & 0.1355 & 0.3825 & 7.38E-01 & $3.38 \mathrm{E}-02$ & 7.05E-01 \\
\hline & & 7200 & SE-121 & 0.5190 & 0.0090 & 0.5099 & $9.83 \mathrm{E}-01$ & 4.15E-02 & $9.41 \mathrm{E}-01$ \\
\hline & \multirow{7}{*}{20} & 900 & SE-127 & 0.5167 & 0.4353 & 0.0814 & $1.58 \mathrm{E}-01$ & $1.46 \mathrm{E}-02$ & $1.43 \mathrm{E}-01$ \\
\hline & & 1800 & SE-146 & 0.5200 & 0.3645 & 0.1556 & 2.99E-01 & $1.84 \mathrm{E}-02$ & $2.81 \mathrm{E}-01$ \\
\hline & & 2700 & SE-131 & 0.5176 & 0.2486 & 0.2690 & $5.20 \mathrm{E}-01$ & $2.23 \mathrm{E}-02$ & 4.97E-01 \\
\hline & & 3600 & SE-128 & 0.5181 & 0.1621 & 0.3560 & $6.87 \mathrm{E}-01$ & 2.61E-02 & $6.61 \mathrm{E}-01$ \\
\hline & & 3600 & SE-064 & 0.5183 & 0.1326 & 0.3858 & 7.44E-01 & $2.61 \mathrm{E}-02$ & $7.18 \mathrm{E}-01$ \\
\hline & & 3600 & SE-099 & 0.5169 & 0.0698 & 0.4472 & $8.65 \mathrm{E}-01$ & 2.61E-02 & $8.39 \mathrm{E}-01$ \\
\hline & & 5400 & SE-075 & 0.5191 & 0.0322 & 0.4869 & $9.38 \mathrm{E}-01$ & $3.38 \mathrm{E}-02$ & $9.04 \mathrm{E}-01$ \\
\hline & \multirow{6}{*}{30} & 1800 & SE-238 & 0.5194 & 0.1855 & 0.3339 & 6.43E-01 & $1.84 \mathrm{E}-02$ & $6.24 \mathrm{E}-01$ \\
\hline & & 2700 & SE-237 & 0.5191 & 0.0345 & 0.4846 & $9.33 \mathrm{E}-01$ & $2.23 \mathrm{E}-02$ & $9.11 \mathrm{E}-01$ \\
\hline & & 900 & SE-239 & 0.5178 & 0.4151 & 0.1027 & $1.98 \mathrm{E}-01$ & $1.46 \mathrm{E}-02$ & $1.84 \mathrm{E}-01$ \\
\hline & & 2250 & SE-241 & 0.5188 & 0.1514 & 0.3674 & $7.08 \mathrm{E}-01$ & 2.04E-02 & $6.88 \mathrm{E}-01$ \\
\hline & & 2700 & SE-244 & 0.5194 & 0.0658 & 0.4536 & $8.73 \mathrm{E}-01$ & $2.23 \mathrm{E}-02$ & $8.51 \mathrm{E}-01$ \\
\hline & & 2250 & SE-256 & 0.5187 & 0.1650 & 0.3537 & $6.82 \mathrm{E}-01$ & 2.04E-02 & $6.61 \mathrm{E}-01$ \\
\hline
\end{tabular}




\begin{tabular}{|c|c|c|c|c|c|c|c|c|c|}
\hline Temp. & $\begin{array}{c}\mathbf{P}_{\mathrm{H} 2 \mathrm{O}} \\
(\mathrm{kPa})\end{array}$ & $\begin{array}{c}\text { Exposure } \\
\text { time (s) }\end{array}$ & $\begin{array}{c}\text { Sample } \\
\text { ID }\end{array}$ & $\begin{array}{c}\text { Pre- } \\
\text { oxidation } \\
\text { weight (g) }\end{array}$ & $\begin{array}{c}\text { Post- } \\
\text { oxidation } \\
\text { weight (g) }\end{array}$ & $\begin{array}{l}\text { Weight } \\
\text { loss (g) }\end{array}$ & $\begin{array}{c}\text { Normalized } \\
\text { weight loss }\end{array}$ & $\begin{array}{c}\text { Residual } \\
\text { oxygen } \\
\text { weight } \\
\text { loss }\end{array}$ & $\begin{array}{c}\text { Adjusted } \\
\text { oxidation } \\
\text { weight } \\
\text { loss }\end{array}$ \\
\hline & & 288 & SE-069 & 0.5182 & 0.5143 & 0.0039 & 7.53E-03 & ------ & ------ \\
\hline & & 1800 & SE-088 & 0.5166 & 0.5094 & 0.0072 & $1.39 \mathrm{E}-02$ & ------ & ------ \\
\hline & & 3600 & SE-094 & 0.5163 & 0.4949 & 0.0214 & $4.15 \mathrm{E}-02$ & ------ & ------ \\
\hline & & 7200 & SE-100 & 0.5163 & 0.4982 & 0.0181 & $3.51 \mathrm{E}-02$ & ------ & ------ \\
\hline \multirow{8}{*}{$1500^{\circ} \mathrm{C}$} & \multirow{5}{*}{10} & 1800 & SE-272 & 0.5183 & 0.3515 & 0.1668 & $3.22 \mathrm{E}-01$ & $3.19 \mathrm{E}-02$ & $2.90 \mathrm{E}-01$ \\
\hline & & 3600 & SE-283 & 0.5186 & 0.1873 & 0.3312 & $6.39 \mathrm{E}-01$ & 5.03E-02 & $5.88 \mathrm{E}-01$ \\
\hline & & 2700 & SE-294 & 0.5187 & 0.2455 & 0.2732 & $5.27 \mathrm{E}-01$ & $4.11 \mathrm{E}-02$ & $4.86 \mathrm{E}-01$ \\
\hline & & 2250 & SE-288 & 0.5190 & 0.3031 & 0.2159 & 4.16E-01 & $3.65 \mathrm{E}-02$ & $3.79 \mathrm{E}-01$ \\
\hline & & 2700 & SE-284 & 0.5200 & 0.2064 & 0.3136 & $6.03 \mathrm{E}-01$ & $4.11 \mathrm{E}-02$ & $5.62 \mathrm{E}-01$ \\
\hline & \multirow{3}{*}{------ } & 3600 & SE-273 & 0.5193 & 0.4925 & 0.0268 & $5.16 \mathrm{E}-02$ & ------ & ------ \\
\hline & & 2700 & SE-275 & 0.5177 & 0.4978 & 0.0199 & $3.84 \mathrm{E}-02$ & ------ & ------ \\
\hline & & 1800 & SE-240 & 0.5178 & 0.5006 & 0.0172 & 3.32E-02 & ------ & ------ \\
\hline
\end{tabular}





\section{APPENDIX C. INDIVIDUAL MEASUREMENTS AND TEST CONDITIONS FOR OXIDATION KINETICS EVALUATION}

Table C-1. Results from oxidation kinetics evaluation testing showing test conditions and associated measured rate

\begin{tabular}{|c|c|c|c|c|c|c|}
\hline \multirow{2}{*}{ Date } & \multirow{2}{*}{ Sample ID } & \multicolumn{2}{|c|}{$\mathbf{P}_{\mathrm{H} 2 \mathrm{O}}(\mathrm{Pa})$} & \multirow{2}{*}{$\mathbf{P}_{\mathrm{H} 2}(\mathbf{P a})$} & \multirow{2}{*}{$\begin{array}{c}\text { Temp. } \\
\left({ }^{\circ} \mathrm{C}\right)\end{array}$} & \multirow{2}{*}{ Rate $\left(\mathrm{s}^{-1}\right)$} \\
\hline & & Target & Actual & & & \\
\hline $2 / 27 / 18$ & $\mathrm{~T}-164$ & 20 & 23 & 0 & 800 & $3.51 \mathrm{E}-09$ \\
\hline $2 / 25 / 18$ & $\mathrm{~T}-162$ & 20 & 40 & 0 & 800 & $0.00 \mathrm{E}+00$ \\
\hline $2 / 12 / 18$ & $\mathrm{~T}-157$ & 100 & 119 & 0 & 800 & 4.24E-10 \\
\hline $3 / 22 / 18$ & $\mathrm{~T}-170$ & 100 & 122 & 0 & 800 & $6.21 \mathrm{E}-10$ \\
\hline $2 / 9 / 18$ & $\mathrm{~T}-154$ & 100 & 123 & 0 & 800 & $8.78 \mathrm{E}-10$ \\
\hline $2 / 14 / 18$ & $\mathrm{~T}-155$ & 200 & 222 & 0 & 800 & $4.22 \mathrm{E}-10$ \\
\hline $2 / 16 / 18$ & $\mathrm{~T}-160$ & 200 & 240 & 0 & 800 & $1.37 \mathrm{E}-10$ \\
\hline $3 / 5 / 18$ & T-169 & 300 & 293 & 0 & 800 & 1.13E-09 \\
\hline $3 / 7 / 18$ & $\mathrm{~T}-165$ & 300 & 331 & 0 & 800 & $1.65 \mathrm{E}-10$ \\
\hline $2 / 22 / 18$ & $\mathrm{~T}-161$ & 500 & 480 & 0 & 800 & $1.51 \mathrm{E}-09$ \\
\hline $2 / 19 / 18$ & $\mathrm{~T}-156$ & 500 & 507 & 0 & 800 & $9.66 \mathrm{E}-10$ \\
\hline $2 / 27 / 18$ & T-164 & 20 & 24 & 0 & 850 & $3.69 \mathrm{E}-09$ \\
\hline $2 / 25 / 18$ & $\mathrm{~T}-162$ & 20 & 34 & 0 & 850 & $8.34 \mathrm{E}-10$ \\
\hline $2 / 12 / 18$ & $\mathrm{~T}-157$ & 100 & 122 & 0 & 850 & $1.08 \mathrm{E}-09$ \\
\hline $3 / 22 / 18$ & $\mathrm{~T}-170$ & 100 & 124 & 0 & 850 & $1.52 \mathrm{E}-09$ \\
\hline $2 / 9 / 18$ & $\mathrm{~T}-154$ & 100 & 154 & 0 & 850 & $3.35 \mathrm{E}-09$ \\
\hline $2 / 14 / 18$ & $\mathrm{~T}-155$ & 200 & 224 & 0 & 850 & $1.30 \mathrm{E}-09$ \\
\hline $2 / 16 / 18$ & $\mathrm{~T}-160$ & 200 & 258 & 0 & 850 & $5.61 \mathrm{E}-10$ \\
\hline $3 / 5 / 18$ & $\mathrm{~T}-169$ & 300 & 328 & 0 & 850 & $2.84 \mathrm{E}-09$ \\
\hline $3 / 7 / 18$ & $\mathrm{~T}-165$ & 300 & 381 & 0 & 850 & $2.37 \mathrm{E}-09$ \\
\hline $2 / 22 / 18$ & $\mathrm{~T}-161$ & 500 & 543 & 0 & 850 & $2.89 \mathrm{E}-09$ \\
\hline $2 / 19 / 18$ & T-156 & 500 & 617 & 0 & 850 & 2.03E-09 \\
\hline $2 / 27 / 18$ & T-164 & 20 & 24 & 0 & 900 & $4.89 \mathrm{E}-09$ \\
\hline $2 / 25 / 18$ & $\mathrm{~T}-162$ & 20 & 34 & 0 & 900 & $2.78 \mathrm{E}-09$ \\
\hline $3 / 22 / 18$ & $\mathrm{~T}-170$ & 100 & 121 & 0 & 900 & $3.08 \mathrm{E}-09$ \\
\hline $2 / 9 / 18$ & $\mathrm{~T}-154$ & 100 & 137 & 0 & 900 & $1.34 \mathrm{E}-08$ \\
\hline $2 / 12 / 18$ & $\mathrm{~T}-157$ & 100 & 144 & 0 & 900 & 3.97E-09 \\
\hline $2 / 14 / 18$ & $\mathrm{~T}-155$ & 200 & 234 & 0 & 900 & 4.19E-09 \\
\hline $2 / 16 / 18$ & T-160 & 200 & 243 & 0 & 900 & $7.18 \mathrm{E}-09$ \\
\hline $3 / 7 / 18$ & T-165 & 300 & 347 & 0 & 900 & 7.11E-09 \\
\hline $3 / 5 / 18$ & T-169 & 300 & 385 & 0 & 900 & $8.32 \mathrm{E}-09$ \\
\hline $2 / 22 / 18$ & T-161 & 500 & 573 & 0 & 900 & $1.14 \mathrm{E}-08$ \\
\hline $2 / 19 / 18$ & T-156 & 500 & 614 & 0 & 900 & $1.07 \mathrm{E}-08$ \\
\hline $2 / 27 / 18$ & T-164 & 20 & 24 & 0 & 950 & $1.06 \mathrm{E}-08$ \\
\hline
\end{tabular}




\begin{tabular}{|c|c|c|c|c|c|c|}
\hline \multirow{2}{*}{ Date } & \multirow{2}{*}{ Sample ID } & \multicolumn{2}{|c|}{$\mathbf{P}_{\mathrm{H} 2 \mathrm{O}}(\mathrm{Pa})$} & \multirow{2}{*}{$\mathbf{P}_{\mathrm{H} 2}(\mathrm{~Pa})$} & \multirow{2}{*}{$\begin{array}{c}\text { Temp. } \\
\left({ }^{\circ} \mathrm{C}\right)\end{array}$} & \multirow{2}{*}{ Rate $\left(s^{-1}\right)$} \\
\hline & & Target & Actual & & & \\
\hline $2 / 25 / 18$ & $\mathrm{~T}-162$ & 20 & 34 & 0 & 950 & $7.40 \mathrm{E}-09$ \\
\hline $3 / 22 / 18$ & $\mathrm{~T}-170$ & 100 & 127 & 0 & 950 & $2.24 \mathrm{E}-08$ \\
\hline $2 / 9 / 18$ & $\mathrm{~T}-154$ & 100 & 130 & 0 & 950 & $6.75 \mathrm{E}-08$ \\
\hline $2 / 12 / 18$ & $\mathrm{~T}-157$ & 100 & 139 & 0 & 950 & $2.13 \mathrm{E}-08$ \\
\hline $2 / 14 / 18$ & $\mathrm{~T}-155$ & 200 & 239 & 0 & 950 & $2.83 \mathrm{E}-08$ \\
\hline $2 / 16 / 18$ & $\mathrm{~T}-160$ & 200 & 249 & 0 & 950 & 4.47E-08 \\
\hline $3 / 5 / 18$ & T-169 & 300 & 367 & 0 & 950 & $4.50 \mathrm{E}-08$ \\
\hline $3 / 7 / 18$ & $\mathrm{~T}-165$ & 300 & 446 & 0 & 950 & 4.95E-08 \\
\hline $2 / 22 / 18$ & $\mathrm{~T}-161$ & 500 & 573 & 0 & 950 & 7.62E-08 \\
\hline $2 / 19 / 18$ & $\mathrm{~T}-156$ & 500 & 617 & 0 & 950 & 8.64E-08 \\
\hline $2 / 27 / 18$ & $\mathrm{~T}-164$ & 20 & 24 & 0 & 1000 & $2.44 \mathrm{E}-08$ \\
\hline $2 / 25 / 18$ & $\mathrm{~T}-162$ & 20 & 33 & 0 & 1000 & $2.10 \mathrm{E}-08$ \\
\hline $3 / 22 / 18$ & $\mathrm{~T}-170$ & 100 & 129 & 0 & 1000 & $7.85 \mathrm{E}-08$ \\
\hline $2 / 9 / 18$ & $\mathrm{~T}-154$ & 100 & 130 & 0 & 1000 & $2.51 \mathrm{E}-07$ \\
\hline $2 / 12 / 18$ & $\mathrm{~T}-157$ & 100 & 134 & 0 & 1000 & $9.06 \mathrm{E}-08$ \\
\hline $2 / 14 / 18$ & $\mathrm{~T}-155$ & 200 & 245 & 0 & 1000 & $1.06 \mathrm{E}-07$ \\
\hline $2 / 16 / 18$ & $\mathrm{~T}-160$ & 200 & 256 & 0 & 1000 & $1.72 \mathrm{E}-07$ \\
\hline $3 / 5 / 18$ & T-169 & 300 & 349 & 0 & 1000 & $1.54 \mathrm{E}-07$ \\
\hline $3 / 7 / 18$ & $\mathrm{~T}-165$ & 300 & 419 & 0 & 1000 & $1.84 \mathrm{E}-07$ \\
\hline $2 / 22 / 18$ & $\mathrm{~T}-161$ & 500 & 573 & 0 & 1000 & $2.64 \mathrm{E}-07$ \\
\hline $2 / 19 / 18$ & $\mathrm{~T}-156$ & 500 & 688 & 0 & 1000 & $2.80 \mathrm{E}-07$ \\
\hline $2 / 25 / 18$ & $\mathrm{~T}-162$ & 20 & 16 & 0 & 1050 & $3.58 \mathrm{E}-08$ \\
\hline $2 / 27 / 18$ & $\mathrm{~T}-164$ & 20 & 24 & 0 & 1050 & $5.47 \mathrm{E}-08$ \\
\hline $2 / 12 / 18$ & $\mathrm{~T}-157$ & 100 & 125 & 0 & 1050 & $2.07 \mathrm{E}-07$ \\
\hline $2 / 9 / 18$ & $\mathrm{~T}-154$ & 100 & 131 & 0 & 1050 & 4.89E-07 \\
\hline $3 / 22 / 18$ & $\mathrm{~T}-170$ & 100 & 171 & 0 & 1050 & $2.31 \mathrm{E}-07$ \\
\hline $2 / 14 / 18$ & $\mathrm{~T}-155$ & 200 & 245 & 0 & 1050 & $2.67 \mathrm{E}-07$ \\
\hline $2 / 16 / 18$ & $\mathrm{~T}-160$ & 200 & 255 & 0 & 1050 & 4.13E-07 \\
\hline $3 / 7 / 18$ & $\mathrm{~T}-165$ & 300 & 340 & 0 & 1050 & 4.04E-07 \\
\hline $3 / 5 / 18$ & $\mathrm{~T}-169$ & 300 & 350 & 0 & 1050 & $3.68 \mathrm{E}-07$ \\
\hline $2 / 22 / 18$ & $\mathrm{~T}-161$ & 500 & 570 & 0 & 1050 & $6.45 \mathrm{E}-07$ \\
\hline $2 / 19 / 18$ & $\mathrm{~T}-156$ & 500 & 582 & 0 & 1050 & $6.31 \mathrm{E}-07$ \\
\hline $2 / 25 / 18$ & $\mathrm{~T}-162$ & 20 & 16 & 0 & 1100 & $8.14 \mathrm{E}-08$ \\
\hline $2 / 27 / 18$ & $\mathrm{~T}-164$ & 20 & 24 & 0 & 1100 & $1.22 \mathrm{E}-07$ \\
\hline $6 / 4 / 18$ & T-162-1 & 20 & 54 & 0 & 1100 & $2.17 \mathrm{E}-07$ \\
\hline $3 / 22 / 18$ & $\mathrm{~T}-170$ & 100 & 117 & 0 & 1100 & 4.13E-07 \\
\hline $2 / 12 / 18$ & $\mathrm{~T}-157$ & 100 & 126 & 0 & 1100 & 4.67E-07 \\
\hline $2 / 9 / 18$ & $\mathrm{~T}-154$ & 100 & 131 & 0 & 1100 & $9.66 \mathrm{E}-07$ \\
\hline $5 / 22 / 18$ & $\mathrm{~T}-157-1$ & 100 & 174 & 0 & 1100 & 7.17E-07 \\
\hline
\end{tabular}




\begin{tabular}{|c|c|c|c|c|c|c|}
\hline \multirow{2}{*}{ Date } & \multirow{2}{*}{ Sample ID } & \multicolumn{2}{|c|}{$\mathbf{P}_{\mathrm{H} 2 \mathrm{O}}(\mathrm{Pa})$} & \multirow{2}{*}{$\mathbf{P}_{\mathrm{H} 2}$ (Pa) } & \multirow{2}{*}{$\begin{array}{c}\text { Temp. } \\
\left({ }^{\circ} \mathrm{C}\right)\end{array}$} & \multirow{2}{*}{ Rate $\left(\mathrm{s}^{-1}\right)$} \\
\hline & & Target & Actual & & & \\
\hline $5 / 24 / 18$ & $\mathrm{~T}-155-1$ & 200 & 227 & 0 & 1100 & $7.39 \mathrm{E}-07$ \\
\hline $2 / 14 / 18$ & $\mathrm{~T}-155$ & 200 & 242 & 0 & 1100 & $6.50 \mathrm{E}-07$ \\
\hline $2 / 16 / 18$ & $\mathrm{~T}-160$ & 200 & 256 & 0 & 1100 & $9.72 \mathrm{E}-07$ \\
\hline $5 / 29 / 18$ & T-169-1 & 300 & 304 & 0 & 1100 & 8.93E-07 \\
\hline $3 / 7 / 18$ & $\mathrm{~T}-165$ & 300 & 340 & 0 & 1100 & $9.39 \mathrm{E}-07$ \\
\hline $5 / 30 / 18$ & $\mathrm{~T}-156-1$ & 500 & 417 & 0 & 1100 & $1.42 \mathrm{E}-06$ \\
\hline $3 / 5 / 18$ & T-169 & 300 & 460 & 0 & 1100 & $1.06 \mathrm{E}-06$ \\
\hline $2 / 22 / 18$ & $\mathrm{~T}-161$ & 500 & 572 & 0 & 1100 & $1.59 \mathrm{E}-06$ \\
\hline $2 / 19 / 18$ & $\mathrm{~T}-156$ & 500 & 611 & 0 & 1100 & $1.60 \mathrm{E}-06$ \\
\hline $2 / 19 / 18$ & $\mathrm{~T}-156$ & 20 & 67 & 0 & 1150 & 4.67E-07 \\
\hline $2 / 19 / 18$ & $\mathrm{~T}-156$ & 100 & 118 & 0 & 1150 & $1.20 \mathrm{E}-06$ \\
\hline $3 / 22 / 18$ & $\mathrm{~T}-170$ & 100 & 129 & 0 & 1150 & $9.75 \mathrm{E}-07$ \\
\hline $2 / 19 / 18$ & $\mathrm{~T}-156$ & 200 & 217 & 0 & 1150 & $1.56 \mathrm{E}-06$ \\
\hline $2 / 19 / 18$ & $\mathrm{~T}-156$ & 300 & 294 & 0 & 1150 & $1.85 \mathrm{E}-06$ \\
\hline $2 / 19 / 18$ & $\mathrm{~T}-156$ & 500 & 433 & 0 & 1150 & $3.02 \mathrm{E}-06$ \\
\hline $3 / 22 / 18$ & $\mathrm{~T}-170$ & 20 & 66 & 0 & 1200 & $9.92 \mathrm{E}-07$ \\
\hline $3 / 22 / 18$ & $\mathrm{~T}-170$ & 100 & 121 & 0 & 1200 & $2.26 \mathrm{E}-06$ \\
\hline $3 / 22 / 18$ & $\mathrm{~T}-170$ & 100 & 130 & 0 & 1200 & $1.89 \mathrm{E}-06$ \\
\hline $3 / 22 / 18$ & $\mathrm{~T}-170$ & 200 & 219 & 0 & 1200 & $3.04 \mathrm{E}-06$ \\
\hline $3 / 22 / 18$ & $\mathrm{~T}-170$ & 300 & 296 & 0 & 1200 & $3.56 \mathrm{E}-06$ \\
\hline $3 / 22 / 18$ & $\mathrm{~T}-170$ & 500 & 434 & 0 & 1200 & $5.65 \mathrm{E}-06$ \\
\hline $4 / 19 / 18$ & $\mathrm{~T}-175$ & 20 & 62 & 20 & 800 & $0.00 \mathrm{E}+00$ \\
\hline $3 / 31 / 18$ & $\mathrm{~T}-167$ & 100 & 121 & 21 & 800 & $5.95 \mathrm{E}-10$ \\
\hline $3 / 27 / 18$ & $\mathrm{~T}-172$ & 100 & 191 & 21 & 800 & $9.75 \mathrm{E}-10$ \\
\hline $4 / 2 / 18$ & $\mathrm{~T}-174$ & 200 & 237 & 21 & 800 & $1.08 \mathrm{E}-09$ \\
\hline $4 / 4 / 18$ & $\mathrm{~T}-168$ & 300 & 323 & 20 & 800 & $4.53 \mathrm{E}-10$ \\
\hline $4 / 9 / 18$ & $\mathrm{~T}-178$ & 500 & 495 & 21 & 800 & $1.35 \mathrm{E}-09$ \\
\hline $4 / 30 / 18$ & $\mathrm{~T}-182$ & 100 & 128 & 85 & 800 & $4.90 \mathrm{E}-10$ \\
\hline $4 / 23 / 18$ & $\mathrm{~T}-176$ & 200 & 220 & 84 & 800 & $3.24 \mathrm{E}-09$ \\
\hline $5 / 2 / 18$ & $\mathrm{~T}-184$ & 300 & 316 & 84 & 800 & $9.87 \mathrm{E}-10$ \\
\hline $5 / 8 / 18$ & T-186 & 500 & 513 & 84 & 800 & $1.08 \mathrm{E}-09$ \\
\hline $4 / 19 / 18$ & $\mathrm{~T}-175$ & 20 & 34 & 20 & 850 & $0.00 \mathrm{E}+00$ \\
\hline $3 / 31 / 18$ & $\mathrm{~T}-167$ & 100 & 123 & 21 & 850 & $8.96 \mathrm{E}-10$ \\
\hline $3 / 27 / 18$ & $\mathrm{~T}-172$ & 100 & 141 & 21 & 850 & $1.07 \mathrm{E}-09$ \\
\hline $4 / 2 / 18$ & $\mathrm{~T}-174$ & 200 & 250 & 21 & 850 & $6.01 \mathrm{E}-10$ \\
\hline $4 / 4 / 18$ & T-168 & 300 & 325 & 20 & 850 & $8.57 \mathrm{E}-10$ \\
\hline 4/9/18 & $\mathrm{T}-178$ & 500 & 571 & 21 & 850 & $9.01 \mathrm{E}-10$ \\
\hline $4 / 30 / 18$ & $\mathrm{~T}-182$ & 100 & 128 & 85 & 850 & $6.27 \mathrm{E}-10$ \\
\hline $4 / 23 / 18$ & $\mathrm{~T}-176$ & 200 & 220 & 84 & 850 & $1.16 \mathrm{E}-09$ \\
\hline
\end{tabular}




\begin{tabular}{|c|c|c|c|c|c|c|}
\hline \multirow{2}{*}{ Date } & \multirow{2}{*}{ Sample ID } & \multicolumn{2}{|c|}{$\mathbf{P}_{\mathrm{H} 2 \mathrm{O}}(\mathrm{Pa})$} & \multirow{2}{*}{$\mathbf{P}_{\mathrm{H} 2}$ (Pa) } & \multirow{2}{*}{$\begin{array}{c}\text { Temp. } \\
\left({ }^{\circ} \mathrm{C}\right)\end{array}$} & \multirow{2}{*}{ Rate $\left(\mathrm{s}^{-1}\right)$} \\
\hline & & Target & Actual & & & \\
\hline $5 / 2 / 18$ & $\mathrm{~T}-184$ & 300 & 329 & 84 & 850 & $5.77 \mathrm{E}-10$ \\
\hline $5 / 8 / 18$ & T-186 & 500 & 571 & 84 & 850 & $8.75 \mathrm{E}-10$ \\
\hline $4 / 19 / 18$ & $\mathrm{~T}-175$ & 20 & 17 & 20 & 900 & $6.87 \mathrm{E}-10$ \\
\hline $3 / 31 / 18$ & $\mathrm{~T}-167$ & 100 & 124 & 21 & 900 & $1.09 \mathrm{E}-09$ \\
\hline $3 / 27 / 18$ & $\mathrm{~T}-172$ & 100 & 162 & 21 & 900 & 4.18E-09 \\
\hline $4 / 2 / 18$ & $\mathrm{~T}-174$ & 200 & 257 & 21 & 900 & $2.12 \mathrm{E}-09$ \\
\hline $4 / 4 / 18$ & $\mathrm{~T}-168$ & 300 & 400 & 20 & 900 & $3.35 \mathrm{E}-09$ \\
\hline 4/9/18 & $\mathrm{T}-178$ & 500 & 581 & 21 & 900 & 5.69E-09 \\
\hline $4 / 30 / 18$ & $\mathrm{~T}-182$ & 100 & 130 & 85 & 900 & $4.46 \mathrm{E}-10$ \\
\hline $4 / 23 / 18$ & $\mathrm{~T}-176$ & 200 & 226 & 84 & 900 & $1.94 \mathrm{E}-09$ \\
\hline $5 / 2 / 18$ & $\mathrm{~T}-184$ & 300 & 368 & 84 & 900 & $1.71 \mathrm{E}-09$ \\
\hline $5 / 8 / 18$ & $\mathrm{~T}-186$ & 500 & 571 & 84 & 900 & $2.99 \mathrm{E}-09$ \\
\hline $4 / 19 / 18$ & $\mathrm{~T}-175$ & 20 & 17 & 20 & 950 & $8.80 \mathrm{E}-10$ \\
\hline $3 / 31 / 18$ & $\mathrm{~T}-167$ & 100 & 124 & 21 & 950 & 4.69E-09 \\
\hline $3 / 27 / 18$ & $\mathrm{~T}-172$ & 100 & 141 & 21 & 950 & $1.29 \mathrm{E}-08$ \\
\hline $4 / 2 / 18$ & $\mathrm{~T}-174$ & 200 & 261 & 21 & 950 & $1.40 \mathrm{E}-08$ \\
\hline $4 / 4 / 18$ & $\mathrm{~T}-168$ & 300 & 368 & 20 & 950 & $2.30 \mathrm{E}-08$ \\
\hline 4/9/18 & $\mathrm{T}-178$ & 500 & 568 & 21 & 950 & $3.89 \mathrm{E}-08$ \\
\hline $4 / 30 / 18$ & $\mathrm{~T}-182$ & 100 & 132 & 85 & 950 & $1.74 \mathrm{E}-09$ \\
\hline $4 / 23 / 18$ & $\mathrm{~T}-176$ & 200 & 244 & 84 & 950 & $5.32 \mathrm{E}-09$ \\
\hline $5 / 2 / 18$ & $\mathrm{~T}-184$ & 300 & 336 & 84 & 950 & 7.35E-09 \\
\hline $5 / 8 / 18$ & $\mathrm{~T}-186$ & 500 & 572 & 84 & 950 & $1.54 \mathrm{E}-08$ \\
\hline $4 / 19 / 18$ & $\mathrm{~T}-175$ & 20 & 17 & 20 & 1000 & $8.72 \mathrm{E}-09$ \\
\hline $3 / 31 / 18$ & $\mathrm{~T}-167$ & 100 & 124 & 21 & 1000 & $2.29 \mathrm{E}-08$ \\
\hline $3 / 27 / 18$ & $\mathrm{~T}-172$ & 100 & 142 & 21 & 1000 & 4.48E-08 \\
\hline $4 / 2 / 18$ & $\mathrm{~T}-174$ & 200 & 267 & 21 & 1000 & $9.37 \mathrm{E}-08$ \\
\hline $4 / 4 / 18$ & $\mathrm{~T}-168$ & 300 & 369 & 20 & 1000 & $1.46 \mathrm{E}-07$ \\
\hline 4/9/18 & $\mathrm{T}-178$ & 500 & 566 & 21 & 1000 & $1.95 \mathrm{E}-07$ \\
\hline $4 / 30 / 18$ & $\mathrm{~T}-182$ & 100 & 132 & 85 & 1000 & $9.32 \mathrm{E}-09$ \\
\hline $4 / 23 / 18$ & $\mathrm{~T}-176$ & 200 & 248 & 84 & 1000 & $3.07 \mathrm{E}-08$ \\
\hline $5 / 2 / 18$ & $\mathrm{~T}-184$ & 300 & 363 & 84 & 1000 & $5.06 \mathrm{E}-08$ \\
\hline $5 / 8 / 18$ & $\mathrm{~T}-186$ & 500 & 575 & 84 & 1000 & $1.21 \mathrm{E}-07$ \\
\hline $4 / 19 / 18$ & $\mathrm{~T}-175$ & 20 & 17 & 20 & 1050 & $2.13 \mathrm{E}-08$ \\
\hline $3 / 31 / 18$ & $\mathrm{~T}-167$ & 100 & 123 & 21 & 1050 & $9.66 \mathrm{E}-08$ \\
\hline $3 / 27 / 18$ & $\mathrm{~T}-172$ & 100 & 142 & 21 & 1050 & $1.28 \mathrm{E}-07$ \\
\hline $4 / 2 / 18$ & $\mathrm{~T}-174$ & 200 & 261 & 21 & 1050 & $2.59 \mathrm{E}-07$ \\
\hline $4 / 4 / 18$ & $\mathrm{~T}-168$ & 300 & 377 & 20 & 1050 & $3.90 \mathrm{E}-07$ \\
\hline $4 / 9 / 18$ & $\mathrm{~T}-178$ & 500 & 574 & 21 & 1050 & $5.03 \mathrm{E}-07$ \\
\hline $4 / 30 / 18$ & $\mathrm{~T}-182$ & 100 & 133 & 85 & 1050 & $4.45 \mathrm{E}-08$ \\
\hline
\end{tabular}




\begin{tabular}{|c|c|c|c|c|c|c|}
\hline \multirow{2}{*}{ Date } & \multirow{2}{*}{ Sample ID } & \multicolumn{2}{|c|}{$\mathbf{P}_{\mathrm{H} 2 \mathrm{O}}(\mathrm{Pa})$} & \multirow{2}{*}{$\mathbf{P}_{\mathrm{H} 2}(\mathbf{P a})$} & \multirow{2}{*}{$\begin{array}{c}\text { Temp. } \\
\left({ }^{\circ} \mathrm{C}\right)\end{array}$} & \multirow{2}{*}{ Rate $\left(\mathrm{s}^{-1}\right)$} \\
\hline & & Target & Actual & & & \\
\hline $4 / 23 / 18$ & $\mathrm{~T}-176$ & 200 & 255 & 84 & 1050 & $1.54 \mathrm{E}-07$ \\
\hline $5 / 2 / 18$ & $\mathrm{~T}-184$ & 300 & 380 & 84 & 1050 & $2.19 \mathrm{E}-07$ \\
\hline $5 / 8 / 18$ & $\mathrm{~T}-186$ & 500 & 576 & 84 & 1050 & $3.71 \mathrm{E}-07$ \\
\hline $4 / 19 / 18$ & $\mathrm{~T}-175$ & 20 & 17 & 20 & 1100 & $5.17 \mathrm{E}-08$ \\
\hline $3 / 31 / 18$ & $\mathrm{~T}-167$ & 100 & 133 & 21 & 1100 & $2.57 \mathrm{E}-07$ \\
\hline $3 / 27 / 18$ & $\mathrm{~T}-172$ & 100 & 140 & 21 & 1100 & $3.04 \mathrm{E}-07$ \\
\hline $4 / 2 / 18$ & $\mathrm{~T}-174$ & 200 & 252 & 21 & 1100 & $6.25 \mathrm{E}-07$ \\
\hline $4 / 4 / 18$ & $\mathrm{~T}-168$ & 300 & 364 & 20 & 1100 & $9.45 \mathrm{E}-07$ \\
\hline $4 / 9 / 18$ & $\mathrm{~T}-178$ & 500 & 535 & 21 & 1100 & $1.15 \mathrm{E}-06$ \\
\hline $4 / 30 / 18$ & $\mathrm{~T}-182$ & 100 & 133 & 85 & 1100 & $1.43 \mathrm{E}-07$ \\
\hline $4 / 23 / 18$ & $\mathrm{~T}-176$ & 200 & 255 & 84 & 1100 & $3.79 \mathrm{E}-07$ \\
\hline $5 / 2 / 18$ & $\mathrm{~T}-184$ & 300 & 384 & 84 & 1100 & $5.90 \mathrm{E}-07$ \\
\hline $5 / 8 / 18$ & T-186 & 500 & 564 & 84 & 1100 & $9.25 \mathrm{E}-07$ \\
\hline $4 / 19 / 18$ & $\mathrm{~T}-175$ & 20 & 17 & 20 & 1150 & $1.04 \mathrm{E}-07$ \\
\hline $3 / 31 / 18$ & $\mathrm{~T}-167$ & 100 & 129 & 21 & 1150 & $6.63 \mathrm{E}-07$ \\
\hline $3 / 27 / 18$ & $\mathrm{~T}-172$ & 100 & 133 & 21 & 1150 & $6.88 \mathrm{E}-07$ \\
\hline $4 / 2 / 18$ & $\mathrm{~T}-174$ & 200 & 251 & 21 & 1150 & $1.38 \mathrm{E}-06$ \\
\hline $4 / 4 / 18$ & $\mathrm{~T}-168$ & 300 & 426 & 20 & 1150 & $2.35 \mathrm{E}-06$ \\
\hline $4 / 9 / 18$ & $\mathrm{~T}-178$ & 500 & 484 & 21 & 1150 & $2.44 \mathrm{E}-06$ \\
\hline $4 / 30 / 18$ & $\mathrm{~T}-182$ & 100 & 133 & 85 & 1150 & $3.76 \mathrm{E}-07$ \\
\hline $4 / 23 / 18$ & $\mathrm{~T}-176$ & 200 & 258 & 84 & 1150 & $9.50 \mathrm{E}-07$ \\
\hline $5 / 2 / 18$ & $\mathrm{~T}-184$ & 300 & 397 & 84 & 1150 & $1.50 \mathrm{E}-06$ \\
\hline $5 / 8 / 18$ & T-186 & 500 & 574 & 85 & 1150 & $2.04 \mathrm{E}-06$ \\
\hline $4 / 19 / 18$ & $\mathrm{~T}-175$ & 20 & 17 & 20 & 1200 & $1.79 \mathrm{E}-07$ \\
\hline $3 / 31 / 18$ & $\mathrm{~T}-167$ & 100 & 130 & 21 & 1200 & $1.49 \mathrm{E}-06$ \\
\hline $3 / 27 / 18$ & $\mathrm{~T}-172$ & 100 & 134 & 21 & 1200 & $1.53 \mathrm{E}-06$ \\
\hline $4 / 2 / 18$ & $\mathrm{~T}-174$ & 200 & 251 & 21 & 1200 & $3.11 \mathrm{E}-06$ \\
\hline $4 / 4 / 18$ & T-168 & 300 & 387 & 20 & 1200 & 4.44E-06 \\
\hline 4/9/18 & $\mathrm{T}-178$ & 500 & 484 & 21 & 1200 & 4.70E-06 \\
\hline $4 / 30 / 18$ & $\mathrm{~T}-182$ & 100 & 133 & 85 & 1200 & $9.46 \mathrm{E}-07$ \\
\hline $4 / 23 / 18$ & $\mathrm{~T}-176$ & 200 & 262 & 84 & 1200 & $2.20 \mathrm{E}-06$ \\
\hline $5 / 2 / 18$ & $\mathrm{~T}-184$ & 300 & 357 & 84 & 1200 & $3.13 \mathrm{E}-06$ \\
\hline $5 / 8 / 18$ & $\mathrm{~T}-186$ & 500 & 576 & 84 & 1200 & $4.43 \mathrm{E}-06$ \\
\hline
\end{tabular}





\section{APPENDIX D. SELECT OPTICAL MICROGRAPHS OF SAMPLES SUBJECTED TO CROSS SECTIONAL ANALYSIS}

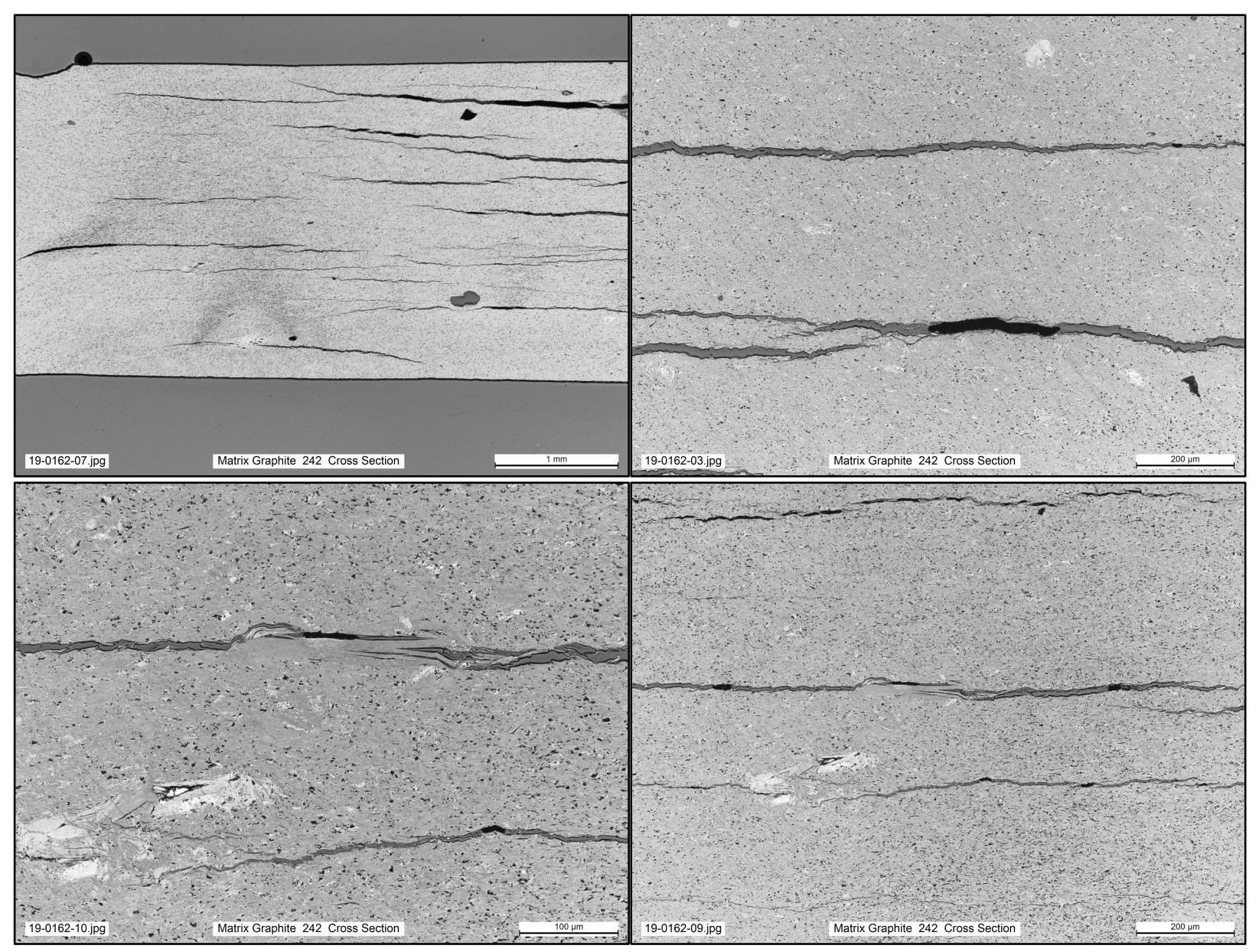

SE-242, As-fabricated 


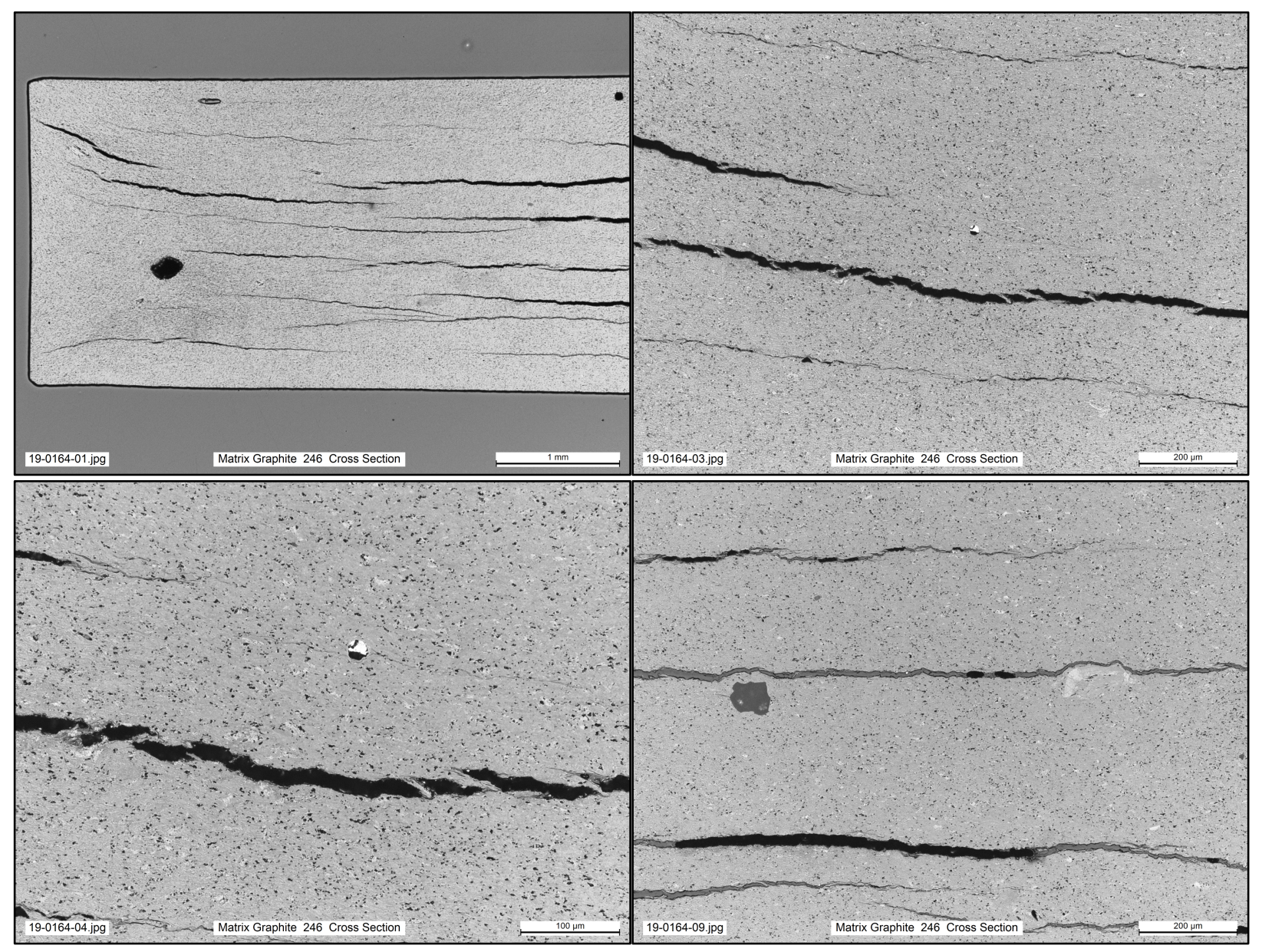

SE-246, As-fabricated 


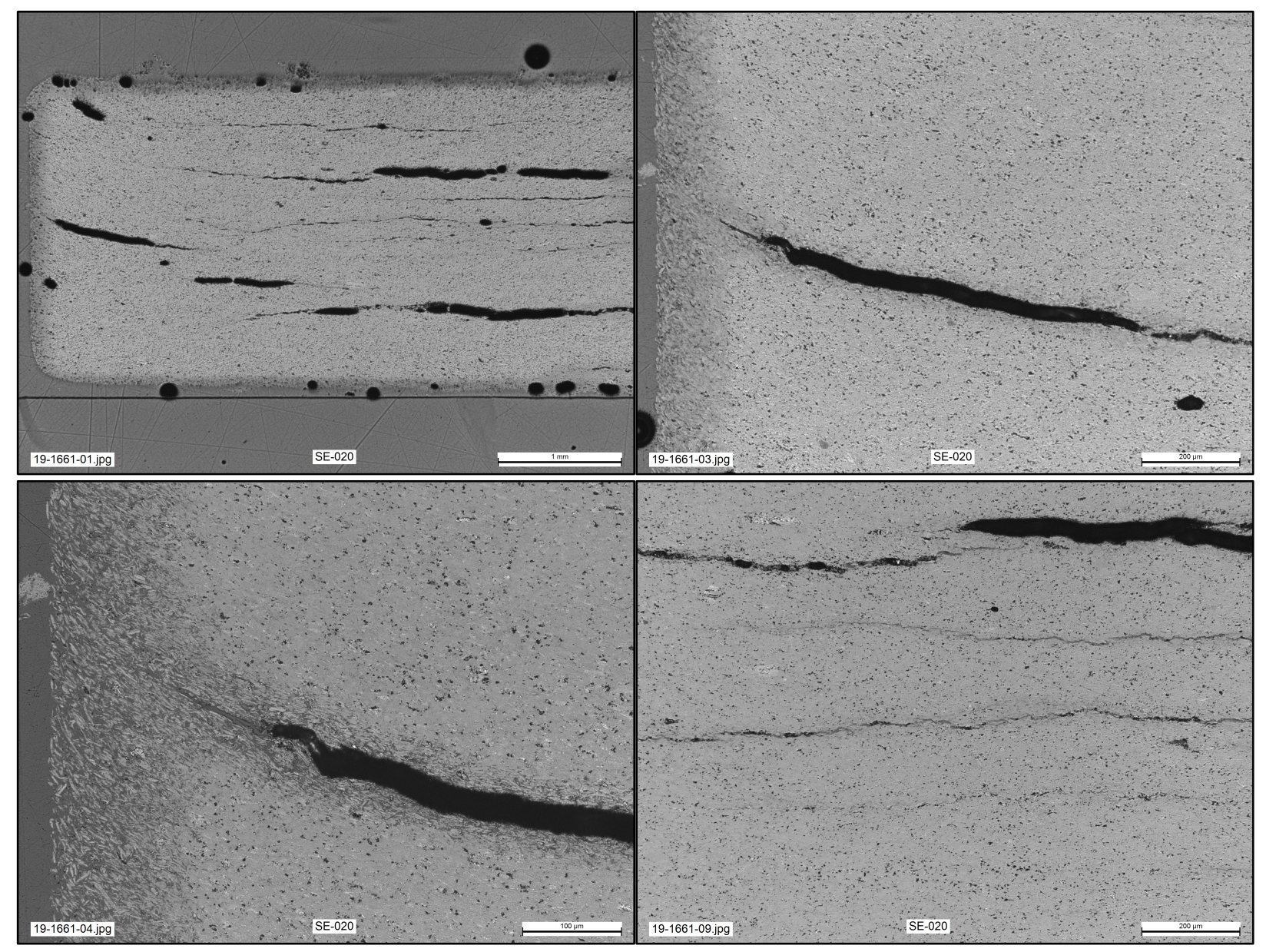

SE-020, 1,200 ${ }^{\circ} \mathrm{C}, 1 \mathrm{~h}, 10 \mathrm{kPa}$ 


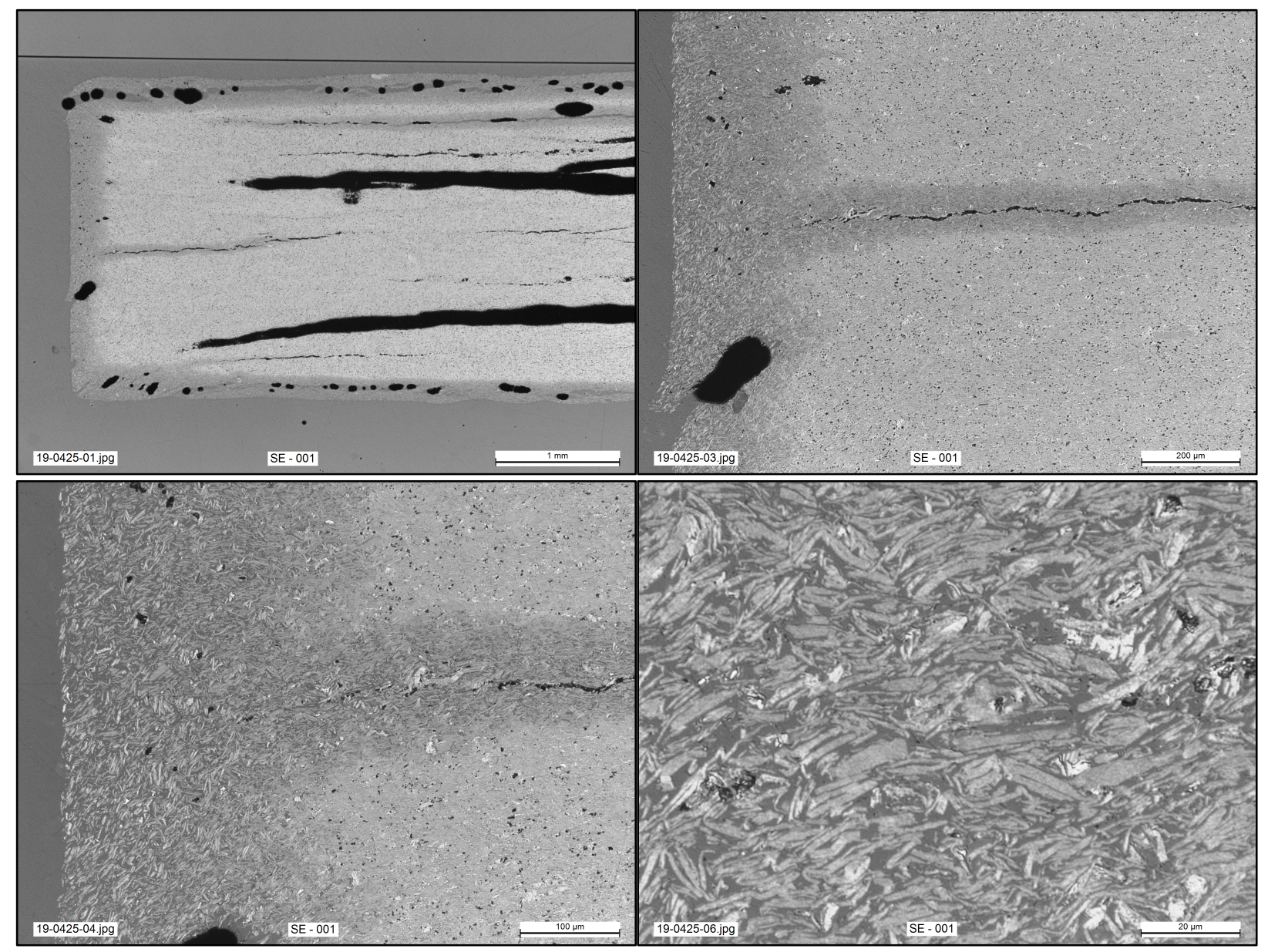

SE-001, 1,200 ${ }^{\circ} \mathrm{C}, 1 \mathrm{~h}, 20 \mathrm{kPa}$ 


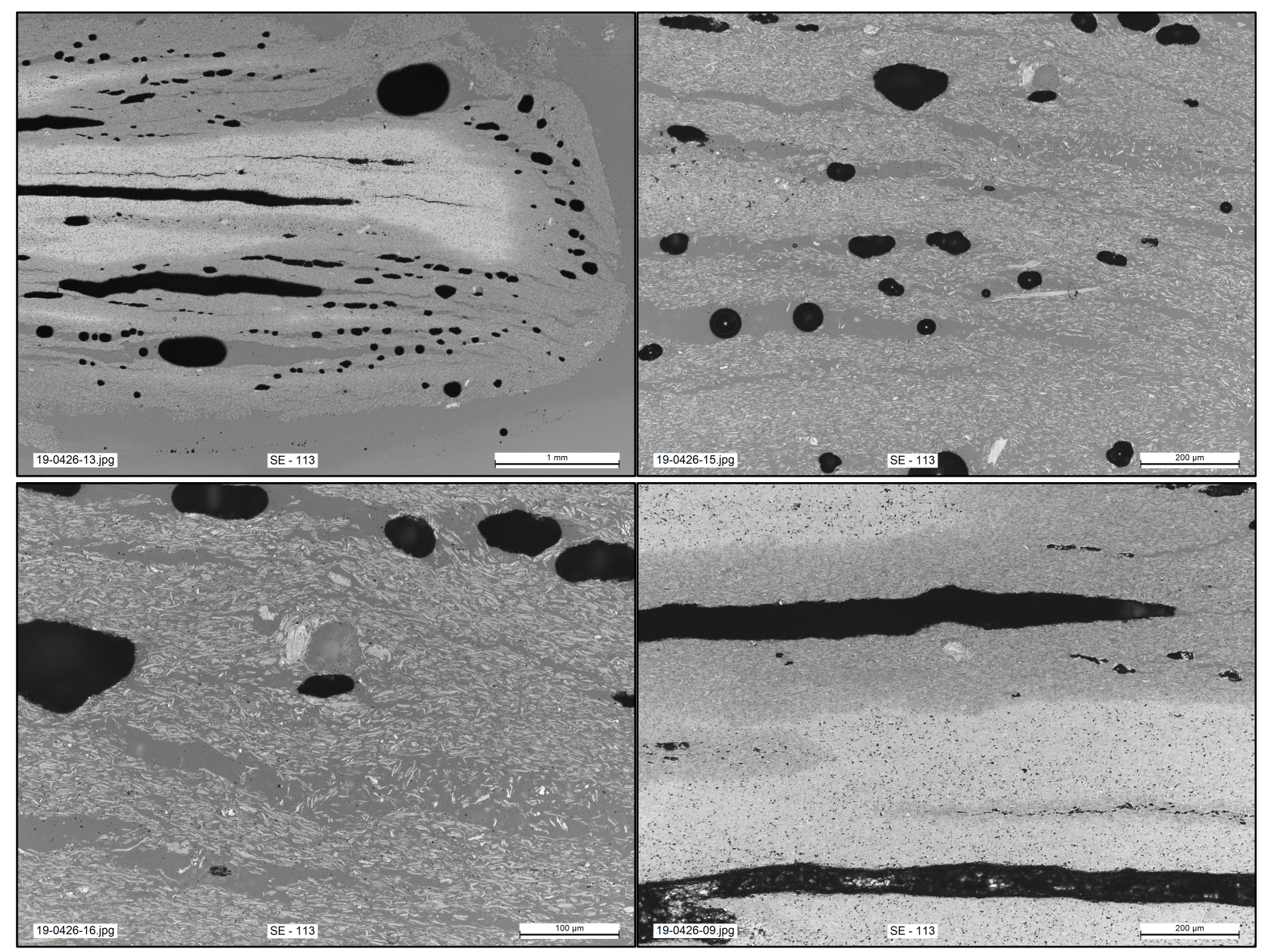

$\mathrm{SE}-113,1,200{ }^{\circ} \mathrm{C}, 1 \mathrm{~h}, 30 \mathrm{kPa}$ 


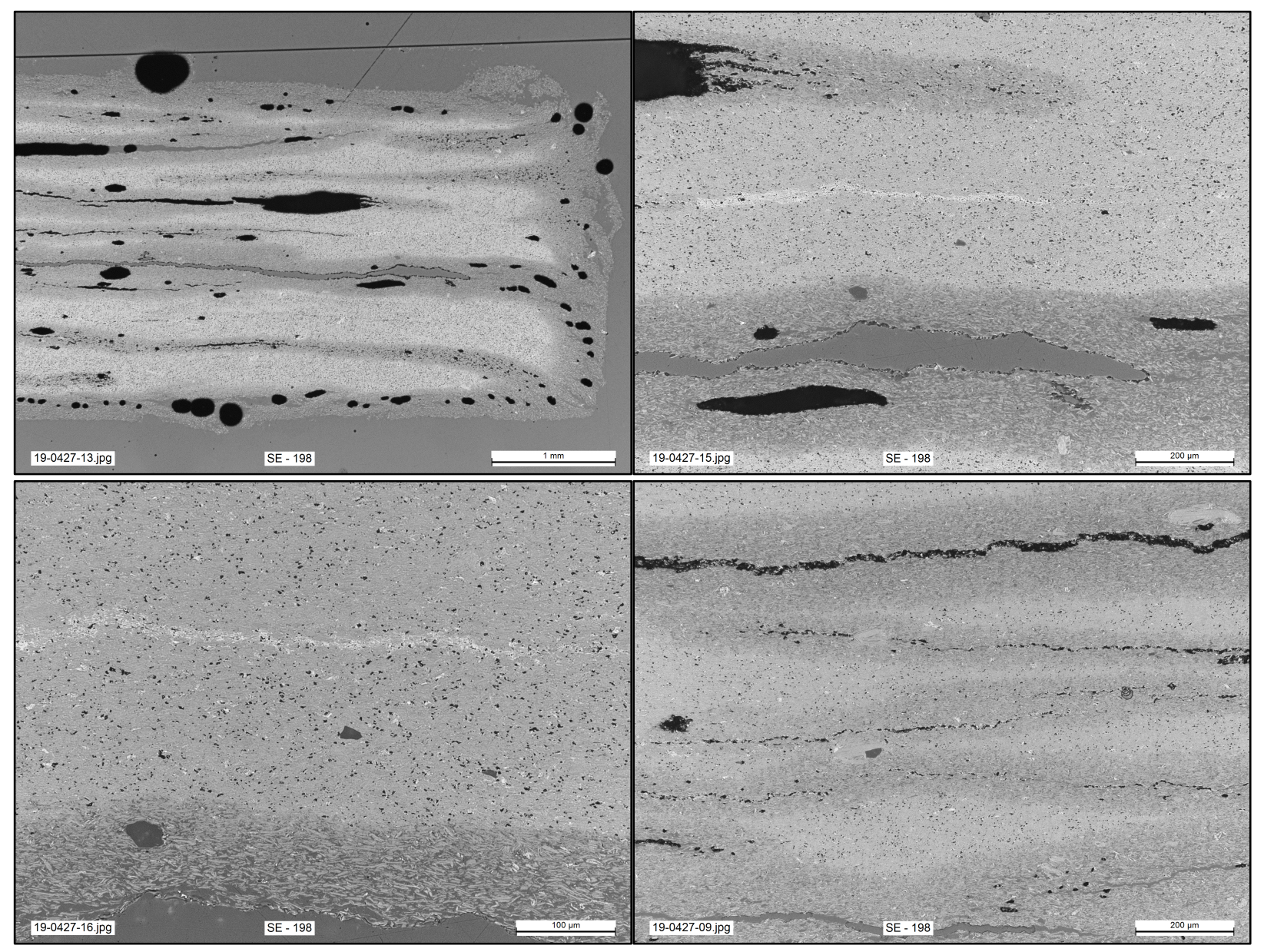

SE-198, 1,200 ${ }^{\circ} \mathrm{C}, 1 \mathrm{~h}, 48 \mathrm{kPa}$ 


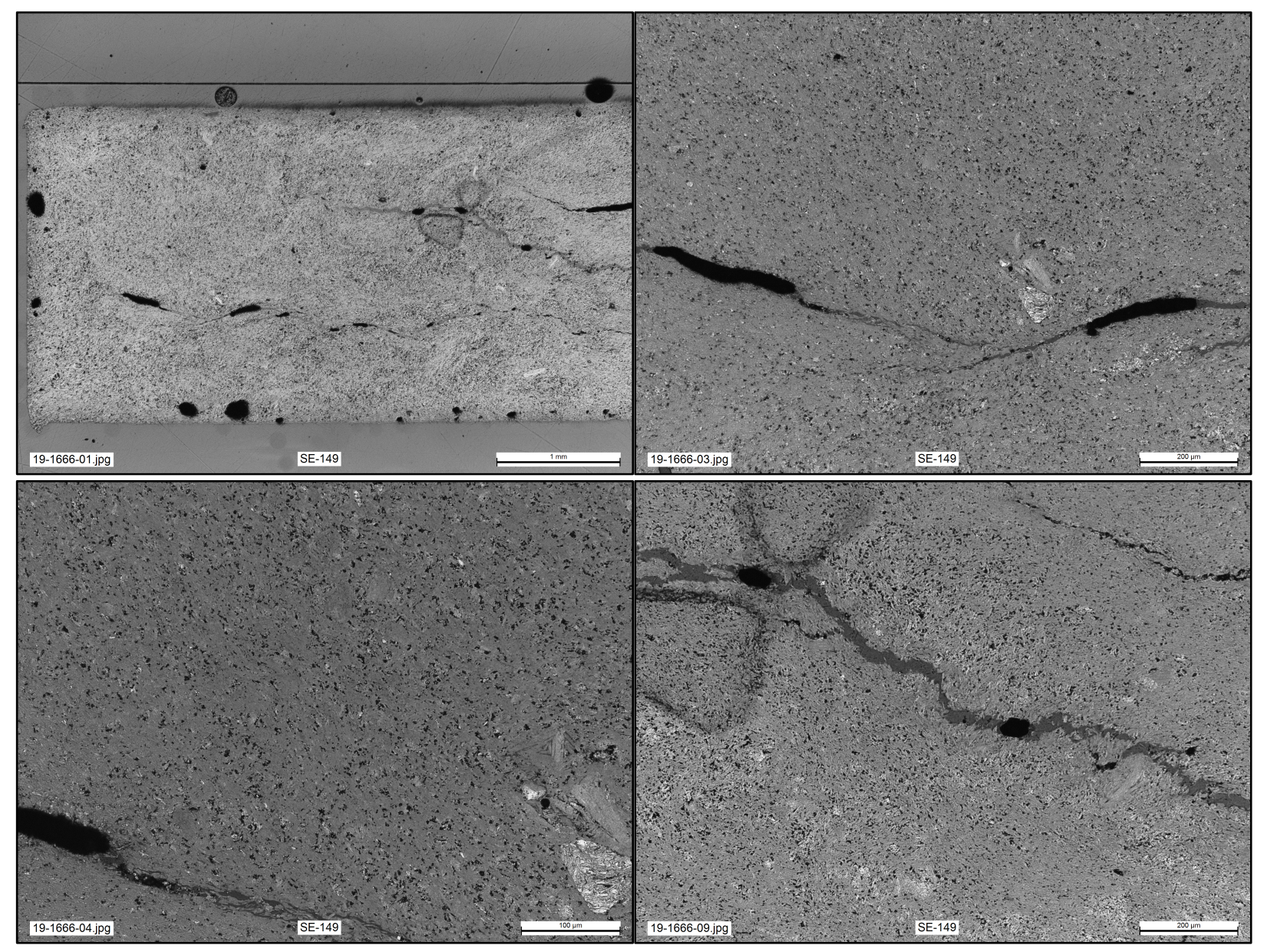

$\mathrm{SE}-149,1,300{ }^{\circ} \mathrm{C}, 0.25 \mathrm{~h}, 20 \mathrm{kPa}$ 


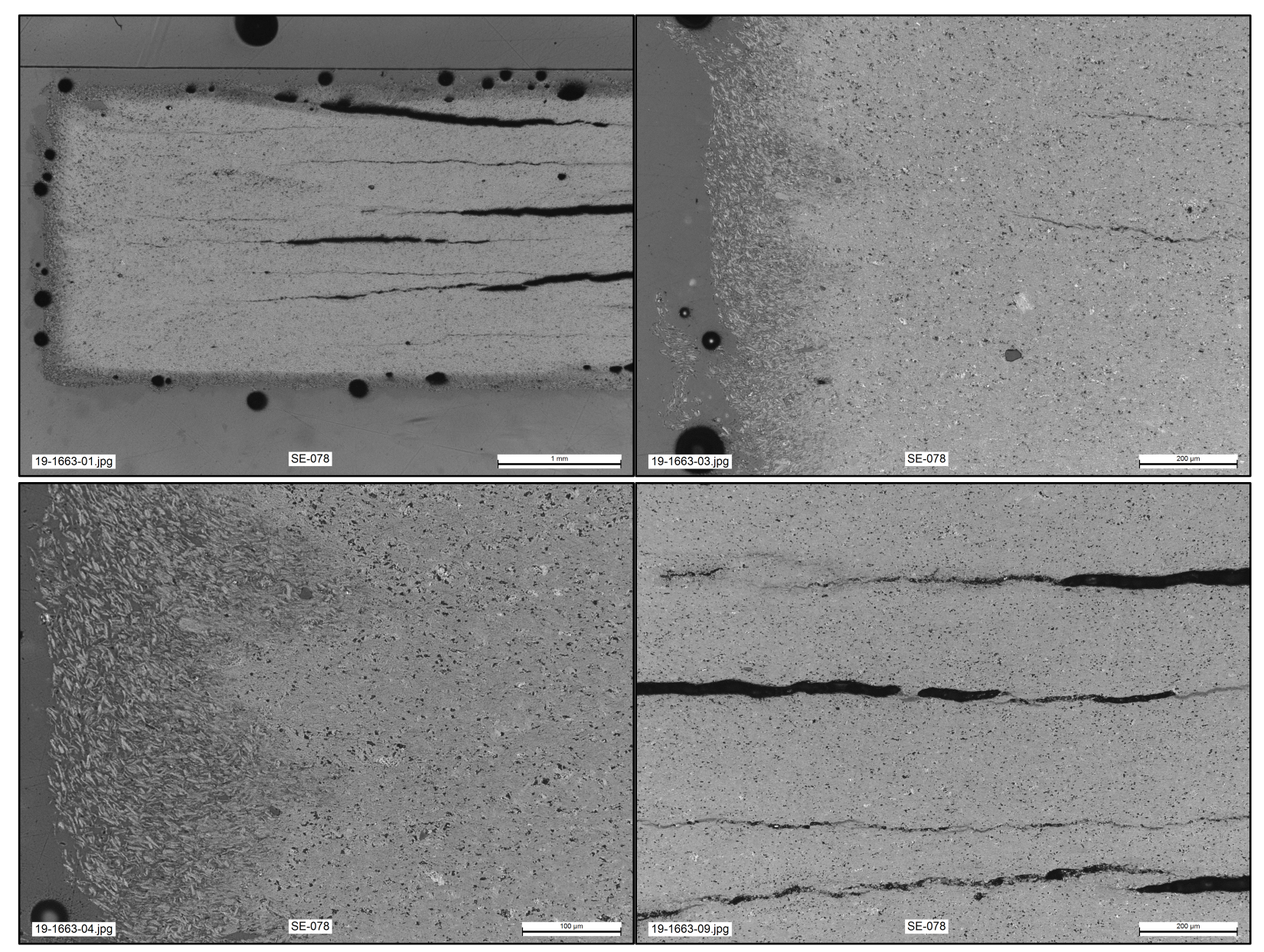

SE-078, $1,300{ }^{\circ} \mathrm{C}, 0.5 \mathrm{~h}, 20 \mathrm{kPa}$ 


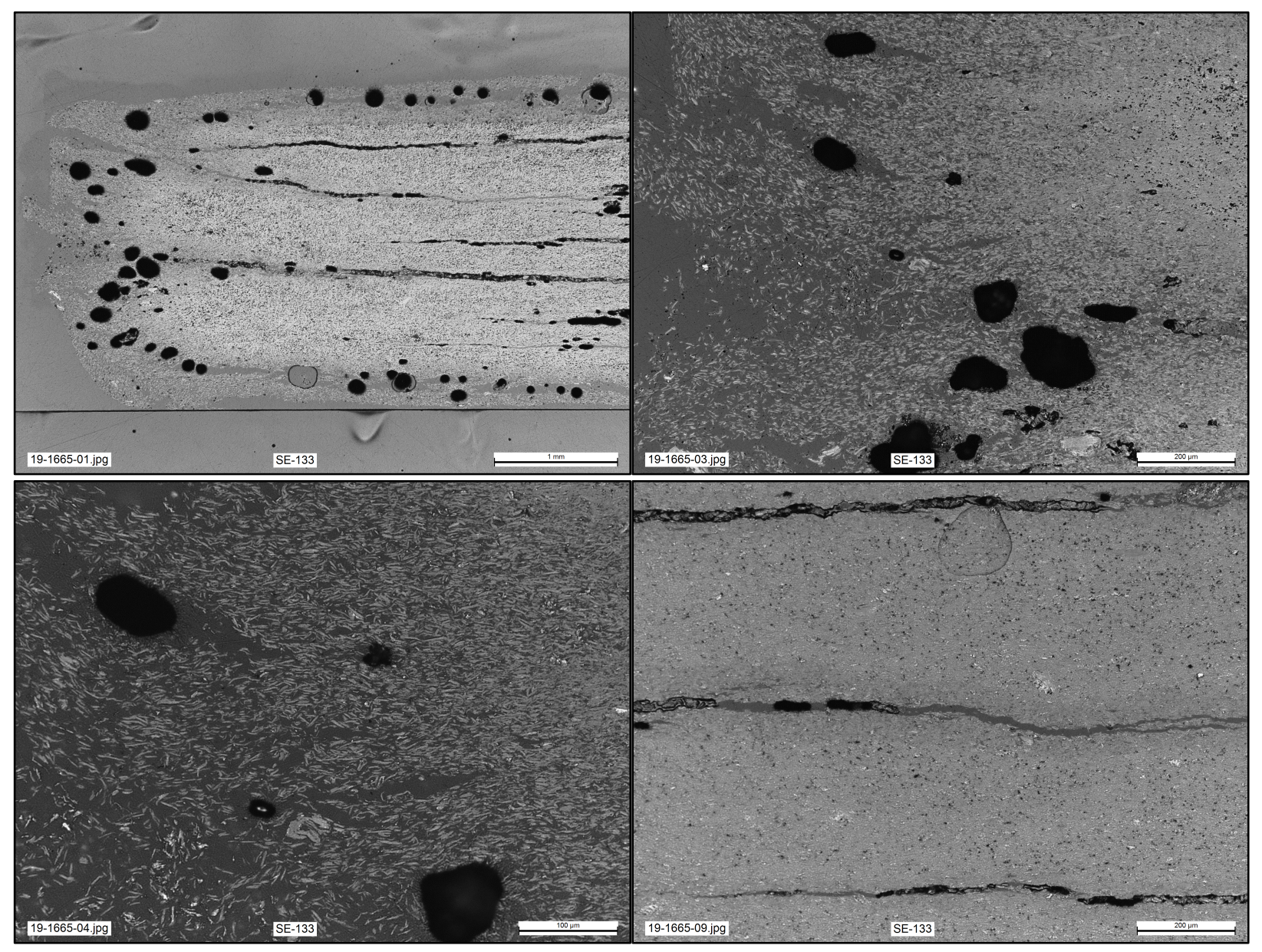

SE- $133,1,300{ }^{\circ} \mathrm{C}, 1 \mathrm{~h}, 20 \mathrm{kPa}$ 


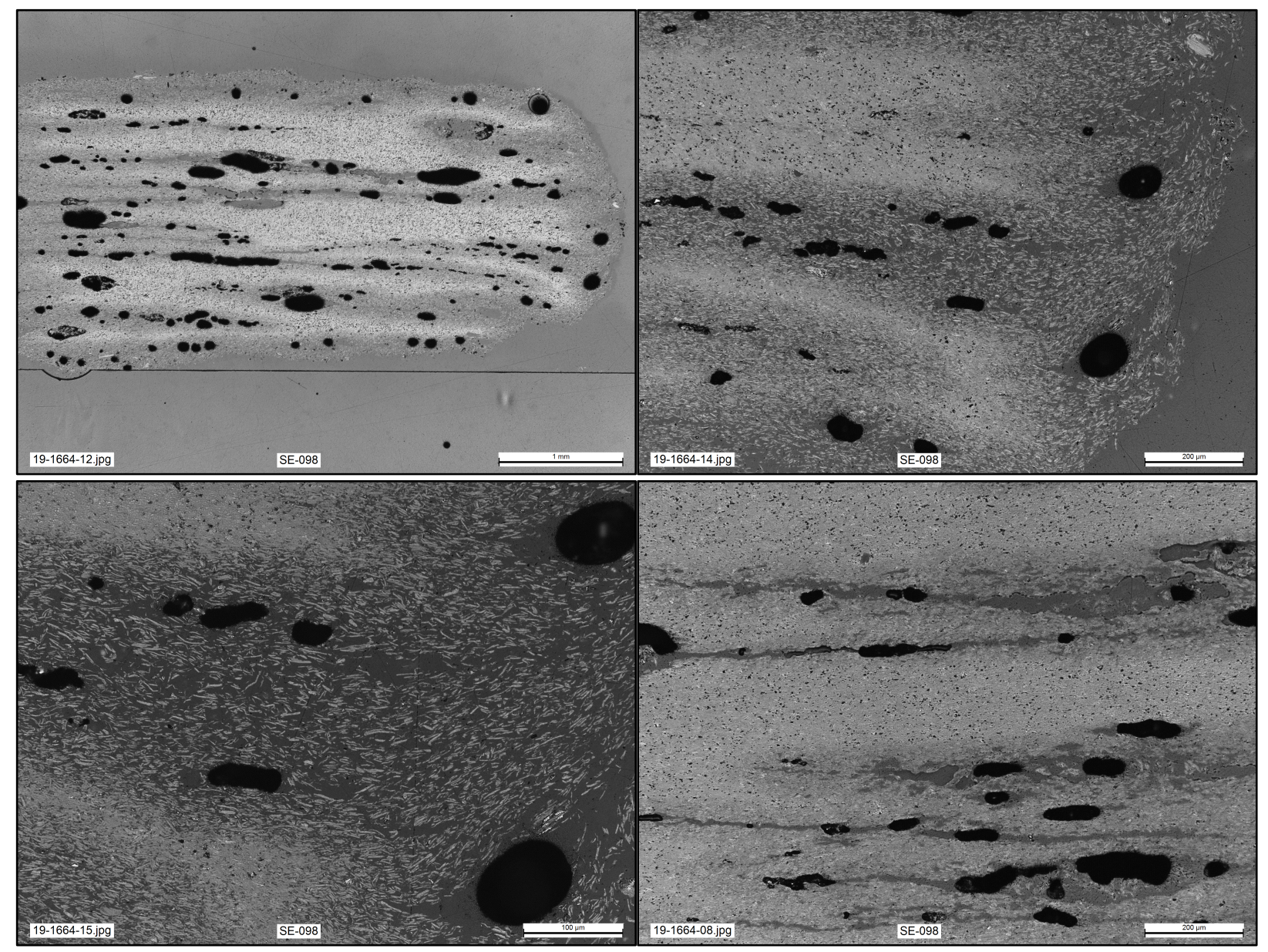

SE-098, $1,300{ }^{\circ} \mathrm{C}, 1.5 \mathrm{~h}, 20 \mathrm{kPa}$ 


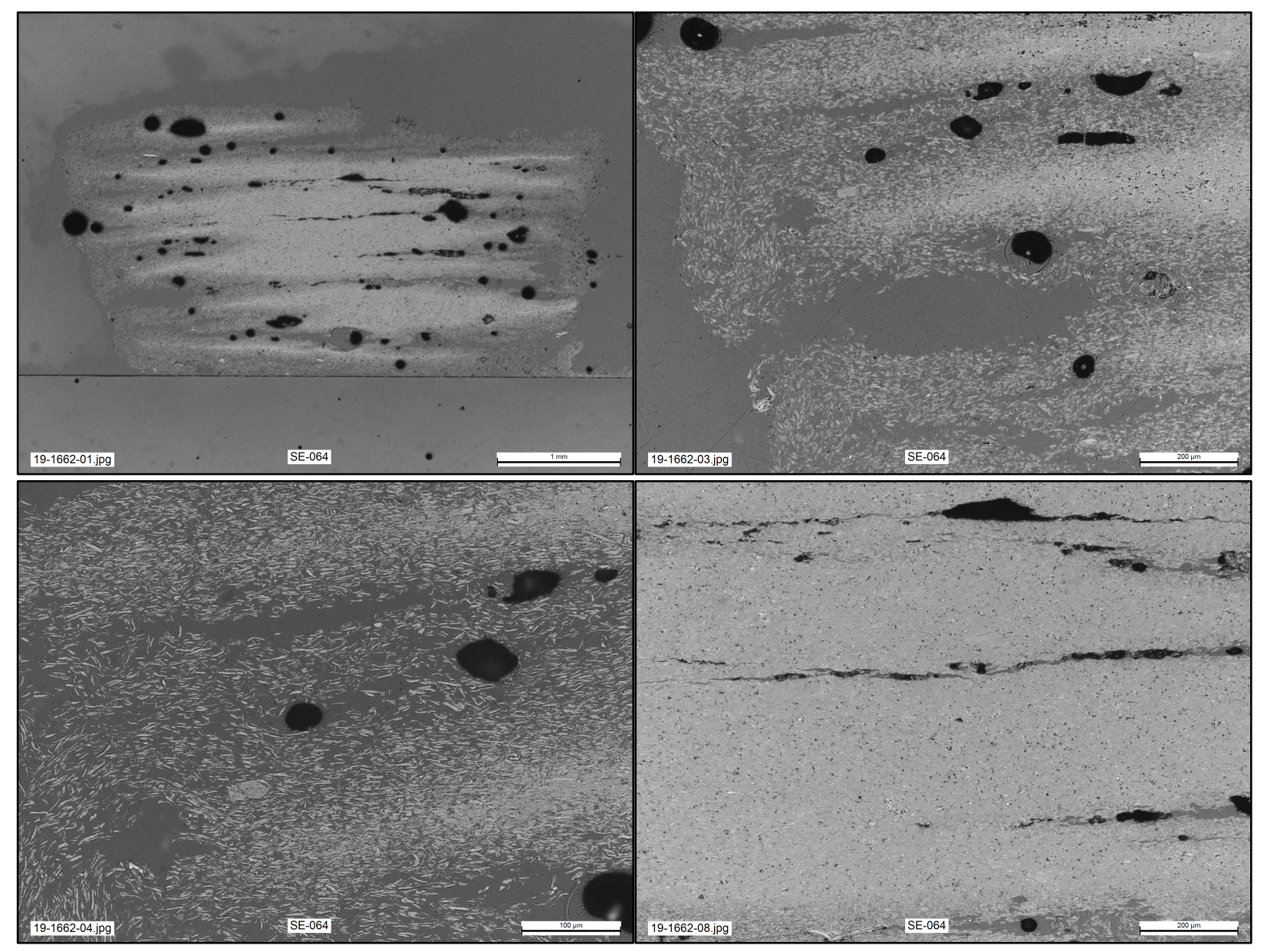

SE-064, 1,400 ${ }^{\circ} \mathrm{C}, 1 \mathrm{~h}, 20 \mathrm{kPa}$ 